Board of Governors of the Federal Reserve System

International Finance Discussion Papers

Number 1301

September 2020

\title{
Exchange Rates and Endogenous Productivity
}

Nils Gornemann, Pablo Guerron-Quintana, and Felipe Saffie

Please cite this paper as:
Goernemann, Nils, Pablo Guerron-Quintana, and Felipe Saffie (2020). "Ex-
change Rates and Endogenous Productivity," International Finance Discussion Pa-
pers 1301. Washington: Board of Governors of the Federal Reserve System,
https://doi.org/10.17016/IFDP.2020.1301.

NOTE: International Finance Discussion Papers (IFDPs) are preliminary materials circulated to stimulate discussion and critical comment. The analysis and conclusions set forth are those of the authors and do not indicate concurrence by other members of the research staff or the Board of Governors. References in publications to the International Finance Discussion Papers Series (other than acknowledgement) should be cleared with the author(s) to protect the tentative character of these papers. Recent IFDPs are available on the Web at www.federalreserve.gov/pubs/ifdp/. This paper can be downloaded without charge from the Social Science Research Network electronic library at www.ssrn.com. 


\title{
Exchange Rates and Endogenous Productivity*
}

\author{
Nils Gornemann, ${ }^{\dagger}$ Pablo Guerrón-Quintana, ${ }^{\ddagger}$ and Felipe Saffie ${ }^{\S}$
}

September 15, 2020

\begin{abstract}
Real exchange rates (RERs) display sizable fluctuations not only over the business cycle, but also at lower frequencies, resulting in large and persistent swings over decades - facts that many business cycle models struggle to match. We propose an international macroeconomics model with endogenous productivity to rationalize these facts. In the model, endogenous growth amplifies stationary fluctuations generating persistent productivity differences between countries that trigger low-frequency cycles in the RER. The estimated model effortlessly replicates the empirical spectrum, autocorrelation, and half-life of the RER. In addition, we document that low frequency movements in aggregate trade flows are crucial to discipline the RER cycles. Finally, we validate the model-implied co-movement between relative prices and technology differentials using a panel of cross industry-country data on patent and industry prices.
\end{abstract}

Keywords: Real Exchange Rate, Endogenous Growth, RBC

JEL Codes: F31, F41, F43, F44

\footnotetext{
${ }^{*}$ The views in this paper are solely the responsibility of the authors and should not be interpreted as reflecting the views of the Board of Governors of the Federal Reserve System or any other person associated with the Federal Reserve System. We thank Matteo Iacoviello, Virgiliu Midrigan, Fabrizio Perri, Ricardo Reyes-Heroles, John Rogers, and especially Andrea Raffo for useful discussions, Nitya Pandalai-Nayar for sharing her data with us, and audiences at the Spring Midwest Macro 2016\&2019, SED 2016\&2019, IADB, and Hitotsubashi University for helpful comments. Karam Kang, Zach Kroff, and Daniel Molon provided excellent research assistance.

${ }^{\dagger}$ Board of Governors, nilsgornemann@gmail.com

‡Boston College, pguerron@gmail.com

§University of Virginia, Darden School of Business, saffieF@darden.virginia.edu
} 


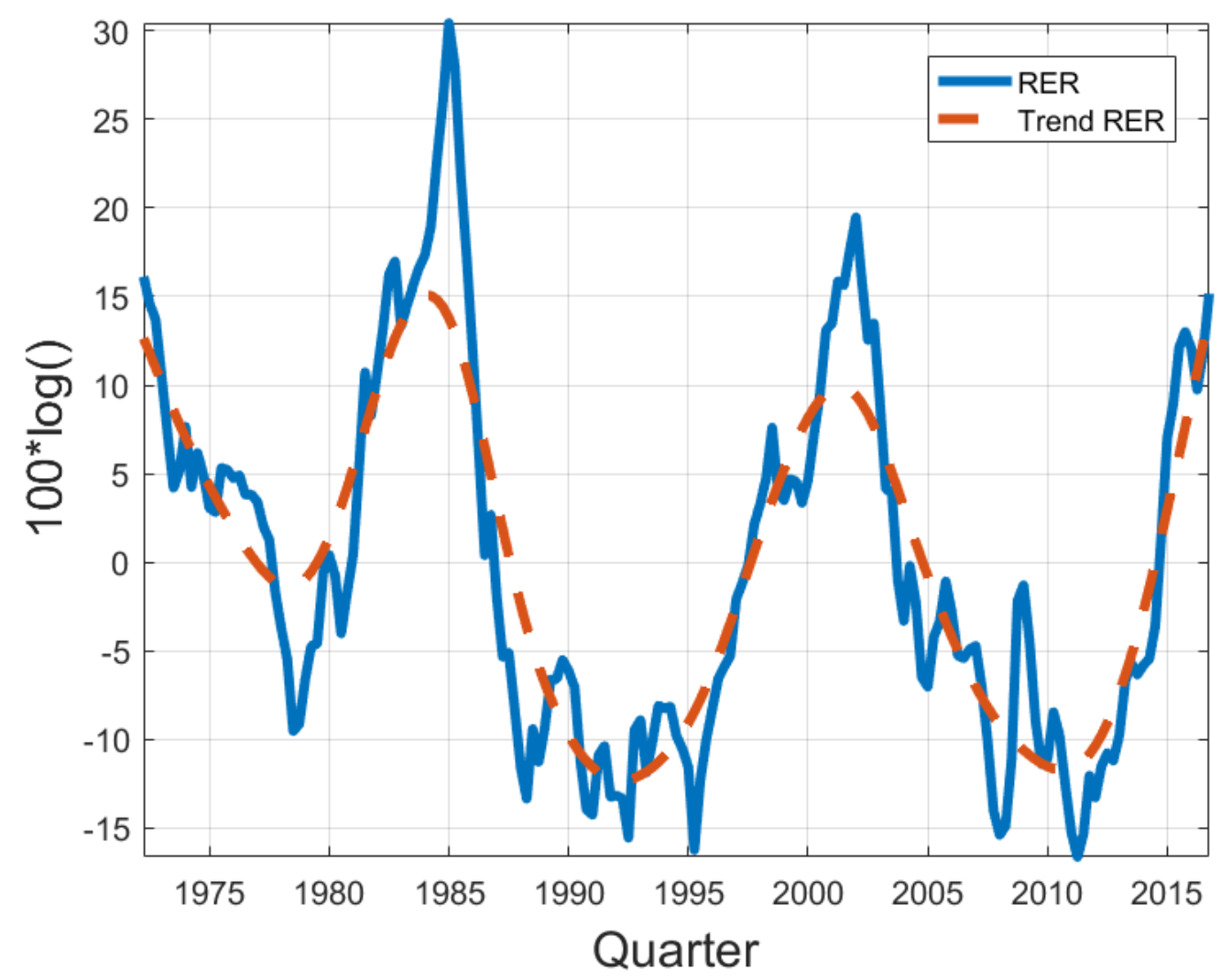

Figure 1: U.S. Real Exchange Rate

Notes: The blue line is the trade weighted quarterly averaged real exchange rate between the U.S and the other G-7 countries for 1972:Q2 - 2016:Q4. The orange line is the HP-1600 trend of the same series. The data sources and construction are described in section 3 .

\section{Introduction}

The excess volatility and persistence of real exchange rates (RERs) relative to other macroeconomic variables such as output and consumption has long challenged models of the international business cycle (see, for example, Chari, Kehoe, and McGrattan (2002)). Figure 1 displays the trade weighted U.S. RERs with the rest of G-7 countries. Four observations characterize the behavior of the RER. First, the detrended series display high volatility at business cycle frequencies (on average, 4.0 percent versus 1.0 percent for GDP over the same period relative to an Hodrick-Prescott (HP) trend). Second, the RER displays high serial correlation (0.96). Third, while the excess volatility is typically documented at business cycle frequency, it is even more pronounced at the mediumand low-frequency component, as the trend itself displays persistent fluctuations, a point raised by Rabanal and Rubio-Ramirez (2015). Fourth, the half-life of the RER - the time it takes its impulse response function to fall below half of its peak-is close to 4.5 years (Steinsson, 2008). ${ }^{1}$

The importance of low-frequency fluctuations can be formalized using the spectrum of the exchange

\footnotetext{
${ }^{1}$ All these observations are robust to using longer samples and individual country pairs.
} 
rate. $^{2}$ Our estimated spectrum peaks at frequency zero, which indicates that the RER displays strong low-frequency fluctuations. Indeed, about 50 percent of the variability of exchange rates is coming from frequencies lower than the business cycle. ${ }^{3}$ In addition, as we can see in the lower panel, the autocorrelation function of the exchange rate indicates a high persistence as well.

The main contribution of this paper is to provide a novel and yet simple framework to capture these rich low-frequency movements in the RER. While these patterns are puzzling for standard open economy models, we tackle them with a model featuring endogenous technical change (Comin and Gertler (2006)). More precisely, we formulate a two-country real business cycle model (Heathcote and Perri (2002)) augmented with an endogenous productivity channel (Romer (1990)) and a slow diffusion of ideas across countries (Eaton and Kortum (1999)). A simplified version of the model shows how endogenous growth can trigger persistent RER dynamics. We then demonstrate that an estimated version of the model can rationalize the spectrum, autocorrelation function, and half-life of the RER in finite sample, while producing reasonable business cycle dynamics. In all our exercises, we fix the short- and long-run trade elasticity to values consistent with recent estimates from the trade literature. Therefore, our mechanism does not rely on a low trade elasticity.

In any international real business cycle (IRBC) model, the RER is strongly influenced by the productivity gap between the countries. Moreover, as the exchange rate is a forward-looking price through its role in clearing international asset markets, it responds to the expected productivity gap between the countries. When a shock makes R\&D more desirable in one country, the resulting additional innovations trigger a permanent increase in the level of productivity of this country and a relative imbalance in the international goods market. The RER adjusts to bring international goods and asset markets into equilibrium. Because the productivity gap is highly persistent, the price adjustment is highly persistent as well. As time passes, changes in relative prices and international spillovers gradually impel the laggard country to innovate so that, in the long run, the relative prices come back to its original level. ${ }^{4}$ In the case of an exogenous growth model, shocks themselves need to be extremely persistent to generate persistent movements in the RER, as the standard real business cycle model lacks sufficient internal propagation. This condition ties the persistence of the RER directly to the persistence of other macro series. Importantly, when the same data is used to estimate our endogenous growth model and a similar exogenous growth model, both estimations

${ }^{2}$ The spectrum of a variable $Y_{t}$ with autocovariances $\left\{\gamma_{j}\right\}_{j=\infty}^{\infty}$ is

$$
s_{Y}(\omega)=\frac{1}{2 \pi} \sum_{j=-\infty}^{\infty} \gamma_{j} e^{-i \omega j} .
$$

Here, we estimate it using the modified Bartlett Kernel with a bandwidth of 13 . This is the largest consecutive lag starting from 0, which is still statistically significantly correlated with the series itself. The main results in this paper are robust to variations in the bandwidth and can be viewed, alternatively, through the lenses of the autocovariance function.

${ }^{3}$ Quarter $^{-1}=0.031$ corresponds to 8 years in our sample, which is the upper limit in the standard definition of business cycles.

${ }^{4}$ Slow cross-country adoption is consistent with the findings in, for example, Irwin and Klenow (1994). 

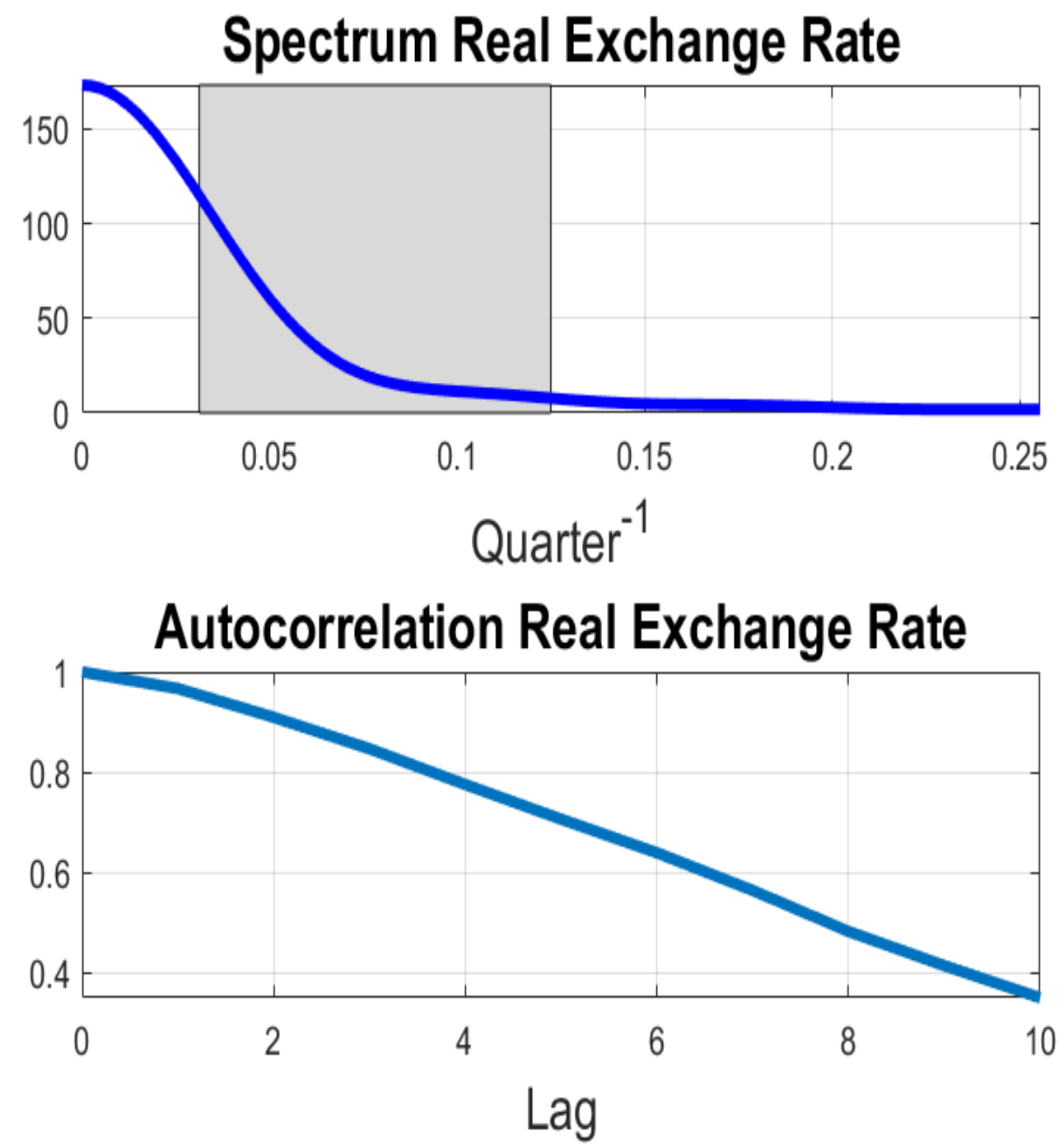

Figure 2: U.S. Rate Exchange Rate: Spectrum and Autocorrelation Notes: The blue line in the top panel is the spectrum of the trade weighted quarterly averaged real exchange rate between the U.S and the other G-7 countries computed using the modified Bartlett Kernel for 1972:Q2 - 2016:Q4. The blue line in the lower panel is the autocorrelation function of the trade weighted quarterly averaged real exchange rate between the U.S and the other G-7 countries for 1972:Q2 - 2016:Q4. The data sources and construction are described in section 3 .

will, by construction, display similar observed filtered Solow residual time series. However, the endogenous growth model will generate more persistent expected productivity gaps at every point in time, therefore displaying low-frequency exchange rate fluctuations-absent on its exogenous growth counterpart-without sacrificing higher frequency performance.

Our mechanism relies on a link between persistent differences in relative prices and productivity dynamics. While we provide empirical evidence consistent with this link, the reader might still wonder 


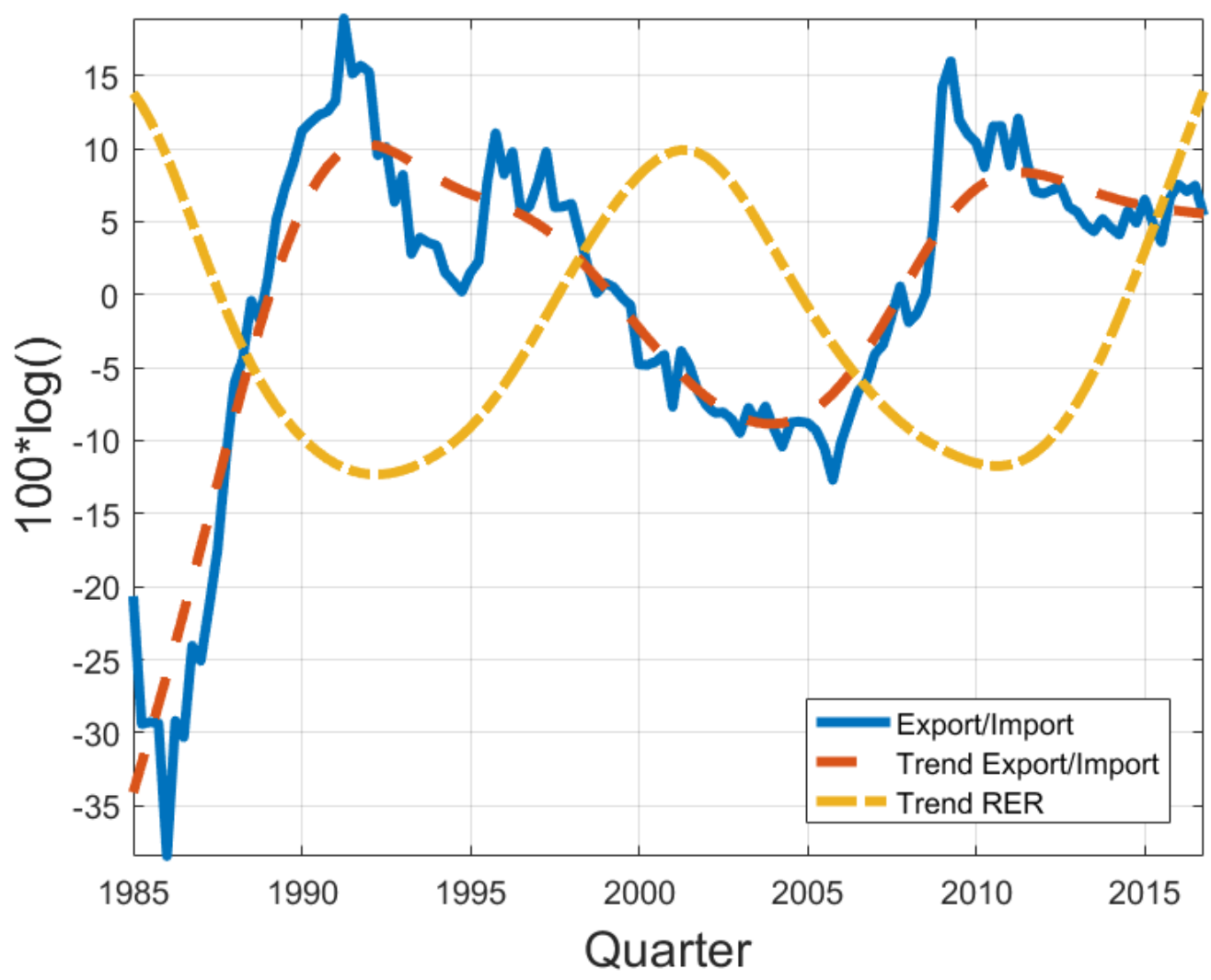

Figure 3: U.S. Real Exchange Rate

Notes: The blue line is the logged ration of exports and imports between the U.S and the other G7 countries for 1985:Q1 - 2016:Q4. The orange line is the HP-1600 trend of the same series. The red line shows the HP-1600 trend of the real exchange rate. The data sources and construction are described in section 3.

if this story contradicts the idea that exchange rates are notoriously hard to forecast. ${ }^{5}$ However, it is important to keep in mind that the exchange rate disconnect puzzle refers mainly to short-term dynamics. Figure 3 shows a robust low-frequency co-movement between the export-to-import ratio and the exchange rate. This relationship turns out to be the key to disciplining our estimation by forcing a re-connection between the RER and quantities at low frequencies.

In our main quantitative exercise, we estimate a richer IRBC model. The main comparison point is a model with the same features but where productivity in both countries is exogenous. The models are estimated using Bayesian methods. Both estimations deliver consistent HP-filtered moments. Nevertheless, only the endogenous growth model can replicate the spectrum and autocorrelation function from Figure 2. This result is robust to the particular modeling choices of R\&D, and the exclusion of the additional frictions. Furthermore, the robustness section shows that nothing in our quantitative results requires that the adjustment in the RER actually occurs through relative nominal prices. In fact, our mechanism is fully consistent with a strong role of the nominal exchange

\footnotetext{
${ }^{5}$ This observation goes back, at least, to Meese and Rogoff (1983). See Itskhoki and Mukhin (2017) for a recent analysis of this idea.
} 
rate in this adjustment.

At the core of the empirical success of the endogenous growth model is the interaction between trade flows and exchange rates. To illustrate this point, we estimate the model without exchange rate data and compare the model implied exchange rate dynamics with their empirical counterpart. Even without the commonly used uncovered interest parity shocks, the baseline endogenous growth model tracks the dynamics of the RER well (correlation 0.66). When trade data are excluded from the estimation, the model can generate low frequency movements in the RER, but these dynamics are disconnected from the empirical exchange rate (the correlation drops to -0.29). Therefore, the low-frequency co-movement between trade flows and exchange rate informs the endogenous growth model on how to use the internal propagation to trigger well-paced low-frequency exchange rate dynamics.

We purposely endow our model with many shocks and structural features. The reason is that there is limited empirical evidence on what drives exchange rates (Itskhoki and Mukhin, 2017). Here, the estimation step is crucial for our purposes because it imposes discipline on what different shocks and blocks of the model can and cannot explain. In this sense, we follow the path used in other areas of macroeconomics, such as monetary economics (Smets and Wouters, 2007) and macro/finance (Christiano, Motto, and Rostagno, 2014). Our hope is that the empirical findings in this paper serve as a road map for the next generation of exchange rate dynamics models.

Finally, as an empirical validation for the relationship between innovation and relative prices at the core of the model, we collect data on industry-level relative prices and new patents at the industry level across 15 countries. We show that variations in the relative number of new patents between a given industry-country pair and the U.S. predicts the level of the industry level exchange rate in the following years and forecasts changes in the exchange rate for the following years, both with a sign consistent with our model.

Related Literature Starting with the early work on international real business cycle models by Backus, Kehoe, and Kydland (1992), and Baxter and Crucini (1995), a large literature has explored the international transmission of shocks, co-movements between countries, and the dynamics of the RER in multi-country DSGE models. The dynamics of the RER have been found troubling to reproduce, be it in real models driven by TFP shocks as in Heathcote and Perri (2002)), or richer models as in Chari, Kehoe, and McGrattan (2002). Relative to this general literature, we show that our endogenous growth model can improve the ability of the IRBC to generate exchange rate dynamics by making productivity endogenous and responsive to other shocks. Closest to ours is probably the paper by Rabanal and Rubio-Ramirez (2015), who argue for looking at the full spectrum of the RER to validate models and demonstrate that a model with co-integrated TFP shock processes can match these dynamics. However, their model relies on very low short- and long-run trade elasticities. In contrast, we are able to match a richer set of facts while using a trade elasticity in line with micro estimates and using only stationary shocks to endogenously induce 
persistent movements in the RER. Because of this, we do not rely either on the strong pricing effect at the core of Corsetti, Dedola, and Leduc (2008). ${ }^{6}$

There is a long tradition in international macroeconomics in analyzing the ability of various business cycle models to capture aspects of the dynamics of the RER. In putting demand and technology shocks at the forefront, we depart from the tradition of using nominal models with monetary shocks to explain RER fluctuations. In this respect, we share Berka, Devereux, and Engel (2012)'s view that monetary shocks do not contribute strongly to the dynamics of RERs not only in the short run (a view also shared by Chari, Kehoe, and McGrattan (2002) and Steinsson (2008)) but also in the long run.

Our paper is also related to models that study entry and innovation in the open economy. Ghironi and Melitz (2005) show how entry of new varieties into production and export can lead to deviations from PPP in an IRBC and, through discrepancies between the welfare-relevant and the statistical price index, improve some of the international co-movement implications of the model. Our setup, while related, does not work through mismeasured prices and focuses on the dynamics of the RER. Alfaro, Cunat, Fadinger, and Liu (2018) studies the effect of changes of the RER on innovative behavior at the micro level. In our model, RER and innovation are jointly determined and our focus is on macro-dynamics. ${ }^{7}$

Another recent strand of the literature has explored the ability of models with Epstein-Zin preferences to explore international asset prices and their co-movement. Salient examples can be found in Colacito and Croce (2011), Colacito and Croce (2013), and Farhi and Gabaix (2015). Using this framework, Grüning (2017) and Gavazzoni and Santacreu (2019) demonstrate that the addition of endogenous growth can help explain a set of otherwise puzzling facts in international finance. Relative to these papers, we do not rely on the long-run risk channel to explain the exchange rate and we provide a full model estimation, forcing it to be consistent with larger set of facts. Most importantly, we provide, for the first time, a fully endogenous framework rationalizing low-frequency exchange rate dynamics.

Finally, we share many aspects with the estimation exercise of Alessandria and Choi (2019), especially as both focus on the role of trade flows. However, while they use their model to account for the dynamics of the U.S trade balance in a rich trade model, we focus on the RER on an international finance framework imposing extra constraints coming from macro aggregates. Part of the short-run dynamics induced by endogenous growth resonate with the work by Raffo (2010), and Karabarbounis (2014). That literature combines Greenwood, Hercowitz, and Huffman (1988)-preferences with investment specific technology shocks or shocks to the labor wedge, to generate short-run dynamics

\footnotetext{
${ }^{6}$ Another recent paper looking at the spectrum of some macro time series is Beaudry, Galizia, and Portier (2020), who study the spectrum of labor market, investment, and credit variables. Their focus is different from ours. While we are mainly pointing to the large mass at frequencies longer than the business cycle, Beaudry, Galizia, and Portier (2020) focus on the shape of the spectrum to argue for the presence of cyclical swins with a length of roughly 10 years. For our study the exact shape of the spectrum is less central.

${ }^{7}$ For recent evidence of the importance of technology (news) for the U.S. business cycle see also the study by Cascaldi-Garcia and Vukotić (2020), who use patents to identify U.S. TFP news shocks in a VAR.
} 
in trade prices and quantities. The comovement arises as a result of an increase in consumption and investment demand that initially outpaces supply. In our endogenous growth framework, the desire to expand the technological frontier induces on impact similar dynamic forces. Nevertheless, our baseline model has additional supply and slow diffusion effects that shape the low-frequency dynamics of the exchange rate.

The structure of the paper is as follows. Section 2 present the full model. Section 3 explains the estimation exercise, while Section 4 collects the main results and performs robustness analysis. Section 5 shows the industry-level evidence. Section 6 concludes. The appendix collects additional empirical results and the equations characterizing a model equilibrium.

\section{Two-Country Model}

This section describes our two-country real business cycle model with endogenous growth. Time is discrete. Each country is populated by a representative household owning the capital stock and all firms within her country. Households trade a real non-contingent bond with each other, the only asset that is internationally traded. We call the first country the home country and the second country the foreign country. ${ }^{8}$ Our exposition concentrates on the description of the home country. All equations beside the structure of the bond are symmetric. Foreign variables are denoted by ' ${ }^{\prime}$.

\subsection{Household}

The representative household maximizes her expected discounted utility over consumption and labor given by

$$
\mathbb{E}_{0} \sum_{t=0}^{\infty} \prod_{s=0}^{t-1} \beta_{s}\left[\frac{\left(c_{t}-\psi_{1, t} x_{t} l_{t}^{1+\psi_{2}}\right)^{1-\sigma}}{1-\sigma}\right]
$$

where $c_{t}$ and $l_{t}$ denote consumption, and labor supply in period $t . \sigma$ is the household's parameter of risk aversion and $\psi_{2}$ the inverse Frisch elasticity. $\psi_{1, t}$ captures the level of dis-utility from working, which is subject to persistent shocks with law of motion:

$$
\log \left(\psi_{1, t}\right)=\bar{\psi}\left(1-\rho_{\psi}\right)+\rho_{\psi} \log \left(\psi_{1, t-1}\right)+\sigma_{\psi} \epsilon_{t}^{\psi}
$$

Here, $\rho_{\psi}$ parameterizes the persistence and $\sigma_{\psi}$ the volatility of deviations from the mean $\bar{\psi}$ of logged disutility. $\epsilon_{t}^{\psi}$ is an i.i.d. normally distributed disturbance with mean zero and variance one. Finally, $\beta_{t}$ denotes the household's discount factor between period $t$ and $t+1$. We assume the following law of motion for it:

$$
\log \left(\beta_{t}\right)=\bar{\beta}\left(1-\rho_{\beta}\right)+\rho_{\beta} \log \left(\beta_{t-1}\right)+\sigma_{\beta} \epsilon_{t}^{\beta},
$$

\footnotetext{
${ }^{8}$ In our quantitative analysis, we will identify the home country with the United States, and the foreign country with an aggregate of the other G7 countries.
} 
where $\rho_{\beta}$ parameterizes the persistence and $\sigma_{\beta}$ the volatility of deviations from the mean $\bar{\beta}$ of logged disutility. $\epsilon_{t}^{\beta}$ is an i.i.d. normally distributed disturbance with mean zero and variance one.

The dis-utility from working is also affected by the habit term $x_{t}$, which is governed by:

$$
x_{t}=\left(\bar{c}_{t}\right)^{\gamma} x_{t-1}^{1-\gamma}
$$

$\bar{c}_{t}$ is average consumption in the economy, which in equilibrium is equal to $c_{t}$, but is considered exogenous by the household. This specification allows us to have a low short-run wealth elasticity, while allowing for a balanced growth path in the absence of shocks. ${ }^{9}$

The household chooses $c_{t}, l_{t}$, investment $i_{t}$, capital utilization $u_{t}$, and holdings of foreign bonds $b_{t}$ subject to the budget constraint:

$P_{t} c_{t}+P_{t} i_{t}+P_{t}^{*} b_{t}=P_{t} W_{t} l_{t}+P_{t} R_{t}^{k} u_{t} k_{t-1}+\Pi_{t}+T_{t}+R_{t-1}^{*} P_{t}^{*} b_{t-1} \exp \left(U_{t}\right) \exp \left(\frac{\bar{b}_{t-1}}{A_{t-1}}\right)^{-\phi_{1}}\left(\frac{\mathbb{E}_{t-1} R E R_{t}}{R E R_{t-2}}\right)^{-\phi_{2}}$.

Here, $P_{t}$ is the price of the retail goods in the home country, while $P_{t}^{*}$ is the price of retail goods in the foreign country. $W_{t}$ and $R_{t}^{k}$ are the wage per unit of labor supply and the rental rate per unit of capital services, both in units of the retail good. $\bar{b}_{t-1}$ is last period choice of the level of bonds in the country, which the household takes as exogenous. $\Pi_{t}$ are profits and $T_{t}$ lump sum taxes, which are paid to the household by firms and the government, respectively. $R E R_{t}:=\frac{P_{t}^{*}}{P_{t}}$ is the real exchange rate between the two countries. $R_{t}^{*}$ is the return on a foreign bond from period $t$ to $t+1$ in units of the foreign good. We assume that the bond's return is affected by an adjustment cost in levels consistent with Schmitt-Grohé and Uribe (2003). ${ }^{10} \phi_{1}$ parameterizes those adjustment costs (for a structural interpretation, see Fisher (2014)). In addition, in some of our experiments we allow for the additional adjustment cost parameterized by $\phi_{2} \geq 0$ following Adolfson, Laséen, Lindé, and Villani (2008). ${ }^{11} A_{t}$ is the total number of varieties the home country uses in production, a measure of its technical development as explained later. Here, we use $A_{t-1}$ to normalize the cost of holding bonds to induce stationarity relative to the endogenous trend.

$k_{t}$ denotes the capital stock at the end of period $t$, which follows the law of motion:

$$
k_{t}=\left(1-\delta_{k}\left(u_{t}\right)\right) k_{t-1}+q_{t}\left(1-\phi_{i}\left(\frac{i_{t}}{i_{t-1}}\right)\right) i_{t}
$$

$\delta_{k}($.$) denotes the change in capital depreciation when the household adjusts capital utilization, while$ $\phi_{i}($.$) denotes investment adjustment costs. The accumulation of capital is subject to a marginal$

\footnotetext{
${ }^{9}$ Here we deviate from Jaimovich and Rebelo (2009) and follow, for example, Galí, Smets, and Wouters (2012) and Campbell, Fisher, Justiniano, and Melosi (2017).

${ }^{10}$ We assume that portfolio adjustment costs are rebated back to the household as a lump sum payment.

${ }^{11}$ As we discuss in the result section, this addition is not crucial for our results. The main effect of these costs is to induce hump shaped exchange rate dynamics in the short run.
} 
efficiency shock with law of motion:

$$
\log \left(q_{t}\right)=\rho_{q} \log \left(q_{t-1}\right)+\sigma_{q} \epsilon_{t}^{q},
$$

where $\rho_{q}$ parametrizes the persistence and $\sigma_{q}$ the volatility of the disturbance. $\epsilon_{t}^{q}$ is an i.i.d. normally distributed shock with mean zero and variance one. $U_{t}$ is a shock to the uncovered interest rate parity (UIP) condition with the law of motion given by:

$$
\log \left(U_{t}\right)=\rho_{U} \log \left(U_{t-1}\right)+\sigma_{U} \epsilon_{t}^{U},
$$

where $\rho_{U}$ parametrizes the persistence and $\sigma_{U}$ the volatility of deviations from $0 . \epsilon_{t}^{U}$ is an i.i.d. normally distributed disturbance with mean zero and variance one.

The problem of the foreign household differs in two aspects. From her perspective, the bond is settled in the final good of her country and, therefore, following a common convention in the literature she is not subject to a bond adjustment cost or UIP shocks.

\subsection{Retailers}

Final goods, which are used for private and public consumption, investment, and the development of new input goods, are assembled by retailers using domestic and imported brands purchased from wholesalers. They sell their output in competitive markets and are price takers in their interaction with wholesalers. There is a continuum of wholesalers of each type, indexed by $i \in[0,1]$, who produce the wholesale good as explained in the next subsection, which they sell in competitive markets to retailers.

Given the domestic price level $P_{t}$, the retailer buys $y_{D, t}$ units of the domestic wholesale good and $y_{I, t}$ units of import wholesale good at prices $p_{D, t}$ and $p_{I, t}$ to produce $Y_{t}$ units of the final good. The decision problem of the representative retailer is:

$$
\begin{gathered}
\max _{Y_{t}, y_{D, t}, y_{I, t}} \sum_{t}^{\infty} \Lambda_{t \mid 0}\left(P_{t} Y_{t}-p_{D, t} y_{D, t}-p_{I, t} y_{I, t}\right) \\
\text { s.t. } Y_{t}=\left(a_{D} y_{D, t}^{\rho}+a_{I}\left(\phi_{t} y_{I, t}\right)^{\rho}\right)^{\frac{1}{\rho}} \\
\phi_{t}=1-\frac{\iota}{2}\left(\frac{\frac{y_{I, t}}{y_{D, t}}}{\frac{y_{I, t-1}}{y_{D, t-1}}}-1\right)^{2} .
\end{gathered}
$$

Here $a_{D}$ and $a_{I}$ are constants that parameterize the degree of home bias in goods, while $\rho$ parameterizes the elasticity of substitution. We assume that production is subject to adjustment costs on the mix of import and domestic goods to capture a lower short-term elasticity of substitution parameterized by $\iota{ }^{12}$ Therefore, the retailer's problem is intertemporal and the retailer uses a discount

\footnotetext{
${ }^{12}$ Ruhl et al. (2008) discusses the need for different short run and long run elasticities. We address this issue using
} 
factor $\Lambda_{t \mid 0}$ induced by its owner, the household, to make its decisions.

\subsection{Wholesalers}

Domestic wholesalers produce their goods using labor and capital services rented from the domestic household and intermediate good varieties bought from domestic intermediate good producers. They are price takers with respect to their inputs and output good. The problem of the wholesaler of a domestic brand is:

$$
\max _{y_{D, t}, L_{D, t}, \bar{K}_{D, t},\left[m_{i, D, t}\right]_{i=0}^{1}, M_{D, t}} p_{D, t} y_{D, t}-P_{t} W_{t} L_{D, t}-P_{t} R_{t}^{k} \bar{K}_{D, t}-\int_{0}^{A_{t-1}} q_{i, t} m_{i, D, t} d i .
$$

$p_{D, t}$ denotes the sales price charged by the wholesaler, $L_{D, t}$ and $\bar{K}_{D, t}$ are the amounts of labor and capital services, respectively, used in production. $A_{t-1}$ is the mass of intermediate good varieties available at time $t$. Variety $i$ has price $q_{i, t}$ and $m_{i, D, t}$ units are purchased by the wholesaler. $M_{D, t}$ is a Dixit-Stiglitz aggregator of the different varieties of intermediate goods, where $\mu$ parametrizes the elasticity of substitution,

$$
M_{D, t}=\left(\int_{0}^{A_{t-1}} m_{i, D, t}^{\mu} d i\right)^{\frac{1}{\mu}} .
$$

The production function of the wholesaler is

$$
\begin{aligned}
y_{D, t} & =Z_{t} \bar{K}_{D, t}^{\alpha_{K}} L_{D, t}^{\alpha_{L}} M_{D, t}^{\alpha_{M}} \\
\log \left(Z_{t}\right) & =\log (\bar{Z})\left(1-\rho_{Z}\right)+\rho_{Z} \log \left(Z_{t-1}\right)+\epsilon_{t}^{Z} .
\end{aligned}
$$

Here, $\alpha_{K}, \alpha_{L}, \alpha_{M}$ parametrize the weights of capital, labor, and the aggregate of intermediate goods in the production function. $Z_{t}$ is a TFP shock, where $\rho_{Z}$ parametrizes the persistence and $\sigma_{Z}$ the volatility of deviations from the mean $\bar{Z}$ of logged productivity. $\epsilon_{t}^{Z}$ is an i.i.d. normally distributed disturbance with mean zero and variance one.

The problem of the wholesalers of imported brands is similar but with two distinctions: the goods are produced in the foreign economy and they are subject to a trade cost shock. ${ }^{13}$

$$
\max _{y_{I, t}, L_{I, t}^{*}, \bar{K}_{I, t}^{*},\left[m_{i, I, t}^{*}\right]_{i=0}^{1}, M_{I, t}^{*}} p_{I, t} y_{I, t}-P_{t}^{*} W_{t}^{*} L_{I, t}^{*}-P_{t}^{*} R_{t}^{k, *} \bar{K}_{I, t}^{*}-\int_{0}^{A_{t-1}^{*}} q_{i, t}^{*} m_{i, I, t}^{*} d i
$$

adjustment costs following Erceg, Guerrieri, and Gust (2006). The cost allows our model to have a lower short-run elasticity of substitution relative to the long-run elasticity. The presence of these costs limits the pass-through of temporary exchange rate movements into quantities, given all models considered a better chance at generating volatile exchange rates while having empirical plausible implications for consumption and GDP. See also Drozd, Kolbin, Nosal, et al. (2019) for a discussion of the importance of these costs in generating plausible co-movement between countries and of plausible micro-foundations for the cost.

${ }^{13}$ For part of the paper, these shocks are turned off. However, when we estimate the model using import and export data, we add the shocks to give the model enough flexibility to match the data. 


$$
\begin{aligned}
M_{I, t}^{*} & =\left(\int_{0}^{A_{t-1}^{*}}\left(m_{i, I, t}^{*}\right)^{\mu} d i\right)^{\frac{1}{\mu}} \\
y_{I, t} & =\Omega_{t}^{g} \Omega_{t}^{l} Z_{t}^{*}\left(\bar{K}_{I, t}^{*}\right)^{\alpha_{K}}\left(L_{I, t}^{*}\right)^{\alpha_{L}}\left(M_{I, t}^{*}\right)^{\alpha_{M}} \\
\log \left(Z_{t}^{*}\right) & =\log \left(\bar{Z}^{*}\right)\left(1-\rho_{Z}^{*}\right)+\rho_{Z}^{*} \log \left(Z_{t-1}^{*}\right)+\epsilon_{t}^{Z, *} \\
\log \left(\Omega_{t}^{g}\right) & =\rho_{\Omega^{g}} \log \left(\Omega_{t-1}^{g}\right)+\epsilon_{t}^{\Omega^{g}} \\
\log \left(\Omega_{t}^{l}\right) & =\rho_{\Omega^{l}} \log \left(\Omega_{t-1}^{l}\right)+\epsilon_{t}^{\Omega^{l}}
\end{aligned}
$$

$\Omega_{t}^{g}$ and $\Omega_{t}^{l}$ are two shocks to the productivity of producing exports, where for $x \in\{g, l\} \rho_{\Omega^{x}}$ parametrizes the persistence and $\sigma_{\Omega^{x}}$ the volatility of deviations from the mean of 1 . $\epsilon_{t}^{\Omega}$ is an i.i.d. normally distributed disturbance with mean zero and variance one. We deviate slightly from the way we treat most of the shocks in the model. $\Omega_{t}^{g}$ is assumed to affect the producers of exports in both countries symmetrically, while $\Omega_{t}^{l}$ affects exports to country one as displayed above while it enters the other export problem as $\frac{1}{\Omega_{t}^{l}} \cdot{ }^{14}$

\subsection{Intermediate Good Producers}

Our setup for technological growth follows Comin and Gertler (2006) in the tradition of the endogenous growth model of Romer (1990). However, the economic mechanism that links endogenous technical change and exchange rates in this model is not specific to a particular model of technological progress. ${ }^{15}$

\subsubsection{Existing Intermediate Good Producers}

At the beginning of each period, there is a mass $A_{t-1}$ of intermediate good producers. Existing intermediate good producers turn final goods into intermediate goods. They are monopolists for the sail of their variety. In the following, we suppress the dependence on the producers' index $i$. Each period their optimization problem is given by

$$
\max _{q_{t}}\left(p_{t}-P_{t}\right) D_{M, t}\left(q_{t}\right)-\Phi .
$$

$D_{M, t}$ is the demand for each variety in period $t$, derived from the wholesaler's problem above. Denote the solution of the optimization problem as $\pi_{t}$, the per-period profits of the intermediate

\footnotetext{
${ }^{14}$ Here, we follow Alessandria and Choi (2019). The formulation allows us to capture better the symmetric expansion of trade over time. Results are very similar if we assume the two shocks to affect the export productivity in the country independently. However, filtered shocks to the two processes would be fairly correlated.

${ }^{15}$ An alternative would be to build on the Schumpeterian framework of Grossman and Helpman (1991) and Aghion and Howitt (1992), extended by Ates and Saffie (forthcoming) to the international business cycle literature. In fact, our results are consistent with the relative price movements in Benguria, Matsumoto, and Saffie (2020).
} 
producer. $\Phi$ is a fixed cost of operation. ${ }^{16}$ Each of them leaves the market at the end of the period with probability $\delta_{a}$ and the underlying variety is gone. Therefore, the value of a producer, $H_{t}$, at the beginning of the period is given by the recursive pricing equation:

$$
H_{t}=\pi_{t}+\mathbb{E}_{t}\left(1-\delta_{a}\right) \Lambda_{t, t+1} H_{t+1}
$$

$\Lambda_{t, t+1}$ denotes the stochastic discount factor induced by the household's preferences between period $t$ and $t+1$ as the domestic household is the final owner of the intermediate good producer.

\subsubsection{Technology Evolution and Innovation}

Entrepreneurs with a total measure of one, on behalf of the representative household, spend resources to generate new intermediate goods by developing new ideas on which they own monopoly rights. The introduction of new varieties follows a two-step process. First, entrepreneurs choose how much of the final good to invest into new technologies $N_{t}$. This investment is denoted by $S_{i, t}$, while $S_{t}$ denotes the aggregate investment. The maximization problem of the entrepreneur working on the first stage is

$$
\max _{S_{i, t}} \mathbb{E}_{t}\left(\zeta_{t} \frac{\left(N_{t-1}+\tau N_{t-1}^{*}\right)^{1-\eta}}{S_{t}^{1-\eta}} S_{i, t} \Lambda_{t, t+1} J_{t+1}-P_{t} S_{i, t}\right)
$$

The entrepreneur chooses $S_{i, t}$ to produce $\zeta_{t} \frac{\left(N_{t-1}+\tau N_{t-1}^{*}\right)^{1-\eta}}{S_{t}^{1-\eta}}$ new technologies tomorrow. Those still need to be turned into varieties that can be produced. Such an idea has a value $J_{t+1}$ tomorrow, whose determination is described below. As that value is determined tomorrow, it needs to be discounted with the factor $\Lambda_{t, t+1}$. Beside the investment itself, the number of varieties depends on three parts. First, $\zeta_{t}$ is a factor that scales the output. Second, $\tau N_{t-1}^{*}$ captures an exogenous spillover between countries. ${ }^{17}$ For $\tau>0$, a larger number of varieties in the foreign country makes R\&D in the home country more efficient, as the entrepreneurs can learn from the existing varieties. Finally, $\frac{N_{t-1}^{1-\eta}}{S_{t}^{1-\eta}}$ captures that higher aggregate spending on new technologies relative to the stock of existing technologies has decreasing returns to scale parametrized by $\eta$.

The production of new technologies is subject to a marginal efficiency shock with law of motion:

$$
\log \left(\zeta_{t}\right)=\left(1-\rho_{\zeta}\right) \bar{\zeta}+\rho_{\zeta} \log \left(\zeta_{t-1}\right)+\sigma_{\zeta} \epsilon_{t}^{\zeta}
$$

where $\rho_{\zeta}$ parametrizes the persistence and $\sigma_{\zeta}$ the volatility of the disturbance. $\epsilon_{t}^{\zeta}$ is an i.i.d. normally distributed shock with mean zero and variance one.

\footnotetext{
${ }^{16}$ We choose the size of the fixed cost, so that, in concert with all other calibration targets and parameter restrictions, we arrive at a plausible profit share in GDP along the balanced growth path.

${ }^{17}$ This formulation follows, for example, Gavazzoni and Santacreu (2019).
} 
The aggregate law of motion of technologies is

$$
N_{t}=\left(1-\delta_{n}\right) N_{t-1}+\gamma_{t}
$$

where, in a symmetric equilibrium $S_{i, t}=S_{t}$.

$$
\gamma_{t}:=\zeta_{t}\left(N_{t-1}+\tau N_{t-1}^{*}\right)^{1-\eta} S_{t}^{\eta}
$$

In the second step, entrepreneurs choose how much final goods $a_{t}$ to invest in each unadopted technology to turn them into the blueprint for a new intermediate good. Their problem at this stage is

$$
J_{t}=\max _{a_{t}}\left[-P_{t} a_{t}+\mathbb{E}_{t} \Lambda_{t, t+1}\left(\lambda_{t}\left(a_{t}\right) H_{t+1}+\left(1-\lambda_{t}\left(a_{t}\right)\right)\left(1-\delta_{n}\right) J_{t+1}\right)\right] .
$$

The cost of adopting an idea is $P_{t} a_{t}$. The probability of turning the unadopted idea into a new variety next period is $\lambda_{t}\left(a_{t}\right) . \lambda_{t}$ is a concave, increasing function measuring the basic probability of adoption. If adoption is not successful, the unadopted technology becomes obsolete with probability $\delta_{n}$, otherwise the entrepreneur can try again next period. ${ }^{18}$

The resulting aggregate law of motion of intermediate goods at the end of the period is then

$$
A_{t}=\left(1-\delta_{a}\right) A_{t-1}+\lambda_{t}\left(a_{t}\right)\left(N_{t-1}-A_{t-1}\right)
$$

\subsection{Government}

We assume that the domestic government consumes a fraction $G_{t}$ of the domestic product. This fraction is stochastic and governed by the law of motion:

$$
\log \left(G_{t}\right)=\bar{G}\left(1-\rho_{G}\right)+\rho_{G} \log \left(G_{t-1}\right)+\epsilon_{t}^{G},
$$

where $\rho_{G}$ parameterizes the persistence and $\sigma_{G}$ the volatility of deviations from the mean of the logged government to output ratio $\bar{G}$. $\epsilon_{t}^{G}$ is an i.i.d. normally distributed disturbance with mean zero and variance one. Government spending is financed by lump sum taxes.

\subsection{Equilibrium and Model Solution}

The equations characterizing the dynamic equilibrium are collected in the Appendix. International price movements together with exogenous spillovers ensure that, in the long run, the two economies fluctuate around a common trend. We normalize the model equations by the common stochastic trend and solve by log-linearization around the stochastic growth path.

\footnotetext{
${ }^{18}$ In some of our experiments, we assume that the shock to $\zeta_{t}$ also moves $\lambda_{t}$ proportionally. In these cases $\lambda_{t}$ is replaced by $\lambda_{t} * \frac{\zeta_{t}}{\zeta}$.
} 


\subsection{Exogenous Growth Benchmark}

To better highlight the role of endogenous growth, we generate an alternative economy with exogenous growth as a comparison point. To keep this alternative model as close as possible to the baseline economy, we only introduce two modifications. First, we assume that the flow of new varieties is constant at the balanced growth path rate targeted in the calibration. Second, we remove the costs of $R \& D$ and adoption from the resource constraint and the definition of profits, and we increase proportionally the fixed cost in order to keep the available resources for production at the same level in the two models along the balanced growth path.

\section{Calibration and Estimation}

To understand the ability of endogenous productivity to generate low-frequency fluctuations of the RER, we will compare two different versions of the baseline and exogenous growth economies. First, we simplify the model along several dimensions to highlight the effect of endogenous productivity on the RER. For this first experiment, we only estimate the parameters related to the shock processes in each model for a subset of these shocks using some basic macroeconomic time series to discipline these. The rest of the parameters are externally calibrated. The second version estimates the full model. Besides all the shocks, we also estimate structural parameters that are important for the model's fit along key dimensions and for which previous work does not give tight priors. Therefore, we can assign parameters to two groups.

The first group of parameters is calibrated to match moments along the balanced growth path or assigned typical values from other studies. The second group is estimated across all experiments using Bayesian methods and quarterly data from 1972 to 2016. The Bayesian estimation of the parameters uses the methods discussed, for example, in An and Schorfheide (2007). ${ }^{19}$

\subsection{Calibrated Parameters}

We calibrate most parameters in the first group targeting moments of the United States over the period from the first quarter of 1973 to the last quarter of 2016. Trade and exchange rate related moments are with respect to the other G-7 countries (Canada, France, Germany, Italy, Japan, U.K.) weighted by U.S trade weights. ${ }^{20}$ Besides the shock processes, every fundamental parameter is symmetrical between the countries. Therefore, both countries share a common non-stochastic balanced growth path.

\footnotetext{
${ }^{19}$ The estimation is performed using Dynare. For an introduction to Dynare, see Adjemian, Bastani, Juillard, Mihoubi, Perendia, Ratto, and Villemot (2011). In each estimation, we first found the posterior mode and then explored the posterior with the Metropolis Hasting algorithm. We drew multiple chains with 200,000 steps and kept the last 50 percent of each.

${ }^{20}$ Our trade data starts only in 1985 given data restrictions. We treat the previous quarters as missing when constructing our empirical targets.
} 


\section{Parameters: Household}

As we abstract from other factors influencing risk preferences, we set the risk aversion $\sigma$ to 5 , often argued to be a plausible upper bound on this parameter and commonly used in the international macroeconomics literature studying exchange rates (see, for example, Chari, Kehoe, and McGrattan (2002) and Steinsson (2008)). $\bar{\psi}_{1}$ is chosen to match a labor supply of $\frac{1}{3}$ along the balanced growth path given the other parameter choices. We set $\phi=0.01$ in line with Schmitt-Grohé and Uribe (2003) and Rabanal and Rubio-Ramirez (2015). While this parameter being larger than zero is needed to ensure the existence of a stationary equilibrium relative to trend, it also affects exchange rate dynamics by driving a small wedge into the uncovered interest parity condition. ${ }^{21}$ For the utilization rate, we use the functional form $\delta_{k}(\cdot)=\bar{\delta}_{0}+\bar{\delta}_{1}(\cdot)^{1+\bar{\delta}_{2}} \cdot \bar{\delta}_{0}$ is set to generate a share of investment in GDP of 19 percent along the balanced growth path. $\bar{\delta}_{1}$ is calibrated to set the utilization rate to 1 on the balanced growth path.

\section{Parameters: Trade and Production, Technology Adoption}

In the problem of the retailer, we set $\rho=1.5$ and $\iota=10$, the latter to generate a smaller short-run than long-run elasticity of trade. We follow the parametrization of Erceg, Guerrieri, and Gust (2006), which are in line with recent empirical estimates by Boehm, Levchenko, and Pandalai-Nayar (2020) and related work by Drozd, Kolbin, Nosal, et al. (2019) on trade dynamics. ${ }^{22}$ We set $a_{D}$ and $a_{I}$ to match the average of the import-to-GDP ratio and export-to-GDP ratio of the U.S. with the other G-7 countries, which is 5 percent, and $a_{D}+a_{I}=1 .{ }^{23}$ We calibrate $\alpha_{K}, \alpha_{L}$, and $\alpha_{M}$ to $0.16,0.34$, and 0.5 , respectively. The resulting share of labor in the value added production function is 68 percent and the share of intermediate goods in total expenditures is 50 percent of gross production, both in line with typical calibrations in the literature based on national accounts. $\bar{Z}$ is normalized so that the ratio of GDP to technology $A_{t-1}$ is set to $1 . \Phi$ is calibrated to match a profit share in GDP of 10 percent, roughly at the higher end of values based on national account data. $\mu$ is set to ensure the exis10ce of a balanced growth path, resulting in $\mu=1.52$. We set $\delta_{n}=0.025$ and $\delta_{a}=0.025$, common values in the literature (see, for example, Comin and Gertler (2006) and Anzoategui, Comin, Gertler, and Martinez (2019)). As the functional form for the probability of adoption, we set $\lambda(\cdot):=\bar{\lambda}(\cdot)^{\mu_{\lambda}}$. We calibrate the average adoption rate to five years, pinning down $\bar{\lambda}$ from the balanced growth path (Comin and Gertler (2006)). $\bar{\zeta}$ is set to achieve a growth rate of 1.68 percent annualized, the average growth rate between our two countries in the data. Finally, we calibrate $\bar{g}$, so that the government

\footnotetext{
${ }^{21}$ We have experimented with estimating $\phi_{1}$ or using a smaller value. The results are similar to the one presented in the paper, with only mild changes to the estimated properties of the UIP shock.

${ }^{22}$ By setting a long run trade elasticity clearly above 1, our results are different from the channel proposed by Corsetti, Dedola, and Leduc (2008), which relies on a low short and long run elasticity of substitution

${ }^{23}$ We use GDP, consumption, investment, and trade data to discipline our estimation. As such the government expenditure shock will capture both movements in government expenditures and net-exports with other non-G-7 countries. In this sense, it should be more thought of as an 'autonomous expenditure shock', an interpretation effectively used in many closed economy DSGE models, see, for example, Smets and Wouters (2007).
} 
expenditure to GDP ratio is 19 percent along the balanced growth path, similar to the U.S. value over this time period. Table 1 summarizes the calibrated parameters.

Table 1: Calibrated Parameters

\begin{tabular}{|l|c|l|}
\hline Parameter & Value & Interpretation \\
\hline$\sigma$ & 5 & Risk Aversion \\
$\phi_{1}$ & 0.01 & Bond Holding Cost \\
$\bar{\delta}_{0}$ & 0.015 & Capital Depreciation BGP \\
$\rho$ & 1.5 & Elasticity Substitution Home and Foreign Good \\
$\iota$ & 10 & Trade Adjustment Cost \\
$a_{D}$ & 0.9820 & Scale Preference Home Good \\
$a_{I}$ & 0.0898 & Scale Preference Foreign Good \\
$\alpha_{K}$ & 0.32 & Capital Share Production \\
$\alpha_{L}$ & 0.68 & Labor Share Production \\
$\alpha_{M}$ & 0.5 & Share Intermediate Goods Production \\
$\bar{Z}$ & 2.375 & Scale Production \\
$\Phi$ & 0.258 & Fixed Cost Production \\
$\mu$ & 1.52 & Elasticity of Substitution Intermediate Goods \\
$\delta_{n}$ & 0.025 & Obsolescence of New Ideas \\
$\delta_{a}$ & 0.025 & Obsolescence of Adopted Products \\
$\bar{g}$ & 0.106 & Government Expenditure Share of Production \\
\hline
\end{tabular}

Notes: This table lists the parameters that are calibrated to values shown here in most of our exercises. See the text for the details on the calibration targets. We omit scale parameters like $\bar{\psi}_{1}$ as they depend on estimated parameters and are, therefore varying across different exercises.

\section{Parameters: Calibrated for the simple model}

The following parameters are estimated in our second exercise, but we calibrate them in the simple model that we use for explaining the effects of endogenous growth on the RER dynamics. When they are not estimated, we set them as follows. We choose a Frisch elasticity of $\frac{1}{3}\left(\psi_{2}=3\right)$, well within values in the literature and not too far from our own estimates shown later. The wealth effect of labor supply $\gamma$ is set to 0.05 , slightly higher than Jaimovich and Rebelo (2009), generating small wealth effects in the labor supply. This value is close to our later estimates and close to the one found in the estimation of the exogenous growth model. The same applies to our next choice. We use the following functional form $\phi_{i}(\cdot)=\bar{\phi}_{i}((\cdot)-1)^{2}$ for the investment adjustment cost, setting $\bar{\phi}_{i}=0.5$, within the wide variety of estimates found by the literature. Finally, we set $\phi_{2}=0$ and remove utilization from the simple model.

For the endogenous growth parameters, we face parameter uncertainty as well and so we, again, choose them based on our later estimation results. However, we should mention that the elasticity parameters are towards the lower end typically found and that higher values would lead to even stronger effects of endogenous growth on model dynamics and the RER. Having said this, we set 
$\tau=0.1, \eta=0.15$, and $\mu_{\lambda}=0.15$. Table 2 summarizes the additional calibrated parameters for the simple model.

Table 2: Additional calibrated Parameters for Simple Model

\begin{tabular}{|l|c|l|}
\hline Parameter & Value & Interpretation \\
\hline$\psi_{2}$ & 3 & Inverse Frisch Elasticity \\
$\gamma$ & 0.05 & Wealth Effect on Labor Supply \\
$\bar{\phi}$ & 0.5 & Elasticity of Investment Adjustment Costs \\
$\phi_{2}$ & 0 & Exogenous Persistence of Real Exchange Rate \\
$\tau$ & 0.1 & International innovation Spillover \\
$\eta$ & 0.15 & Elasticity New Technologies to R\&D Spending \\
$\mu_{\lambda}$ & 0.15 & Elasticity Adoption to Adoption Spending \\
\hline
\end{tabular}

Notes: This table lists the parameters that are calibrated to values shown here in our simple model. They will be estimated in the full estimated exercise. See the text for the details on the calibration targets.

\subsection{Data and Estimation}

We interpret the home country as the United States and the foreign country as the other G-7 countries. To estimate the remaining parameters of the model, we take quarterly data on GDP growth, private consumption growth, investment growth, and total hours growth, all in per capita terms and seasonally adjusted, from the database in Ohanian and Raffo (2012) running from the second quarter of 1972 to the last quarter of 2016 for the G-7 countries. We aggregate the G-7 excluding the United States using relative trade weights constructed from import and export data from the BEA. Using data on nominal exchange rates from the Federal Reserve Bank of St.Louis's Fred database with data on the CPI price level from the IFS data set of the IMF, we also construct RER measures for the U.S. relative to the other G-7 countries. We aggregate them in the same fashion as the other series. In addition, we take U.S. import and export data with the other G-7 countries to construct import and export measures going back to $1985 .{ }^{24}$ Finally, we collect R\&D spending data for the U.S. from the Federal Reserve Bank of St. Louis' Fred database and yearly R\&D expenditures for the other G-7 countries from the OECD. All series are adjusted for seasonality. ${ }^{25}$

Using the above data, we perform a set of Bayesian estimations, which we will detail in the result section. We specify standard priors for all parameters, summarized in Table 3, which we hold constant throughout the estimation exercises. ${ }^{26}$

\footnotetext{
${ }^{24}$ Our measures of trade in goods and services do not go back all the way to 1985, but they start in 1999 . To fill in the gap, we extend the series back using growth rates in exports and imports of goods, effectively assuming that the growth rate was the same for both categories.

${ }^{25}$ As mentioned before, we weight data from the G-7 excluding the U.S. based on trade weights constructed from U.S. exports and imports. To be more specific, we weight the observations of each country in each quarter by the sum of exports and imports in that quarter of the country to and from the U.S. divided by the sum of exports and imports of all six countries in that quarter to and from the United States. As our trade data starts only in 1985, we use the trade weights for the first quarter of 1985 to weight observations before 1985. Our results are robust to using,
} 
Table 3: Prior Distributions

\begin{tabular}{|l|l|c|c|}
\hline Parameter & Type & Mean & Standard Deviation \\
\hline$\sigma_{x}, x \in\left\{\psi_{1}, q, g, \zeta, \Omega^{g}, \Omega^{l}\right\}$ & Inverse Gamma & 0.02 & 0.02 \\
$\sigma_{x}^{*}, x \in\left\{\psi_{1}, q, g, \zeta\right\}$ & Inverse Gamma & 0.02 & 0.02 \\
$\sigma_{x}, x \in\{Z, \beta\}$ & Inverse Gamma & 0.002 & 0.002 \\
$\sigma_{x}^{*}, x \in\{Z, \beta\}$ & Inverse Gamma & 0.002 & 0.002 \\
$\sigma_{U}$ & Uniform & 0.005 & 0.003 \\
$\rho_{x}, \forall x$ & Beta & 0.5 & 0.15 \\
$\rho_{x}^{*}, \forall x$ & Beta & 0.5 & 0.15 \\
$\bar{\phi}_{i}$ & Gamma & 2 & 1 \\
$\delta_{2}$ & Gamma & 1 & 0.25 \\
$\psi_{2}$ & Gamma & 2 & 1 \\
$\gamma$ & Gamma & 0.1 & 0.05 \\
$\phi_{2}$ & Beta & 0.5 & 0.2 \\
$\mu_{\lambda}(\#)$ & Beta & 0.5 & 0.15 \\
$\eta(\#)$ & Beta & 0.5 & 0.15 \\
$\tau(\#)$ & Gamma & 0.1 & 0.05 \\
\hline
\end{tabular}

Notes: This table lists the priors used in the estimation. Parameters with a (\#) are absent in the comparison model without endogenous growth.

\section{Results}

In this section, we discuss the main results from the quantitative exercise. We first estimate a streamlined version of the baseline model and compare it to its exogenous growth counterpart to illustrate how endogenous growth generates more persistent exchange rate dynamics. As a second step, we perform a full estimation of the baseline model and its exogenous growth counterpart. This exercise targets the RER in the data, but we find that only the endogenous growth models produce reasonable moments of the RER. The third part of this section explores the main determinants of the model success. The interaction between trade and endogenous productivity is key for the empirical success of the baseline model. For the endogenous growth model, including trade data and shocks in the estimation helps to generating low-frequency fluctuations on the exchange rate.

\subsection{Endogenous Productivity and the Exchange Rate}

We begin with a simplified version of the baseline model. First, we abstract from capital utilization and assume a fixed depreciation rate. Second, we set $\phi_{2}=0$, eliminating the bond adjustment cost à la Adolfson, Laséen, Lindé, and Villani (2008). Third, we remove the trade shocks and the trade adjustment costs from the model. Fourth, we abstract from R\&D, preference, and UIP shocks,

for example, the average weight from 1985 to 1989 instead.

${ }^{26}$ We experimented with the shape and parameters of the priors. In all experiments we performed, as long as the priors were sufficiently diffuse, the results of the paper remained close to the ones reported. For comparability and brevity we do not report these robustness checks. We set the prior for the standard deviation of the UIP shock to a uniform to avoid influencing the estimate as much as possible, but we show results for a prior with more curvature in the robustness section. 
keeping only TFP shocks, government expenditure shocks, investment efficiency shocks, and the labor supply shock. Fixing most parameters at the values discussed in the previous section, we only estimate the shocks processes using consumption, GDP, hours, and investment growth rates. We use the same loose priors summarized in the previous section when estimating the underlying shocks.

Table 10 in the Appendix shows the posterior estimation results. Both models imply similar estimates for the shock processes. The exogenous growth model has more volatile and persistent innovations for the investment efficiency shock as well as higher investment adjustment costs, pointing to less internal amplification of investment fluctuations. Importantly, the log data density clearly favors our endogenous productivity specification over the exogenous version. This finding is consistent with recent studies showing that endogenous productivity models fit the data better (Comin and Gertler (2006) and Guerron-Quintana and Jinnai (2019)).

To assess if the differences between the endogenous and exogenous growth model are due to differences in the estimated parameters of the shock processes, we also include a version of the exogenous growth model, where the shock processes are parameterized to be the ones estimated for the endogenous growth model.
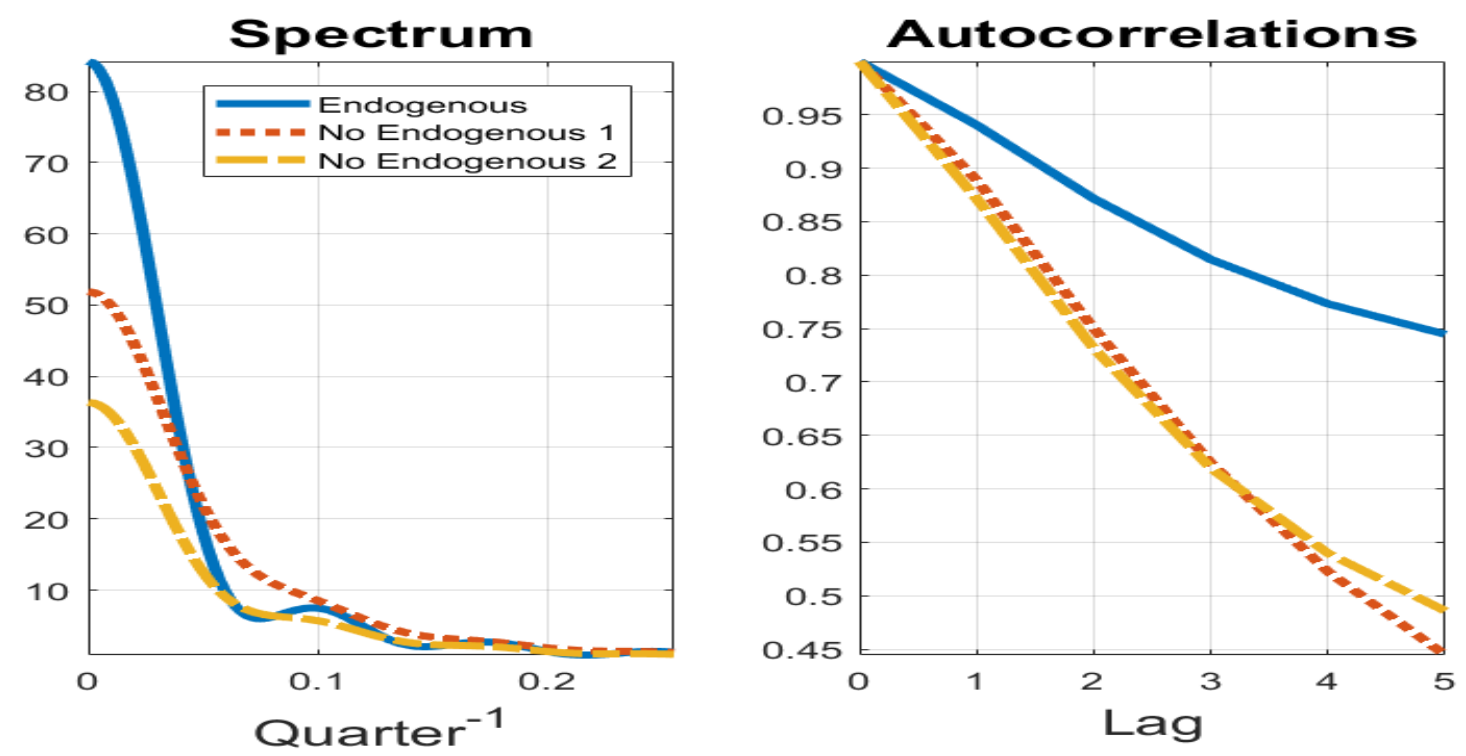

Figure 4: Endogenous Growth and the Exchange Rate

Notes: The left panel shows the spectrum and the right one the autocorrelation generated by the simple model based on the theoretical moments of the model. The blue line shows the results for the estimated simple endogenous growth model. The red line ('No Endogenous 1') shows the results for the estimated simple exogenous growth model. The yellow line ('No Endogenous 2') shows the results for the simple exogenous growth model when we use the standard deviation and persistence parameters estimated for the simple endogenous growth model to compute moments.

Figure 4 compares the spectra and autocorrelation functions for the exchange rate computed at the posterior mode in the three models - here, 'no endogenous 1' denotes the estimated exogenous growth model, while, 'no endogenous 2' denotes the model when we fix the parameters to the ones we estimated from the endogenous growth model. The left panel shows that the endogenous growth model produces significantly more lower-frequency variation as measured by the spectrum relative to 
the two exogenous growth models. The right panel shows that the endogenous growth model exhibits more persistence at any lag. In fact, at the fifth lag, the endogenous growth model almost doubles the autocorrelation of the other two. Thus, the endogenous growth model generates more volatile and persistent exchange rate dynamics. As we can see from comparing the results from the two parametrizations of the exogenous growth model, differences in the estimated stochastic processes do not explain the difference between the endogenous and exogenous growth models with respect to the exchange rate. If anything, switching to the stochastic process estimated endogenous growth model worsens the ability of the exogenous growth model to generate low-frequency variations. Instead, the internal propagation of the model is the key source of the amplification in exchange rate volatility and autocorrelation.

This simple version of the model shows that endogenous growth has the potential to generate a volatile and persistent RER in a standard international real business cycle model. As we will see momentarily, disturbances in our benchmark model trigger persistent gaps in consumption, production, and productivity, which results in the low-frequency movements in exchange rates. The main difference between these models is the stochastic properties behind these series. ${ }^{27}$ In fact, facing the same realization of shocks, agents in the endogenous growth model expect persistent differences in productivity and output, while agents in the exogenous growth models see these differences as transitory. These differences in expectations when facing the same macroeconomic data are the source of the relative volatility and persistence of the endogenous growth model.

A potential caveat with this first analysis is that the exogenous growth model is too simplistic to explain exchange rate dynamics. Hence, it is hardly surprising that the endogenous version outperforms it. The next subsection estimates the full model, which allows for many features that international macroeconomic models have used to rationalize exchange rate movements. Therefore, forcing our mechanism to compete with other potential channels and show that the internal amplification of the baseline model is indeed needed to capture the low-frequency movements of the exchange rate.

\subsection{Full Estimation Results}

Now, we proceed to the estimation of the full model. The estimation of the exogenous growth model includes trade and exchange rate time series. The baseline endogenous growth model estimation also includes $\mathrm{R} \& \mathrm{D}$ data for both countries to force the estimation to match the empirical properties of innovation efforts.

We estimate two versions of the endogenous growth model that only differ on the treatment of the R\&D data. The first version counts development and adoption expenditures as the model counterpart

\footnotetext{
${ }^{27}$ Given that we use GDP, investment, and hours in the estimation, when constructing the capital stock using the perpetual inventory method, as it is often done in the literature, the two models would imply the same in sample Solow residual. We can also use the model capital stock directly to adjust for the effects of variations in depreciation and the investment-specific shock. Using the fully fledged endogenous and exogenous growth model the between-model correlations between filtered TFP growth rates is more than 0.92 for both countries and the volatility is less than ten percent larger in the endogenous growth model. In the simple model discussed here the series are even more similar.
} 
of $R \& D$ and assumes that the $R \& D$ productivity shock boosts both margins, while the second version only uses the expenditure on development of new technologies as the model counterpart. In this subsection we limit most of our analysis to the first version, as, in general, results between the two versions are rather similar, with the former providing a slightly better fit. ${ }^{28}$

Table 11 in the Appendix shows the estimation results for the shock processes in the model. The baseline endogenous growth model requires a less volatile investment shock and less volatility on the UIP shock, pointing to the internal amplification of the model on investment and exchange rate dynamics. Table 4 in turn shows the posterior distributions of the eight parameters included in the estimation. The model selects relatively low elasticities of endogenous growth to spending $\left(\mu_{\lambda}\right.$ and $\left.\eta\right)$. Interestingly, when the $\mathrm{R} \& \mathrm{D}$ expenditure model counterpart only includes the first stage development cost, the estimation results in less curvature in both R\&D stages and less between country technology spillovers $(\tau)$. The endogenous growth model selects lower investment adjustment $\operatorname{costs}\left(\phi_{i}\right)$ given that it needs considerably less volatility on the exogenous investment shock. The estimated depreciation elasticity to capital utilization $\left(\delta_{2}\right)$ is larger in the endogenous growth model while there is no difference on the estimated Frisch Elasticity $\left(\frac{1}{\psi_{2}}\right)$. The endogenous growth model has slightly larger wealth effects $(\gamma)$, and it requires a lower exchange rate based bond adjustment $\operatorname{cost}\left(\phi_{2}\right)$.

Table 4: Posterior Estimation - Main Specifications 2 - Other Parameters

\begin{tabular}{|l|c|c|c|}
\hline Parameter & Endogenous & $\begin{array}{c}\text { Endogenous } \\
\text { Parameter }\end{array}$ & Exogenous \\
\hline$\mu_{\lambda}$ & 0.082 & 0.117 & \\
$\eta$ & {$[0.029,0.132]$} & {$[0.044,0.192]$} & \\
$\tau$ & 0.127 & 0.136 & \\
& {$[0.061,0.193]$} & {$[0.066,0.229]$} & \\
$\phi_{i}$ & 0.097 & 0.081 & \\
$\delta_{2}$ & {$[0.024,0.164]$} & {$[0.016,0.163]$} & \\
& 0.021 & 0.016 & 0.186 \\
$\psi_{2}$ & {$[0.008,0.033]$} & {$[0.005,0.026]$} & {$[0.097,0.273]$} \\
$\gamma$ & 1.789 & 1.729 & 1.104 \\
$\gamma$ & {$[1.285,2.314]$} & {$[1.250,2.517]$} & {$[0.705,1.478]$} \\
$\phi_{2}$ & 4.739 & 5.742 & 4.475 \\
& {$[3.330,6.124]$} & {$[4.185,7.335]$} & {$[3.080,5.848]$} \\
\hline \hline Log Data Density & 0.068 & 0.071 & 0.053 \\
& {$[0.032,0.103]$} & {$[0.033,0.107]$} & {$[0.019,0.084]$} \\
& 0.234 & 0.226 & 0.343 \\
& {$[0.161,0.303]$} & {$[0.156,0.297]$} & {$[0.266,0.420]$} \\
\hline
\end{tabular}

Notes: This table lists the posteriors for selected parameters resulting from the estimation. The remaining results are in the appendix.

Table 5 shows selected business cycle moments (HP-filtered) for the baseline endogenous growth with both R\&D stages and the exogenous growth model. To simulate these moments, we create 10,000 simulations of length 179, the number of periods in our data set, from the model with the estimated parameters set at their posterior mean. To determine the shock realizations, we begin by filtering the historical data from 1972:Q2 to 2016:Q4, which gives us 179 period by period shock

\footnotetext{
${ }^{28}$ We explored both mappings between the data and the model, as it is not clear if adoption spending is fully reflected in the $R \& D$ series. It turns out this distinction matters little for our main result.
} 
realizations. ${ }^{29}$ Then we draw with replacement from these realizations to simulate the model. Finally, we filter the model series, compute the respective moment, and average across the 10,000 repetitions. For exports and imports, we adjust the simulations to take into account that our data series for these variables only start in 1985 .

Broadly speaking, the performance of both models is similar and close to their empirical counterpart. The high-frequency fluctuations of the RER-deviations from the HP-trend-are well matched by both models as are many of the basic business cycle properties, although they are somewhat attenuated relative to the data. The correlation between relative consumption and the RER, is around 0.2 in our models, close to the value of 0.07 in our data. The estimated models are, therefore, consistent with the Backus-Smith statistic. Importantly, the low-frequency success of the endogenous growth model does not come at the cost of under-performing at higher frequencies. The column Cor $^{*}$ shows the correlation between a domestic variable and its foreign counterpart.

Table 5: Business Cycle Moments

\begin{tabular}{|c|c|c|c|c|c|c|c|c|c|c|c|c|}
\hline \multirow[t]{2}{*}{ Series } & \multicolumn{4}{|c|}{ Data } & \multicolumn{4}{|c|}{$\begin{array}{l}\text { Endogenous } \\
\text { Both Stages }\end{array}$} & \multicolumn{4}{|c|}{ Exogenous } \\
\hline & Std & CorY & $\mathrm{ACC}$ & Cor* & Std & CorY & $\mathrm{ACC}$ & Cor* ${ }^{*}$ & Std & CorY & $\mathrm{ACC}$ & $\mathrm{Cor}^{*}$ \\
\hline$G D P$ & 1.48 & 1.00 & 0.88 & 0.76 & 1.06 & 1.00 & 0.72 & 0.35 & 1.03 & 1.00 & 0.75 & 0.45 \\
\hline$G D P^{*}$ & 1.11 & 1.00 & 0.88 & 0.76 & 0.80 & 1.00 & 0.73 & 0.35 & 0.79 & 1.00 & 0.76 & 0.45 \\
\hline$C$ & 1.22 & 0.87 & 0.89 & 0.56 & 0.80 & 0.59 & 0.69 & 0.44 & 0.80 & 0.65 & 0.68 & 0.40 \\
\hline$C^{*}$ & 0.78 & 0.85 & 0.82 & 0.56 & 0.64 & 0.69 & 0.69 & 0.44 & 0.64 & 0.68 & 0.67 & 0.40 \\
\hline$I$ & 6.63 & 0.94 & 0.83 & 0.72 & 5.35 & 0.85 & 0.74 & 0.25 & 5.01 & 0.83 & 0.76 & 0.33 \\
\hline$I^{*}$ & 3.79 & 0.92 & 0.86 & 0.72 & 2.80 & 0.77 & 0.73 & 0.25 & 2.90 & 0.74 & 0.79 & 0.33 \\
\hline$H$ & 1.53 & 0.86 & 0.92 & 0.78 & 0.96 & 0.66 & 0.69 & 0.46 & 0.91 & 0.62 & 0.71 & 0.47 \\
\hline$H^{*}$ & 0.90 & 0.87 & 0.88 & 0.78 & 0.59 & 0.46 & 0.69 & 0.46 & 0.59 & 0.47 & 0.70 & 0.47 \\
\hline$R E R$ & 4.28 & -0.26 & 0.84 & & 3.94 & -0.20 & 0.80 & & 4.03 & -0.20 & 0.79 & \\
\hline Export/GDP & 0.19 & 0.59 & 0.83 & & 0.21 & -0.37 & 0.81 & & 0.17 & -0.22 & 0.77 & \\
\hline Import/GDP & 0.28 & 0.69 & 0.81 & & 0.19 & 0.07 & 0.63 & & 0.20 & -0.03 & 0.64 & \\
\hline
\end{tabular}

Notes: This table lists selected moments. The data moments are generated by filtering the data from 1972:Q2 to 2016:Q4 using a HP-1600 filter. The model moments are generated by simulating the model 10000 times as described in the text and applying the same filter to the model series. We then compute the moments and average across simulations. Variables with a star denote G6 variables, the one without are U.S. variables. C stands for consumption, I for investment, H for total hours. GDP, C, I, H, and RER are logged. Std is the standard deviation, CorY the correlation with the respective countries GDP, ACC is the autocorrelation, and $\mathrm{Cor}^{*}$ the cross-country correlation.

Because there are various shocks in the model, it is important to discuss the main drivers of the key variables. ${ }^{30}$ When we consider domestic GDP, the main drivers of its volatility are the disutility shock, $\psi_{1, t}$, and the exogenous productivity shock, $Z_{t}$, accounting for almost 80 percent of the variability of GDP. The bulk of the fluctuations in domestic consumption is accounted for the discount shock, $\beta_{t}$, the disutility shock, the government spending shock, $G_{t}$, and the shock to the marginal efficiency of producing new technologies, $\zeta_{t}$.

The volatility of international variables comes from shocks that drive wedges in financial and trade

\footnotetext{
${ }^{29}$ We use 1972:Q2 as initial condition here and in the following simulation exercises if not noted otherwise. Results were robust to simulating the model for a long time and only keeping the last 179 observations in each run.

${ }^{30}$ To save space and avoid boring the reader with a long discussion, we omit a complete analysis.
} 
markets, and the production of technology. For example, the UIP disturbance explains 60 percent of the fluctuations in the domestic ratio of exports-to-GDP. Furthermore, the same shock accounts for 46 percent of the volatility of the RER. This finding provides empirical validation to the hypothesis that financial shocks are crucial to exchange rates (Itskhoki and Mukhin, 2017). Yet there is more to be said. In particular, exchange rates also fluctuate due to innovations in the productivity of producing exports and in the marginal efficiency of producing new technologies. The importance of a shock in the endogenous productivity block points once again to the relevance of the main channel proposed in this paper. ${ }^{31}$

Without going into details, it is worth stressing that in the exogenous growth counterpart, the discount factor and UIP shocks become more important. For instance, the first shock explains about 40 percent of the volatility of consumption (versus 26 percent in the endogenous counterpart) and 10 percent of that of the RER (versus 0 percent in the benchmark model). These findings suggest that, in the absence of the endogenous mechanism in the production sector of the economy, the model increases the role of the financial block (bluntly captured by the $\beta$ and $U$ shocks), which is consistent with the theoretical results in Itskhoki and Mukhin (2017).

Although the simple model comparison showed the ability of endogenous growth to generate persistent and volatile exchange rates, the experiment was silent about the likelihood of observing such dynamics on a finite sample. Figure 5 compares the finite sample exchange rate spectra of the models with their empirical counterpart. To construct this figure, we use the unfiltered 10,000 samples of length 179 used to produce the moments in Table 5 and construct the median and the percentiles of the spectrum. As seen in panel a, the median simulation of the baseline endogenous growth model (dashed blue line) closely tracks the empirical spectrum (solid black line). In contrast, the empirical spectrum lies outside the 90 percent bands of the spectrum from the exogenous growth model (dotted blue line, panel b). In fact, the upper bound confidence interval is only 60 percent of its empirical counterpart at frequencies longer than 20 quarters.

The spectrum combines information of the total unfiltered volatility and the autocorrelation function of the exchange rate. A potential concern is that the endogenous growth model under-performs at one or both of those margins but still has a better net effect once we put the information together. The standard deviation of the unfiltered RER in the data is 10.42. In the simulations used to construct the spectrum, the exogenous growth model generates a standard deviation of 7.07. Meanwhile, the endogenous growth model with a volatility of 9.85 is much closer to the data. ${ }^{32}$ Figure 6 shows the autocorrelation functions for both models and compares it with their empirical counterpart.

\footnotetext{
${ }^{31}$ We have also estimated the model without UIP shock, adding iid measurement error to the measurement equation for the RER. Here, we limited the measurement error to explain at most 5 percent of the variance of the exchange rate. As can be seen in the appendix our main result is robust to this change. However, we prefer the version with UIP shocks as there is strong evidence for deviations from UIP.

${ }^{32}$ Using iid normal shocks does not change the conclusion. Under this scenario, the volatility of the exchange rate is 11.53 for the endogenous growth model and 8.34 for the exogenous growth model. The next subsection shows that, under iid shocks, the baseline model also outperforms its exogenous growth counterpart in terms of matching the empirical spectrum.
} 


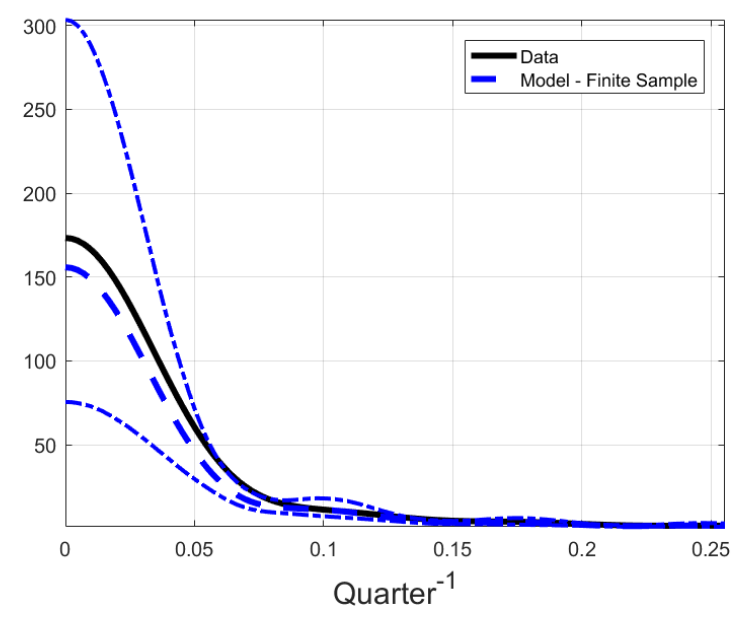

(a) Endogeneous Growth

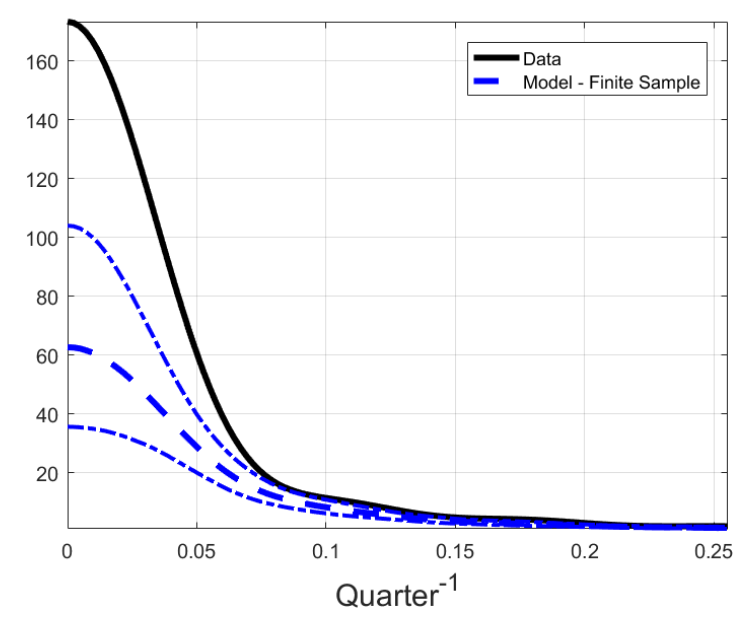

(b) Exogeneous Growth

Figure 5: Exchange Rate spectrums

Notes: The thick, blue, broken line shows the median model spectrum simulated as described in the text, the thinner lines the 90 percent confidence intervals. The black line is the data spectrum.

Consistent with the spectrum analysis, the endogenous growth model can rationalize the empirical autocorrelation function of the exchange rate at every lag, while the credible set of the exogenous growth autocorrelation function cannot capture the first seven autocorrelations. Therefore, the persistent expected productivity differences triggered by endogenous growth dynamics can reconcile the dynamic properties of the exchange rate without deviating from the international real business cycle framework or assuming exogenous non-stationary fluctuations. ${ }^{33}$

Another way to visualize the endogenous channel at work is to study the impulse response function (IRF) in the endogenous and exogenous growth models. Figures 7 to 9 show the IRFs for the R\&D, UIP, and the relative trade shocks, which are the main drivers of the volatility of the RER. ${ }^{34}$ The impulse responses are plotted as percentage deviations from the pre-shock trend.

Figure 7 displays the economy's response to a favorable R\&D shock. This shock is only present in the endogenous growth model, and we use it as a starting point to show how changes in innovation effort can impact exchange rates, especially at medium and long horizons. R\&D is more efficient after the disturbance, and therefore both $R \& D$ stages attract more resources. The increase in $R \& D$ opens a persistent productivity gap between the two countries. As the home economy expects to be more productive in the future, consumption increases in anticipation of future wealth and hours have a slight decrease on impact due to a moderate wealth effect. ${ }^{35}$ Hence, the home economy decreases

\footnotetext{
${ }^{33}$ While we assume stationary TFP shocks in the exogenous growth model, we have repeated the analysis in the same model, but instead using shocks to the growth rate of TFP and assuming co-integration between TFP growth in the two countries as in Rabanal and Rubio-Ramirez (2015). The fit to the data was slightly worse and the ability to match the autocorrelation or spectrum of the real exchange rate did not improve. Detailed results are available upon request.

${ }^{34}$ See Tables 12 and 13 in Appendix for a comprehensive variance decomposition of both models.

${ }^{35}$ Home bias tilts the increase in domestic consumption towards domestic goods.
} 


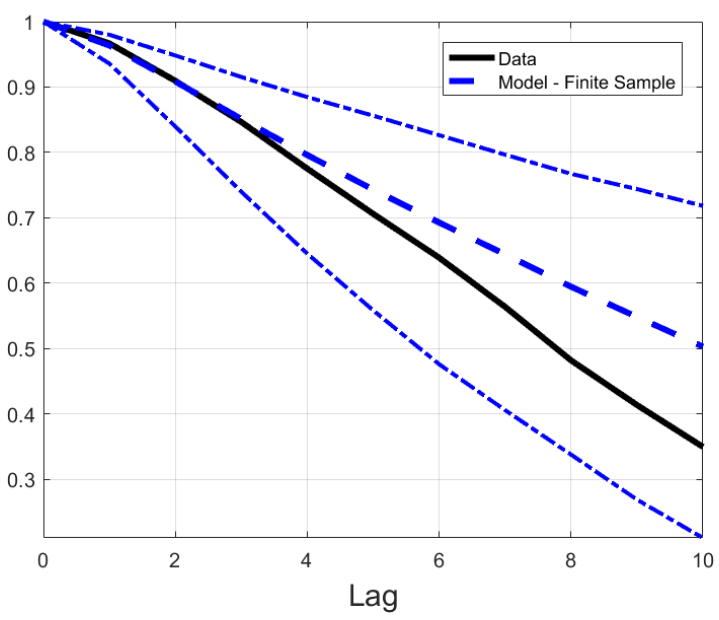

(a) Endogeneous Growth

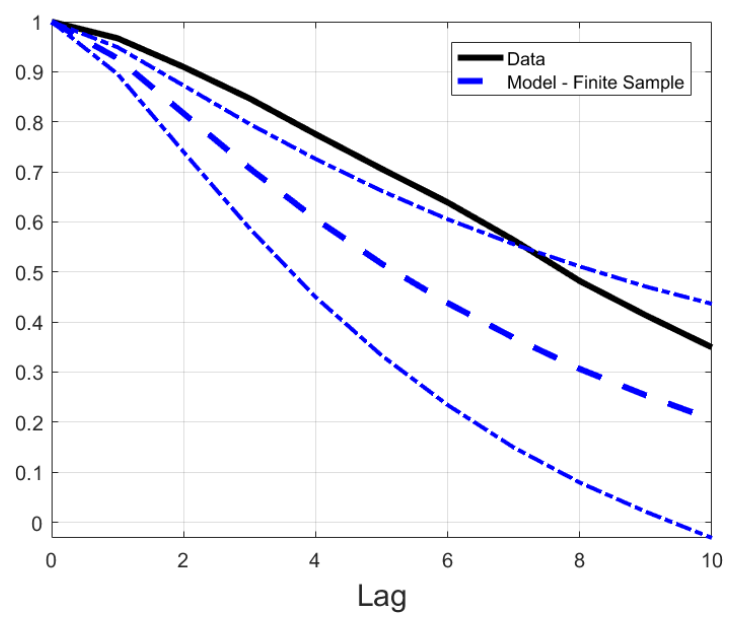

(b) Exogeneous Growth

Figure 6: Exchange Rate Auto-correlation Function

Notes: The thick, blue, broken line shows the median model autocorrelation simulated as described in the text, the thinner lines the 90 percent confidence intervals. The black line is the data autocorrelation.

investment and increases borrowing to allocate more resources to $R \& D$. The decrease in the price of capital triggers an increase in capital utilization. In net, capital input increases, encompassing an increase in labor supply due to factor complementarity and higher productivity. As R\&D will trigger increases in supply only in the medium-run, in the short run the wealth-driven increase in demand outpaces the slow increase in supply and the exchange rate appreciates. ${ }^{36}$ In contrast to the previous literature, this effect slowly reverses as the home economy accumulates a persistent technology advantage that increases investment, hours, and production in the medium- and longrun. This relative abundance of home goods transforms the initial appreciation into a protracted depreciation.

Figure 8 compares the response of the home country-under endogenous and exogenous growth-to a favorable UIP shock. We start by analyzing the response under exogenous growth. The favorable UIP shock decreases the cost of borrowing for the domestic economy, appreciating the exchange rate. From a financial perspective, the bond market has to clear and, therefore, the domestic price increases to boost the return of domestic bonds. As a result of a lower cost of borrowing from abroad, the local interest rate falls, impacting R\&D and investment. First, R\&D expenditures increase due to higher demand and therefore higher profits associated to domestic production. The lingering expansion helps the domestic country repay the borrowed funds without reducing consumption or investment. Second, the lower domestic interest rate increases the present value of future profits, providing further incentive to R\&D investment. The expansion of R\&D triggers the short- and medium-run mechanisms described in Figure 7. Not surprisingly, the responses of every real variable are amplified on impact and more persistent in the endogenous growth economy. Relative to the exogenous growth

\footnotetext{
${ }^{36}$ The underlying economic mechanism governing the short-run exchange rate dynamics is consistent with the analysis of Raffo (2010) and Karabarbounis (2014).
} 

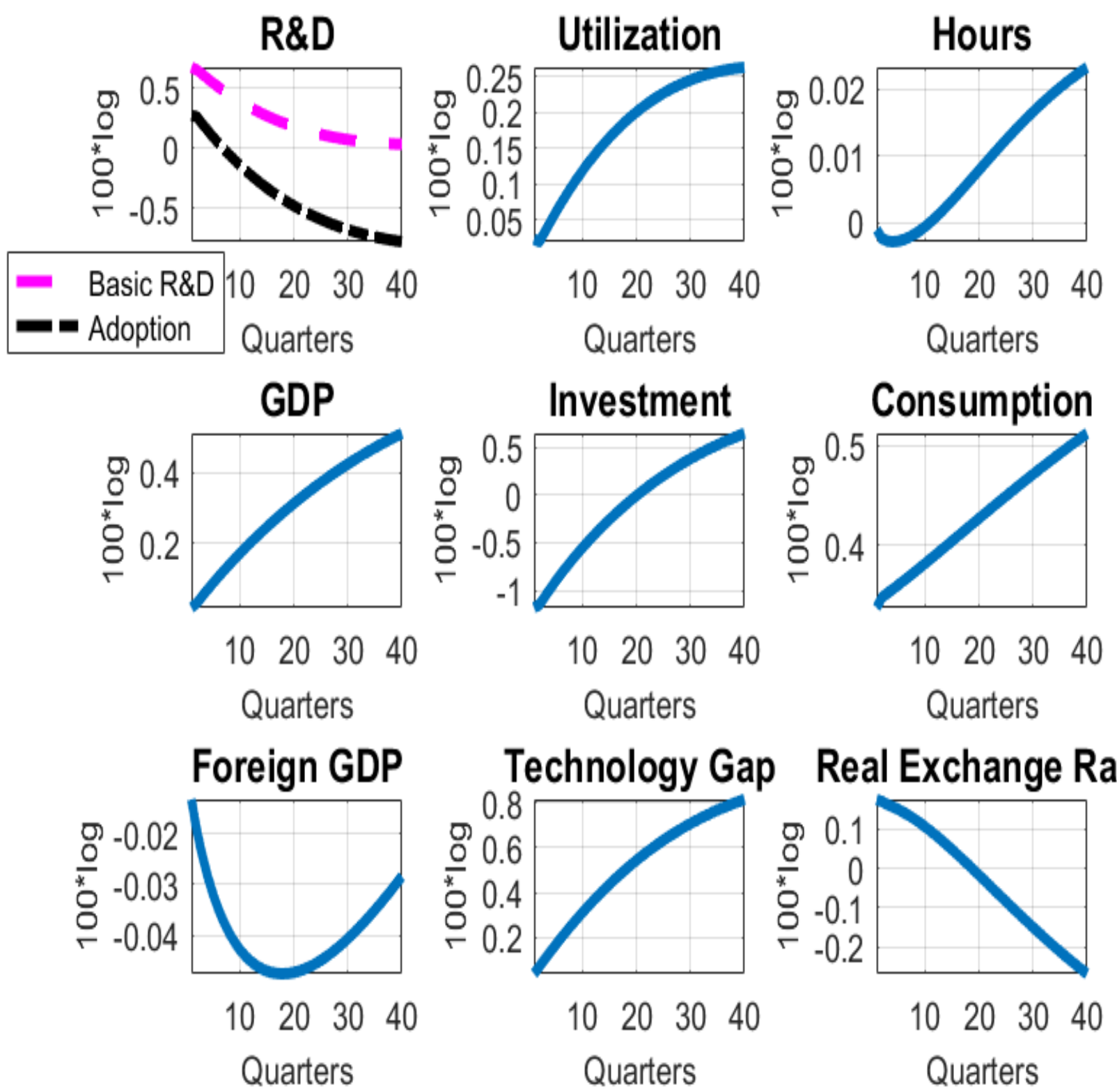

Figure 7: Impulse Response Function to R\&D shock

Notes: The figure shows the IRFs from the endogenous growth model in blue solid lines relative to the model path before the shock. In the upper-left quadrant the dynamics of basic research and development and adoption are shown as black and magenta broken lines.

model (dotted red lines), the endogenous version delivers far more persistent changes in economic activity, resulting in the lower-frequency movements in the RER. Two features of the UIP shock worth stressing are (1) it generates effortlessly co-movement in the domestic economy and (2) it induces a hump-shaped response of the RER. The second feature is crucial to induce realistic half-lives.

Finally, Figure 9 shows the IRFs to a relative trade shock $\left(\Omega_{t}^{l}\right)$. In the exogenous growth model, this shock decreases the cost of exporting from the home economy, making home goods cheaper in 

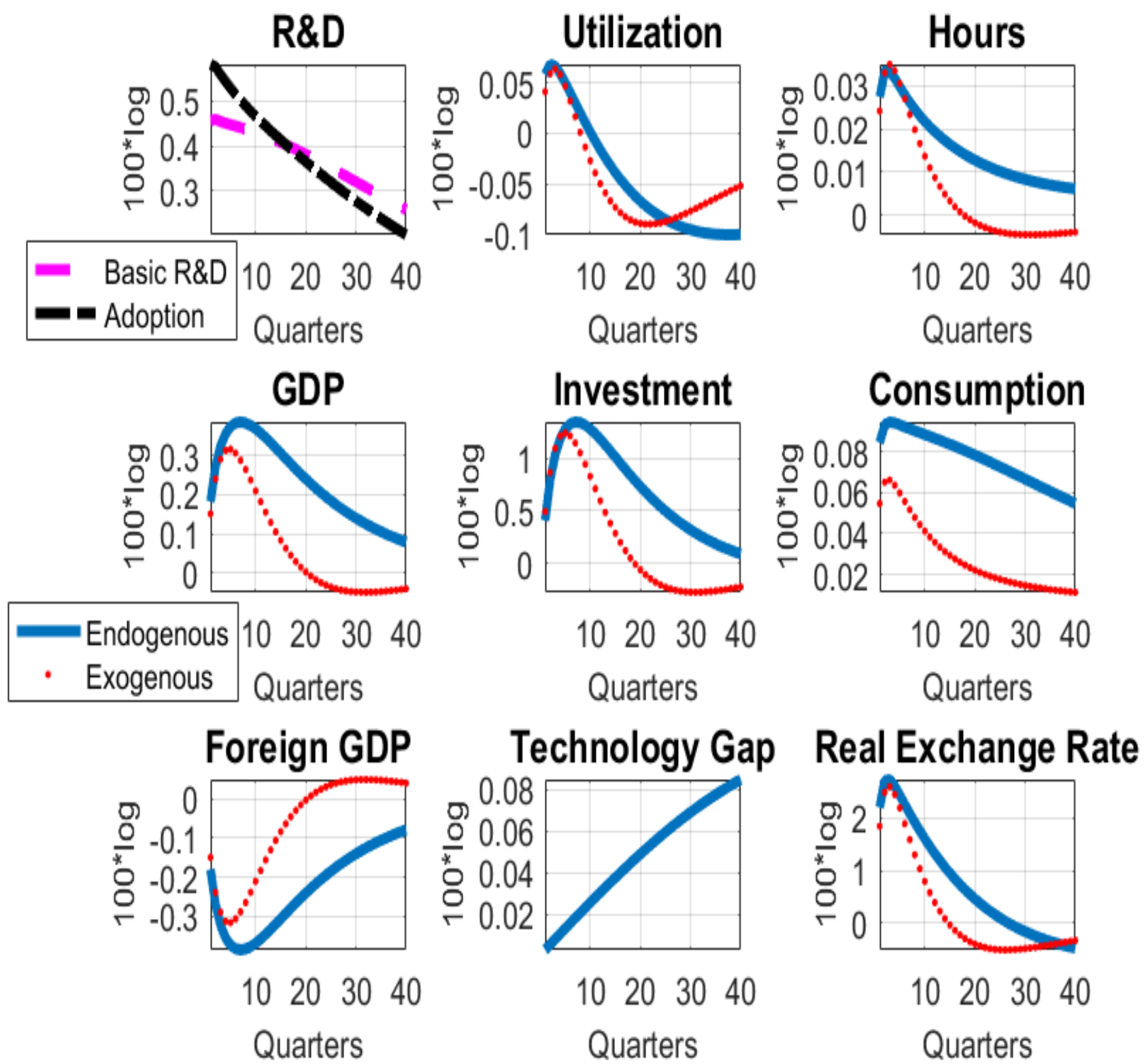

Figure 8: Impulse Response Functions to UIP Shock

Notes: The figure shows the IRFs from the endogenous growth model in blue solid lines relative to the model path before the shock. The red, dotted lines show the same for the exogenous growth model. In the upper-left quadrant the dynamics of basic research and development and adoption are shown as black and magenta broken lines.

the foreign country and therefore triggering a depreciation of the exchange rate. The simultaneous increase in the cost of selling the foreign good to the home economy boosts this effect. Under endogenous growth, the favorable trade shock increases the demand for exports, triggering an increase in the demand for home intermediate goods. This increase in demand translates into higher profits that provide incentives for R\&D investment. Once again, triggering the short-run wealth effects and 
medium-run productivity dynamics described in Figure 7. Therefore, the endogenous growth model amplifies the short-run responses and trigger rich and persistent dynamics to the main shocks that drive the exchange rate.

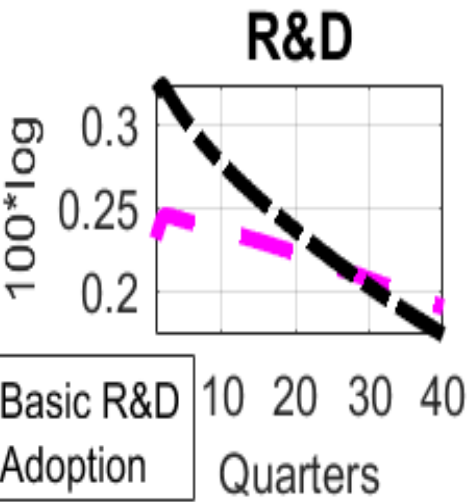

GDP

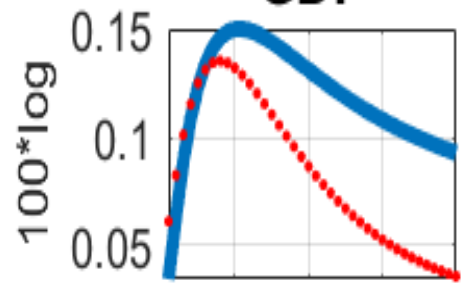

Endogenous 10203040

- Exogenous Quarters

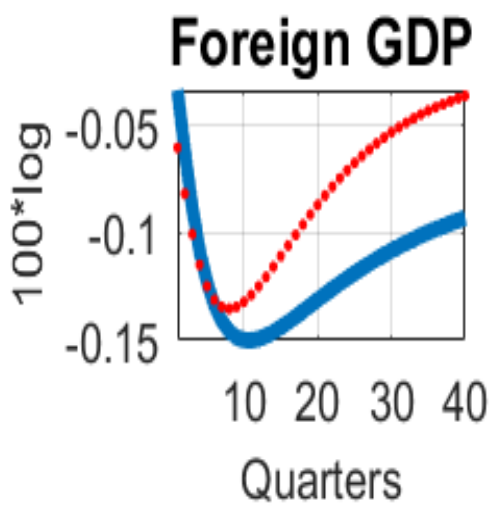

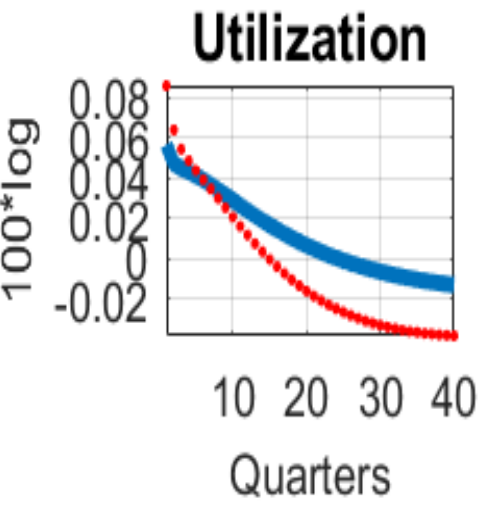

Investment

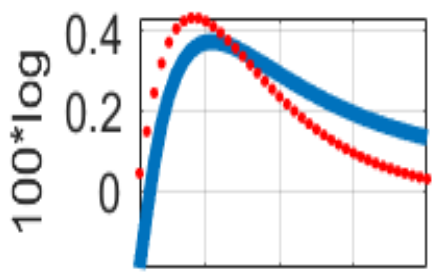

10203040

Quarters

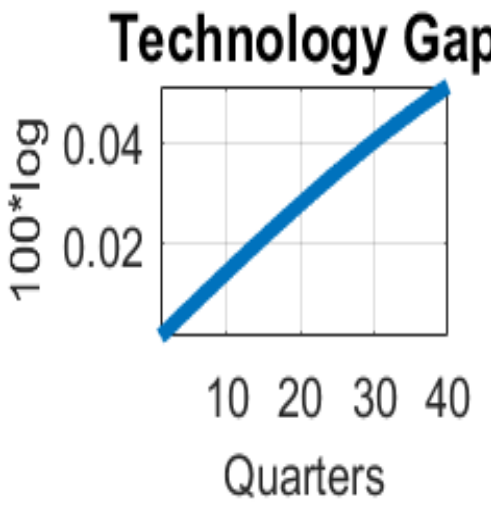

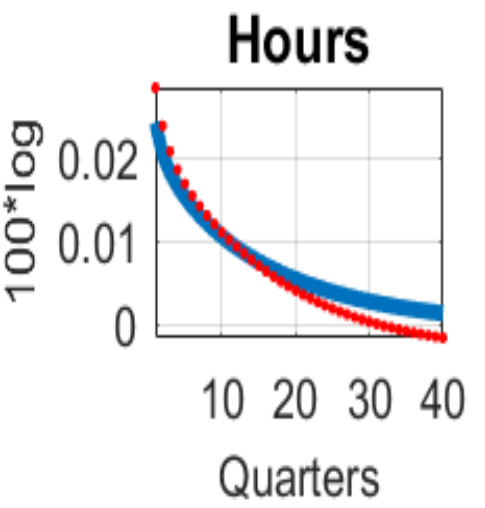

Consumption

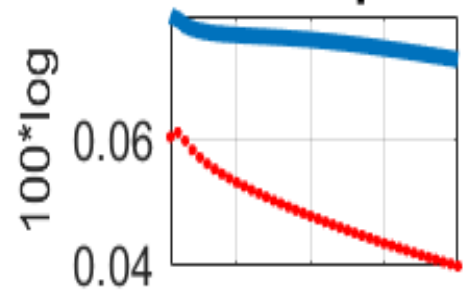

10203040

Quarters

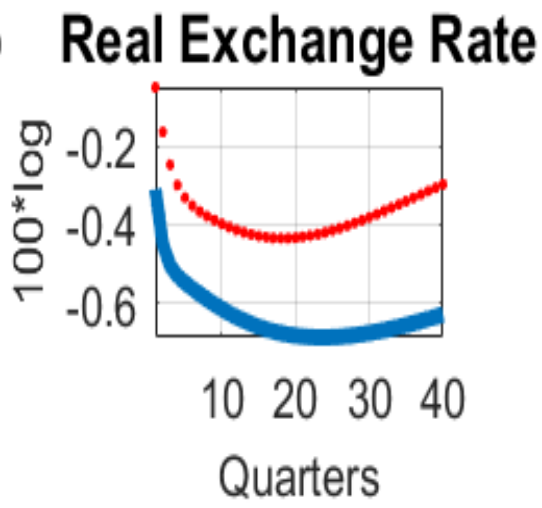

Figure 9: Impulse Response Functions to Trade Cost shock - relative

Notes: The figure shows the IRFs from the endogenous growth model in blue solid lines relative to the model path before the shock. The red, dotted lines show the same for the exogenous growth model. In the upper-left quadrant the dynamics of basic research and development and adoption are shown as black and magenta broken lines.

Before concluding this section, we want to highlight that our model can account for another regularity of RERs: its half-life. Using our data on exchange rates, we repeat the empirical exercise 
in Steinsson (2008) and find that the half-life of the RER is about 4.5 percent years, which coincides with the value reported in his paper. As before, we proceed to generate a 10,000 synthetic dataset, each of length 179, using our model as the data generating process. We then applied to the synthetic RER the same approach used to compute the empirical half-life. The mean half-life in our generated samples is 4.2 (1.8) for the endogenous growth model (standard deviation across simulations in parenthesis). In contrast, the average half-life from the exogenous growth model is 2.0 (0.6). These results are not surprising given that our baseline model can generate volatile and persistent fluctuations in exchange rates, which are required to deliver large half-lives. In fact, the hump-shaped responses of the RER to the UIP and trade shocks foretell large half-lives. Finally, the failure of the exogenous growth model is expected in light of the results in Steinsson (2008).

\subsection{Robustness Analysis}

Having documented the ability of the endogenous growth model to the empirical properties of the exchange rate, we perform several robustness tests and unveil the central role of trade flow data. The robustness analysis focuses only on the exchange rate spectrum, but our conclusions are also valid for the unfiltered exchange rate volatility and the autocorrelation function.

\subsubsection{Robustness: R\&D}

Endogenous growth allows for persistent expected productivity differences at the core of low-frequency exchange rate dynamics. Figure 10 explores if modeling and estimation choices around the R\&D features determine the success of the endogenous growth model. The first panel shows that the success of the endogenous growth model is robust to using the estimation from the second column in Tables 11 and 4 where R\&D data is mapped only to first stage innovation expenditure. The second panel estimates an alternative one-stage endogenous growth model, abstracting from the adoption stage altogether; that is, $N_{t}=A_{t}$ and no expenditures on adoption. This alternative model also generates persistent expected productivity differences populating the low-frequency domain of the exchange rate spectrum. The third panel shows that re-estimating the model without R\&D shocks and not using $R \& D$ data in the estimation only triggers minor deviations on the model spectrum. Therefore, the particular details of the endogenous growth modeling do not affect the big picture of the results.

\subsubsection{Robustness: Alternative Parameters}

The first panel in Figure 11 fixes the structural parameters from the third column in Table 4 and re-estimates the baseline endogenous growth model to show that the differences in the spectrums are not due to differences in fundamental non-growth related parameters. The second panel uses an alternative prior for the UIP shock volatility, replacing the flat distribution with an Inverse Gamma distribution consistent with the priors used for the other volatility parameters. The performance of the endogenous growth model is independent of the UIP prior. Risk aversion is typically an 


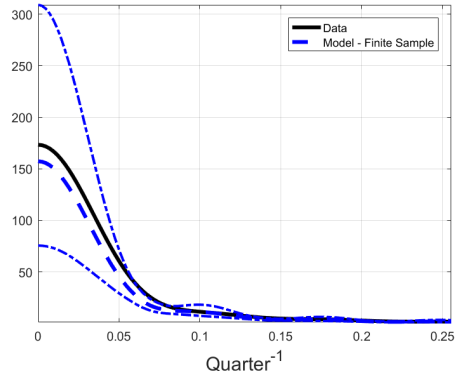

(a) Alternative R\&D Definition

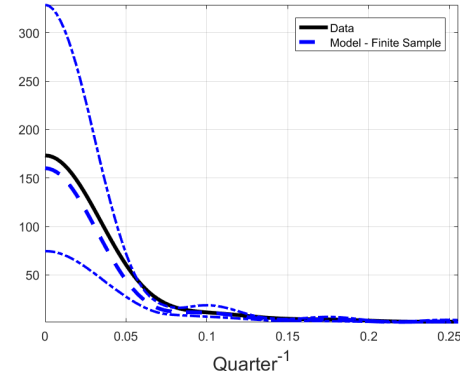

(b) No Adoption

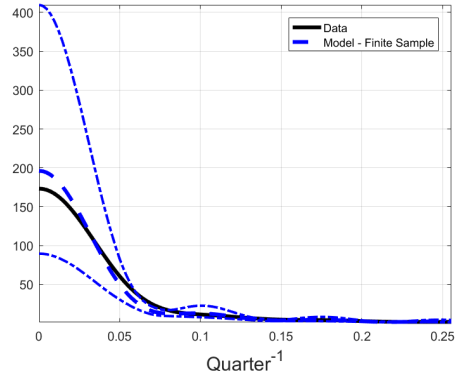

(c) No R\&D Data

Figure 10: Spectrum under different R\&D assumptions.

Notes: The thick, blue, broken line shows the median model spectrum simulated as described in the text, the thinner lines the 90 percent confidence intervals. The black line is the data spectrum.

important parameter for exchange rate dynamics. The third panel shows that estimating the risk aversion with other model parameters does not change our main result. ${ }^{37}$ The fourth panel shows that the endogenous growth model does not need the Adolfson, Laséen, Lindé, and Villani (2008) risk premium to generate persistent and volatile exchange rates, but it improves the quantitative fit, consistent with the literature.

\subsubsection{Robustness: Nominal Exchange Rate}

To round up our discussion, we now briefly turn to an important extension of our model that allows us to talk about the nominal exchange rate. There is a well-established strong connection between adjustments of the real and nominal exchange rate (for a recent discussion, see Eichenbaum, Johannsen, and Rebelo (forthcoming)). Therefore, one concern about our model could be related to the question if our mechanism is compatible with these facts, especially as we abstract from nominal elements all together. However, borrowing from Eichenbaum, Johannsen, and Rebelo (forthcoming), we show that adding nominal inflation and a reasonably parameterized Taylor rule to the model, we arrive at dynamics of the nominal exchange rate and nominal relative prices that are compatible with the common wisdom even without having to add sticky prices and wages. ${ }^{38}$

This approach requires two new ingredients. We add a standard Taylor rule with fairly standard parameters in each country:

$$
\frac{R_{N, t}}{\bar{R}_{N}}=\left(\frac{R_{N, t-1}}{\bar{R}_{N}}\right)^{0.75}\left(\frac{\pi_{t}}{\bar{\pi}}\right)^{1.5(1-0.75)} ; \frac{R_{N, t}^{*}}{\bar{R}_{N}}=\left(\frac{R_{N, t-1}^{*}}{\bar{R}_{N}}\right)^{0.75}\left(\frac{\pi_{t}^{*}}{\bar{\pi}}\right)^{1.5(1-0.75)},
$$

\footnotetext{
${ }^{37}$ It also only barely improves the fit of the exogenous growth model. This suggests that the underlying problem of the exogenous growth model to fit the spectrum is more related to the persistence and not the volatility of the real exchange rate,

${ }^{38}$ Here, we also echo some of the discussion in Itskhoki and Mukhin (2017) and Itskhoki and Mukhin (2019). In particular, they argue that nominal rigidities are not central in explaining the exchange rate disconnect nore in accounting for the Mussa puzzle. Instead, they argue for a central role of financial shocks in the form of UIP deviations for explaining these two empirical regularities.
} 


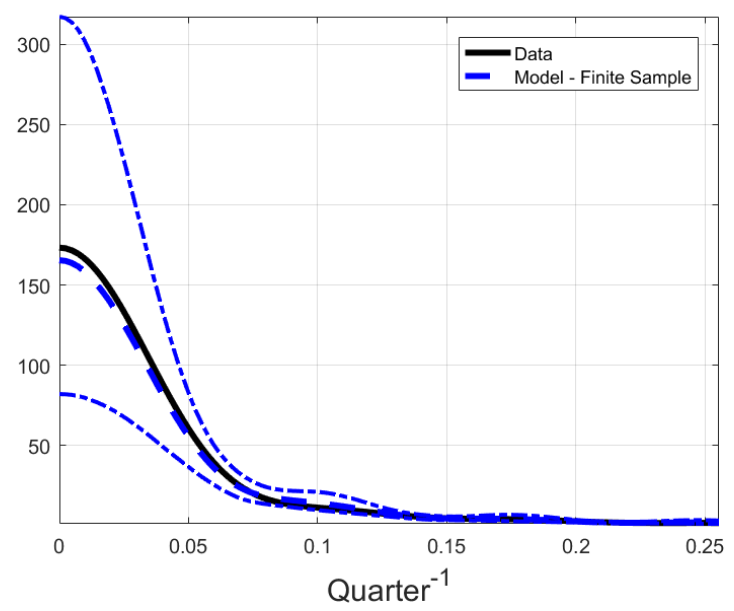

(a) Alternative Parameters

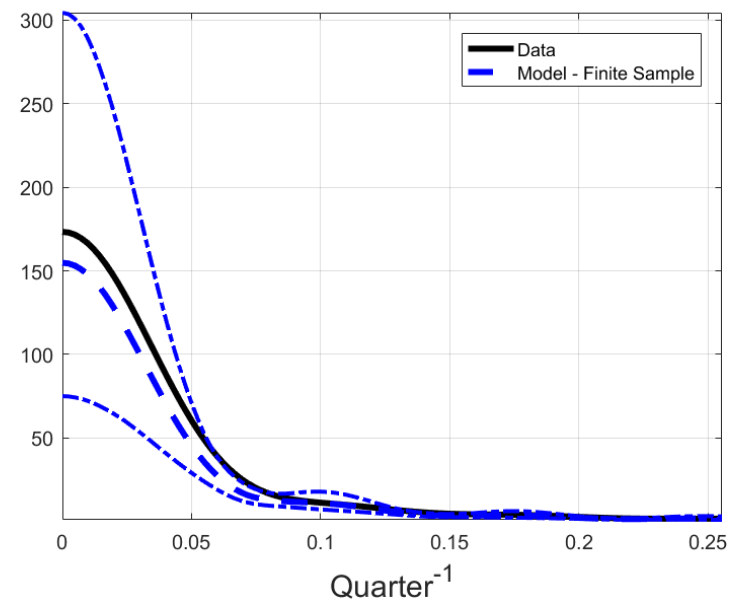

(c) Estimate Risk Aversion

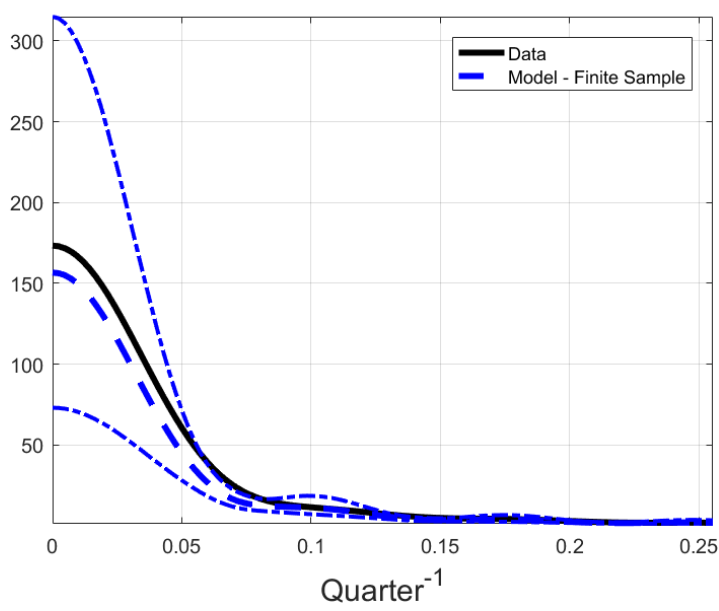

(b) Alternative UIP Prior

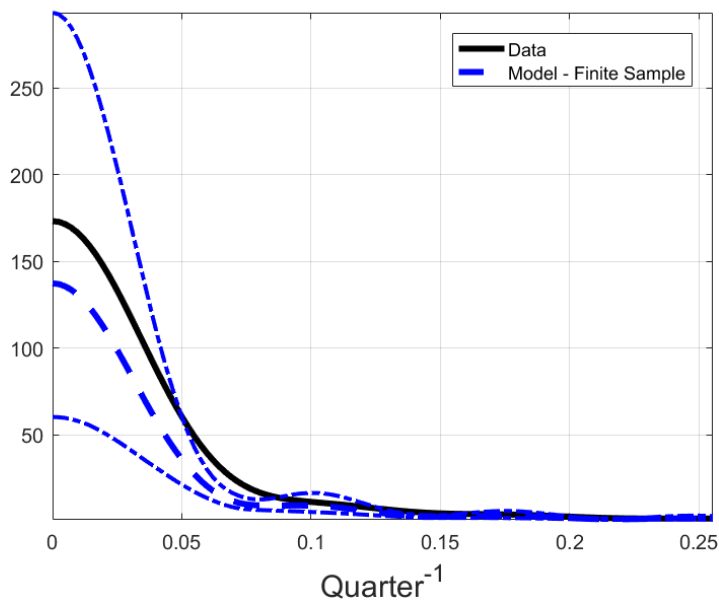

(d) $\phi_{2}=0$

Figure 11: Robustness - Alternative Parameters

Notes: The thick, blue, broken line shows the median model spectrum simulated as described in the text, the thinner lines the 90 percent confidence intervals. The black line is the data spectrum.

and a nominal bond in each country in zero net supply, which results in the following Euler equations:

$$
\nu_{t}^{c}=\mathbb{E}_{t}\left(\nu_{t+1}^{c} \frac{R_{t}}{\pi_{t+1}}\right) ; \nu_{t}^{c, *}=\mathbb{E}_{t}\left(\nu_{t+1}^{c, *} \frac{R_{t}^{*}}{\pi_{t+1}^{*}}\right)
$$

Here, $R_{N, t}$ is the nominal exchange rate, $\pi_{t}$ is the nominal inflation rate, and $\nu_{t}^{c}$ is the marginal utility of consumption (see the Appendix for its definition). Using these expressions, we get a determined inflation rate, while we have no effect on real quantities or real relative prices from monetary policy. We view this exercise as illustrative, while adding a full set New Keynesian elements could be fruitful endeavor for future work. 
Using the inflation dynamics resulting from our additions, we can simulate relative nominal prices and the nominal exchange rate from our baseline endogenous growth model in the same fashion we used to generate series for the RER. We compare the data and model along the two components of the RER. To construct prices, we use the CPI in each country. As the involved series are likely to be non-stationary, we extract a linear trend from them before constructing the spectrum. Figure 12 shows the results.

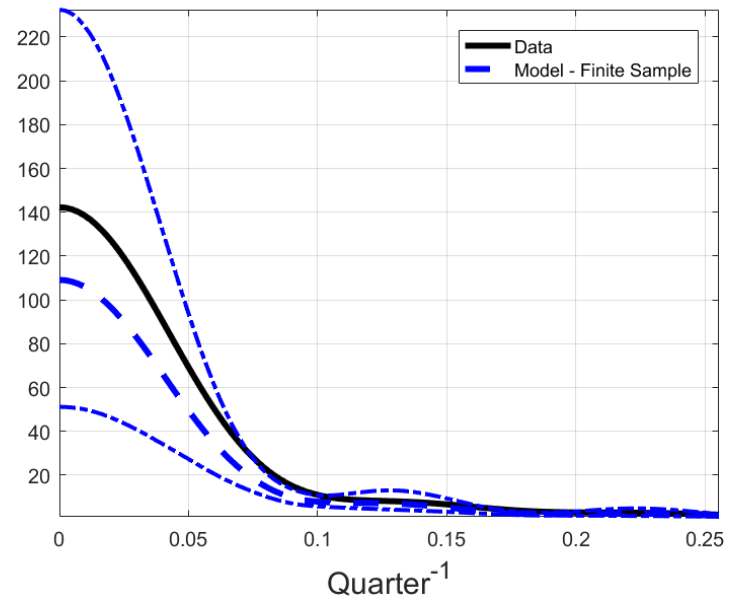

(a) Nominal Exchange Rate

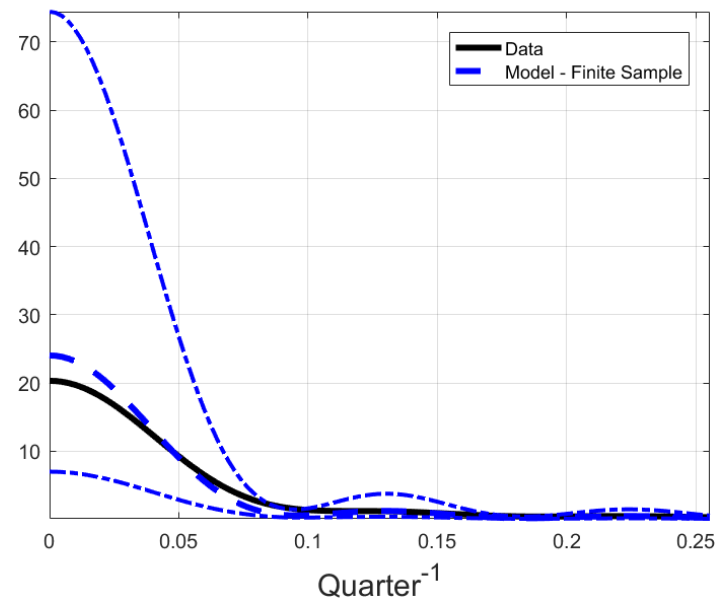

(b) Relative Price

Figure 12: Nominal Exchange Rate and Relative Prices

Notes: The thick, blue, broken line shows the median model spectrum simulated as described in the text, the thinner lines the 90 percent confidence intervals. The black line is the data spectrum.

Focusing first on the black line in both panels of Figure 12, the nominal exchange rate in the data shows a lot more variability than relative prices even after de-trending, in line with common wisdom. Next, turning to the model results, our model preserves this ordering and matches the empirical dynamics reasonably well. The key for this is the relatively stable inflation rate resulting from our simple Taylor Rule and the good fit of the RER in our model.

\subsection{The Importance of Trade Data}

Figure 13 displays the impact that frictions, data, and shocks in the trade sector have on the RER spectrum. The first panel increases the short- and long-run trade elasticity and re-estimates the stochastic forces of the model. ${ }^{39}$ As one can see, the qualitative success of the model is not affected by this feature. The next two panels show that the low-frequency co-movement of trade and exchange rates documented in Figure 1 is one key element to generating a good fit of the RER at low-frequency.

The second panel of Figure 13 shows the spectrum if we estimate the model without trade data. We clearly see a deterioration of the fit. When we remove the trade shocks, the model spectrum moves even further away from the empirical one. Why is this the case? In the estimation without trade

\footnotetext{
${ }^{39}$ The short-run elasticity increases from 1.5 to 2 and the long-run from 10 to 15 .
} 
shocks and data, the UIP shock ends up mainly fitting short-term variations in the exchange rate and filtered shocks show more autocorrelation. Adding the trade shocks without the trade data essentially works like adding an additional transitory shock to the RER to the model. ${ }^{40}$ The UIP shock takes partially the role of matching more persistent movements in the RER, but it still overrides the effects of endogenous growth, as the trade shocks still only play a minor role and trade in the model is not as volatile as in the data. Adding trade data changes the picture, as the model now needs to explain the actual movements of quantities between countries. This increases the importance of trade shocks for the low-frequency movements of the exchange rate and leads the estimation to downplay the volatile UIP shock, focusing it back to shorter-term movements of larger amplitude. In this sense it is key to control for the low-frequency interaction between trade and the RER.

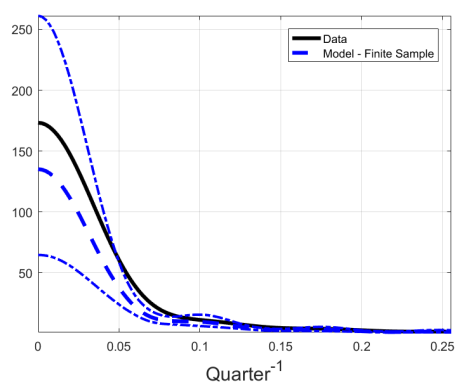

(a) Higher Trade Elasticity

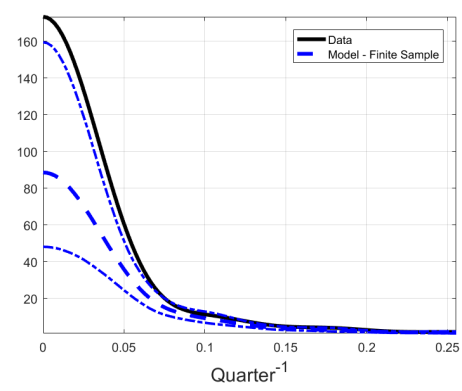

(b) No Trade Data

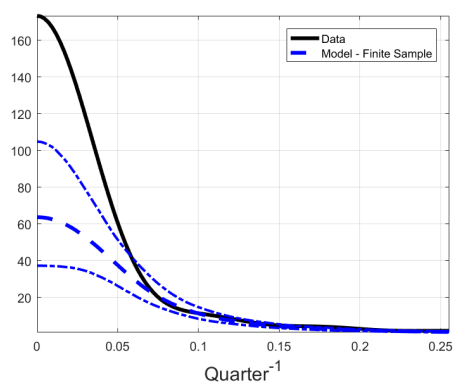

(c) No Trade Data \& no Shocks

Figure 13: The Role of Trade

Notes: The thick, blue, broken line shows the median model spectrum simulated as described in the text, the thinner lines the 90 percent confidence intervals. The black line is the data spectrum.

To further illustrate the central role of trade data, we perform one last experiment. We estimate three additional versions of the baseline endogenous growth model, none of which uses exchange rate data for the estimation, and compare the model-based exchange rate with their empirical counterpart. The first model only removes the RER data from the estimation process, the second version also abstracts from UIP shocks, while the last version removes the trade data as well. Figure 14 compares the empirical exchange rate with the series generated by each of the three models. Because the exchange rate is not used in the estimation, nothing forces the model to perform on this dimension.

As our export and import data starts in 1985, we focus on the match of the models after that date. Figure 14 shows that the two estimations that include trade flow data closely track the exchange rate time series. In fact, the correlation of the implied exchange rates with its empirical counterpart after 1985 is 0.57 on the full model estimated without RER data and 0.66 for the model without UIP shocks. In contrast, the model that does not include trade data fails to track its empirical counterpart, resulting in a negative correlation of -0.29. Simulating data from the models, one can see that abstracting from trade data does not change the ability of the model to generate lowfrequency fluctuations of the RER. However, the trade data pushes the shocks filtered from the

\footnotetext{
${ }^{40} \mathrm{~A}$ transitory shock to relative trade costs has small effects on quantities and large effects on prices, thanks to the trade adjustment costs.
} 


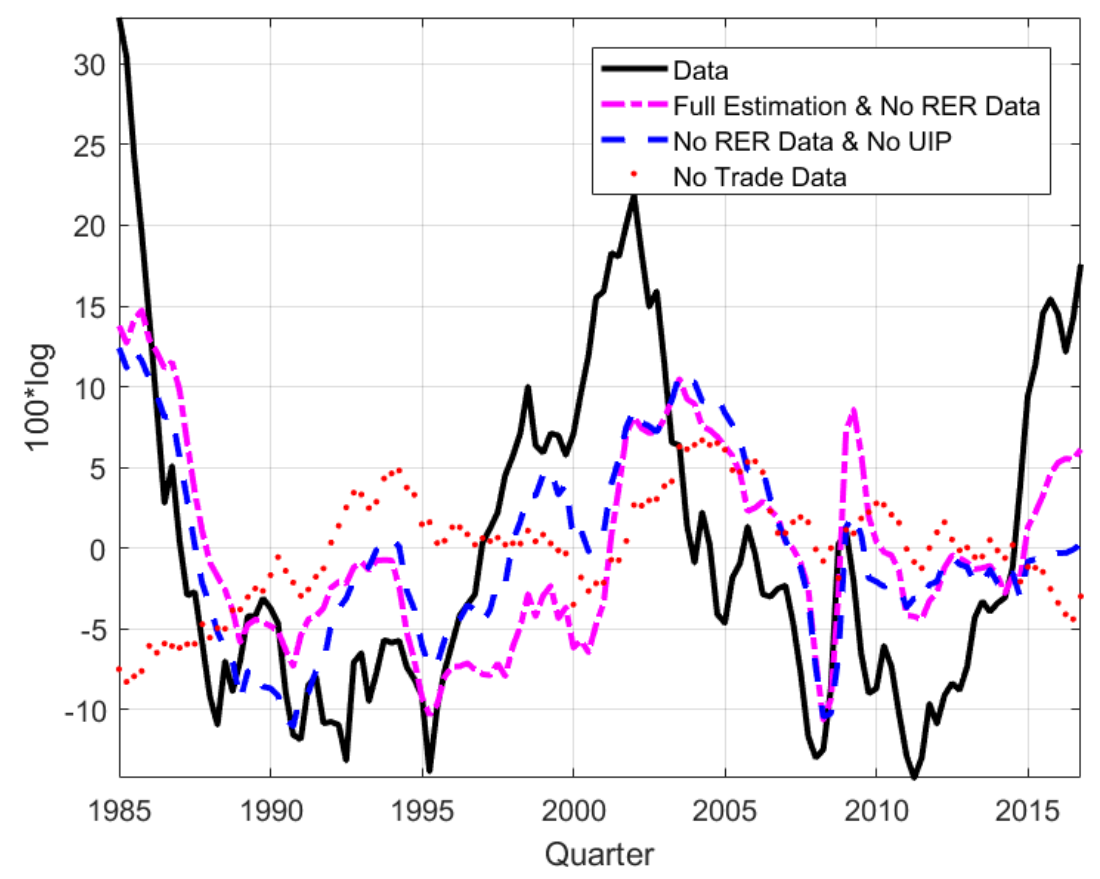

Figure 14: Model Implied Exchange Rate Dynamics

Notes: The black line shows the real exchange rate in the data. The magenta, broken line shows the filtered real exchange rate from the endogenous growth model estimated without exchange rate data. The blue, broken line shows the filtered series from the same model estimated without a UIP shock. The red, dotted line is the filtered real exchange rate data from the model estimated without real exchange rate and trade data, and without UIP shock.

model and the parameter estimates toward explaining the persistent movements in quantities and, thereby, towards loading more on the endogenous growth mechanism.

In sum, the key to the empirical success of the baseline model relies on the joint dynamics of trade, productivity, and the exchange rate. Because the connection between relative productivity and relative prices is central for the endogenous growth model, the next section uses sector-level data to validate this important co-movement.

\section{Evidence from Sector-Level Data}

The estimated model suggests that when the home country increases its technological leadership with respect to the foreign country, the price of foreign goods increases relative to home goods. This section tests this prediction with cross country-industry variation using yearly data for $1970-2009$ for 15 industries in 23 countries. In particular, we show that industries that increase their share of patents registered in the United States patent office (USPTO) relative to the US experience a decrease in their industry level prices relative to the US. 


\subsection{Data Construction}

To understand the construction of our relative price and technological distance measures, it is useful to define the following indexes: $i$ to denote an industry, $c$ to denote a country, and $t$ to denote a year. Our construction of relative prices follows Lewis, Monarch, Sposi, and Zhang (2018). We use gross output prices series for each sector from KLEMS to construct price indices for each year, country, and sector relative to the US. To normalize the series, we use information from the GGDC Productivity Level Database, as described in Inklaar and Timmer (2014). An increase in $F X_{i, c, t}$ implies that the price of industry $i$ in country $c$ is increasing relatively to the US. Note that this measure is directly related to technological progress and less likely to be contaminated by demand factors. In fact, patent-based measures have been widely used as technology proxies in the endogenous technical change literature as they closely relate to the spirit of these models. ${ }^{41}$

The industry-level measure of technological distance for each industry is similar to the one used by Akcigit, Ates, and Impullitti (2018). First, we use the concordance of Goldschlag, Lybbert, and Zolas (2018) to match patent classes in USPTO to industries in KLEMS. Second, for every year and industry, we assign newly granted patents to each country based on the location of the principal inventor in the application, and denote the number of new patents of country $c$ in industry $i$ by $n_{i, c, t}$. Third, we calculate the technological distance of country $c$ in industry $i$ as the log difference of $n_{i, c, t}$ with respect to the same industry in the US, $n_{i, u s a, t}$.

$$
T D_{i, c, t}=\ln \left(\frac{n_{i, c, t}}{n_{i, u s a, t}}\right)
$$

The resulting sample is an unbalanced panel covering 15 industries for 23 countries between 1970 and 2009. Appendix A describes the data sources and presents general statistics for the sample. An increase in $T D_{i, c, t}$ implies that country $c$ is reducing its technology gap in industry $i$ with respect to the US.

\subsection{Empirical Results}

The use of panel data allows us to explore within industry-country variation to study the relationship between relative prices and technological distance, therefore abstracting from cross-country differences in exchange rate regimes or development and cross industry differences in technological dynamics. Moreover, we include time fixed effects to control for common global cycle components like changes in US monetary policy. We start by studying the dynamic relationship between technological distance and exchange rates by conducting a lead lag analysis between the variables. In

\footnotetext{
${ }^{41}$ Appendix A shows that our results are not driven by traditional Solow residual or productivity measures.
} 
particular, we estimate the following set of regressions for $s=0,1, \ldots 5$ :

$$
\begin{aligned}
& \ln F X_{i, c, t}=\alpha+\sum_{j=-s}^{0} \beta_{s, j} T D_{i, c, t+j}+\delta_{t}+\mu_{i, c}+v_{i, c, t}, \\
& \ln F X_{i, c, t}=\alpha+\sum_{0}^{j=s} \beta_{s, j} T D_{i, c, t+j}+\delta_{t}+\mu_{i, c}+v_{i, c, t},
\end{aligned}
$$

where $\delta_{t}$ is a year dummy and $\mu_{i, c}$ is a country-industry fixed effect. Figure 15 plots the estimates for $\beta_{s, j=s}$ for the 11 regressions along with the corresponding $90 \%$ confidence interval of the coefficient. As an example, $\beta_{-2, j=-2}$ captures the effect of technology at $t \leq T-2$ on exchange rate at time $T$.

Figure 15: Lead-lag Analysis

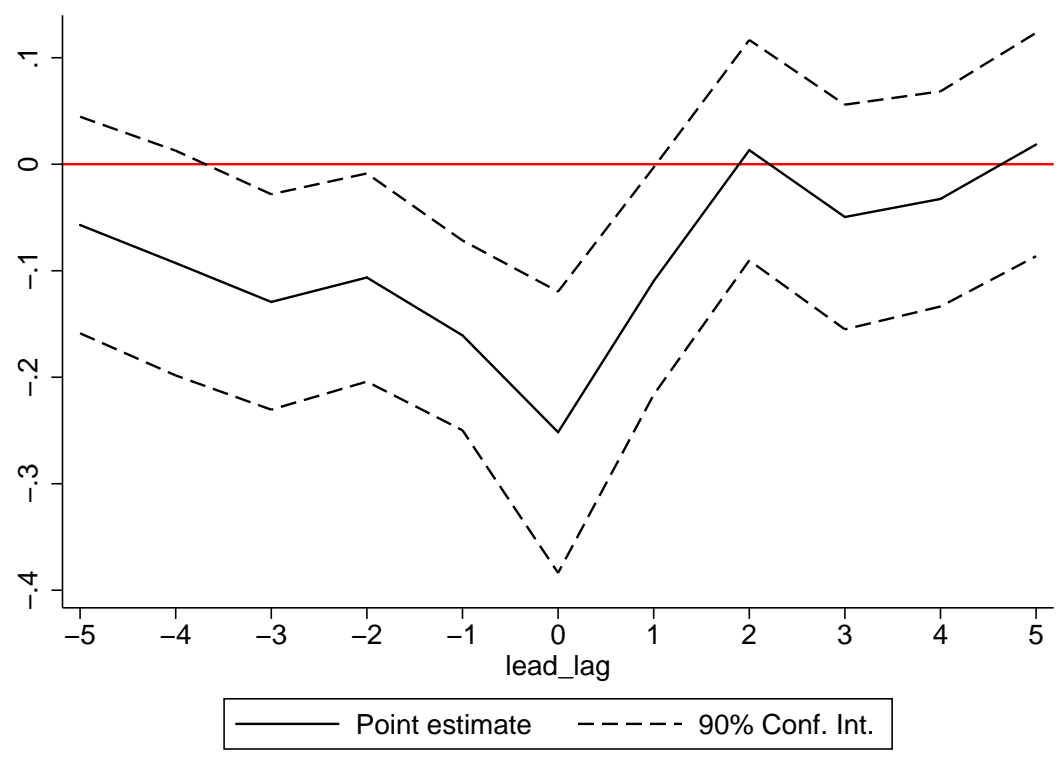

In line with our model, Figure 15 shows that technology gap leads changes in relative prices. Moreover, closing the technological gap decreases relative prices. Thus, the data supports the relationship between technology and relative prices at the core of the model. Considering the dynamic relationship in Figure 15, we specify the following panel regression:

$$
\ln F X_{i, c, t}=\alpha+\sum_{j=-4}^{0} \beta_{j} T D_{i, c, t-j}+\gamma X_{c, t}+\delta_{t}+\mu_{i, c}+v_{i, c, t}
$$

where $X_{c, t}$ represents other potential controls not absorbed by the fixed effects. Table 6 presents the results for seven specifications.

The first three specifications are pooled OLS regressions that illustrate the source of the negative correlation between prices and technology. The first specification only controls for time fixed effects, and only the contemporaneous effect is significant and positive. By including country fixed 
Table 6: Effect of Patent Technology Gaps on Real Exchange Rates

\begin{tabular}{|c|c|c|c|c|c|c|c|}
\hline & $\overline{\ln F X_{i, c, t}}$ & $\overline{l \ln F X_{i, c, t}}$ & $\overline{l \ln F X_{i, c, t}}$ & $\overline{\ln F X_{i, c, t}}$ & $\overline{\overline{\ln F X_{i, c, t}}}$ & $\overline{\overline{\ln F X_{i, c, t}}}$ & $\overline{\ln F X_{i, c, t}}$ \\
\hline$T D_{i, c, t}$ & $\begin{array}{l}0.343^{* * *} \\
(0.0991)\end{array}$ & $\begin{array}{c}0.110 \\
(0.0691)\end{array}$ & $\begin{array}{c}0.0699 \\
(0.0664)\end{array}$ & $\begin{array}{l}-0.0187 \\
(0.0702)\end{array}$ & $\begin{array}{l}-0.0780 \\
(0.0917)\end{array}$ & $\begin{array}{c}-0.107^{*} \\
(0.0632)\end{array}$ & $\begin{array}{c}0.00205 \\
(0.0195)\end{array}$ \\
\hline$T D_{i, c, t-1}$ & $\begin{array}{c}0.0603 \\
(0.0460)\end{array}$ & $\begin{array}{l}-0.0215 \\
(0.0344)\end{array}$ & $\begin{array}{l}-0.0556 \\
(0.0346)\end{array}$ & $\begin{array}{c}-0.0939^{* *} \\
(0.0397)\end{array}$ & $\begin{array}{c}-0.183^{* * *} \\
(0.0586)\end{array}$ & $\begin{array}{c}-0.0961^{*} \\
(0.0531)\end{array}$ & $\begin{array}{l}-0.0173 \\
(0.0143)\end{array}$ \\
\hline$T D_{i, c, t-2}$ & $\begin{array}{c}-0.0600 \\
(0.0424)\end{array}$ & $\begin{array}{c}-0.0719^{* *} \\
(0.0330)\end{array}$ & $\begin{array}{c}-0.0767^{* *} \\
(0.0315)\end{array}$ & $\begin{array}{c}-0.0757^{* *} \\
(0.0359)\end{array}$ & $\begin{array}{c}-0.190^{* * *} \\
(0.0646)\end{array}$ & $\begin{array}{l}-0.0155 \\
(0.0535)\end{array}$ & $\begin{array}{l}-0.0146 \\
(0.0130)\end{array}$ \\
\hline$T D_{i, c, t-3}$ & $\begin{array}{l}-0.0264 \\
(0.0538)\end{array}$ & $\begin{array}{l}-0.0439 \\
(0.0417)\end{array}$ & $\begin{array}{c}-0.0798^{* *} \\
(0.0402)\end{array}$ & $\begin{array}{l}-0.102^{* *} \\
(0.0424)\end{array}$ & $\begin{array}{c}-0.238^{* * *} \\
(0.0685)\end{array}$ & $\begin{array}{c}-0.0497 \\
(0.0433)\end{array}$ & $\begin{array}{c}-0.0388^{* *} \\
(0.0169)\end{array}$ \\
\hline$T D_{i, c, t-4}$ & $\begin{array}{c}0.0184 \\
(0.0901)\end{array}$ & $\begin{array}{c}-0.00104 \\
(0.0671)\end{array}$ & $\begin{array}{l}-0.0610 \\
(0.0631)\end{array}$ & $\begin{array}{c}-0.0928 \\
(0.0641)\end{array}$ & $\begin{array}{l}-0.147 \\
(0.109)\end{array}$ & $\begin{array}{c}-0.0944^{*} \\
(0.0554)\end{array}$ & $\begin{array}{l}-0.0167 \\
(0.0235)\end{array}$ \\
\hline rulc $_{i, c, t}$ & & & & & $\begin{array}{c}2.844^{* * *} \\
(0.592)\end{array}$ & $\begin{array}{c}0.671^{* * *} \\
(0.132)\end{array}$ & \\
\hline Constant & Yes & Yes & Yes & Yes & Yes & Yes & Yes \\
\hline Observations & 5509 & 5509 & 5509 & 5509 & 3859 & 3646 & 5471 \\
\hline Cluster SE & Yes & Yes & Yes & Yes & Yes & No & Yes \\
\hline Country-Industry FE & No & No & No & Yes & Yes & Yes & Yes \\
\hline Year FE & Yes & Yes & Yes & Yes & Yes & No & Yes \\
\hline Country FE & No & Yes & Yes & - & - & - & - \\
\hline Industry FE & No & No & Yes & - & - & - & - \\
\hline Country-Year Interaction & No & $\mathrm{No}$ & No & No & No & $\mathrm{No}$ & Yes \\
\hline
\end{tabular}

Note: Column 6 fits an Arellano-Bond model with 3 lags on the dependent variable

Robust standard errors in parentheses

${ }^{*} p<0.10,{ }^{* *} p<0.05,{ }^{* * *} p<0.01$

effects, the second specification controls for systematic differences on the relative prices of different countries that could be driven by different exchange rate or monetary regimes. In this case, the contemporaneous effect is no longer significant and the second lag of the technological distance measure significantly reduces relative prices. The third specifications also include industry fixed effects, allowing for systematic differences of prices across industries, rendering the second and third lag coefficients significant. The last four regressions are panel fixed effects specifications that exploit within industry-country variation. Consistent with the delay documented by the literature on technology diffusion, regression four shows that the first three lags are significant, with the largest marginal impact hitting with a three-year delay. To understand the economic magnitude of this effect, consider that the standard deviation of $T D$ after removing fixed effects and the common annual effects is 0.36. Therefore, a one standard deviation technological catch-up in $t-3$ decreases relative prices in $t$ by $3.7 \%$, with effects that persist for at least two more years. Berka, Devereux, and Engel (2018) 
show that accounting for labor cost dynamic is crucial when understanding exchange rate dynamics. The fifth specification includes employee-based labor cost measures from the OECD, always relative to the US. ${ }^{42}$ Interestingly, the results are even stronger under this specification, and the sign of the labor cost variable is consistent with the literature as countries where labor costs are higher than the US have higher relative prices. The sixth specification represents an Arellano-Bond estimator that controls for spurious dynamics of the relative prices. ${ }^{43}$ Although the magnitude and significance of the results are reduced, the message is unchanged. The last specification includes country-specific trends that eliminate not only the dynamics of labor costs, but also any monetary or fiscal policy dynamic. Even under this extremely restricted specification, the main correlation of the model remains.

Finally, to better estimate the dynamic effect of technology on prices, we estimate the following set of local projection regressions for $s=0,1, \ldots, 19,20$ :

$$
\ln \left(\frac{F X_{i, c, t+s}}{F X_{i, c, t-1}}\right)=\beta_{s} T D_{i, c, t-1}+\gamma_{s} r u l c_{c, t-1}+\delta_{t}+\mu_{i, c}+u_{i, c, t}
$$

where $\delta_{t}$ and $\mu_{i, c}$ are defined as above, and $u_{i, c, t}$ is an error term. As explained by Jordà (2005), we see this set of regressions as a forecast tool to document how changes in technology are associated with persistent dynamic in prices. The parameter $\beta_{s}$ shows the effect of technology catch up at year $t-1$ on the relative prices in period $t+s$. Reported in Figure 16 are estimates of $\beta_{s}$, with values of $s$ on the horizontal axis.

Figure 16: Prediction Regressions

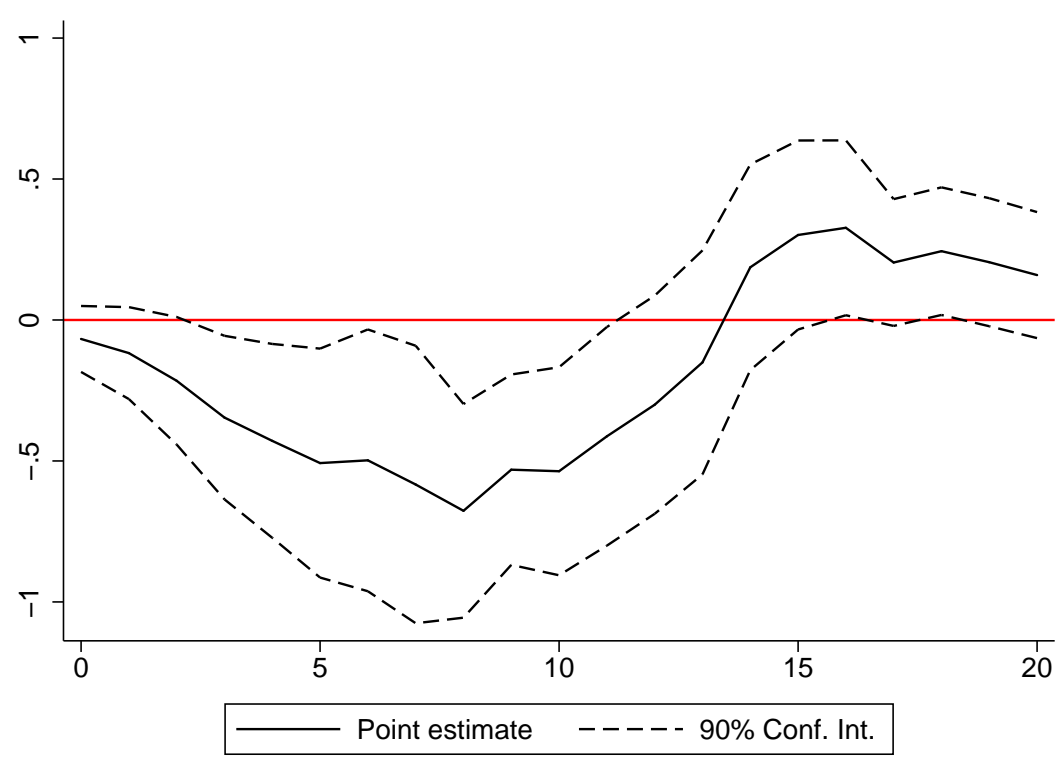

The results are consistent with Table 6: technological improvements predict lower industry prices.

\footnotetext{
${ }^{42}$ We have to drop India and Russia in this case.

${ }^{43}$ Three lags of $\ln F X_{i, c}$ are enough to eliminate the auto-correlation of the residual.
} 
The effect of technology becomes significant at year 3, increases steadily until year 8 , and vanishes slowly after 13 years. Therefore, technological progress triggers low-frequency price dynamics that decrease prices well beyond a decade.

\section{Conclusion}

The volatility and persistence of the exchange rate has challenged quantitative models in international finance for decades. The challenge is even greater at low frequencies, as most of the volatility of the RER is manifested in cycles that last decades. In this paper we show that a two-country real business cycle model with endogenous technology growth and spillovers can help rationalize the volatility and persistence of the RER, while being consistent with standard macro-economic dynamics at business cycle frequencies. Two elements are key for the quantitative success of our framework.

First, endogenous growth provides internal propagation for every shock in the system. In particular, any stationary fluctuation can potentially affect the incentives to perform $R \& D$, thus changing the future path of aggregate productivity. In particular, when a shock increases R\&D investment, agents expect persistent productivity differences across countries and therefore, the exchange rate exhibits persistent low-frequency fluctuations. In addition, variations in adoption cause resource flows between countries, generating additional movements in the RER.

Second, although endogenous growth has the potential to generate long exchange rate cycles, the timing of these cycles can be potentially disconnected from the empirical exchange rate dynamics. The robust low-frequency correlation between trade flows and exchange rates informs the estimation of the model, allowing for a precise timing for the low-frequency cycles. In a nutshell, endogenous growth opens the possibility of low-frequency fluctuations, but the trade data is key for the estimation to take advantage of the internal propagation of the mechanism and separate movements in the RER that are driven by financial effects captured by the UIP shock from other movements at lower frequencies.

We use a simple nominal version of the model to show that our mechanism can jointly explain nominal exchange rate and relative price dynamics. An interesting future avenue for research would be to use a medium scale New Keynesian model to study the interaction of endogenous growth, trade, and inflation on the full frequency domain. In particular, endogenous growth has the potential to affect the degree of price stickiness needed to rationalize short-run exchange rate movements. From an empirical perspective, our industry-level regressions shed light on the connection between relative productivity and prices at the core of our model. Future research could link firm-level prices to patent development to provide further evidence of this important co-movement. 


\section{References}

Adjemian, S., H. Bastani, M. Juillard, F. Mihoubi, G. Perendia, M. Ratto, and S. Villemot (2011): "Dynare: Reference manual, version 4," .

Adolfson, M., S. Laséen, J. Lindé, and M. Villani (2008): "Evaluating an estimated new Keynesian small open economy model," Journal of Economic Dynamics and Control, 32(8), 26902721.

Aghion, P., And P. Howitt (1992): "A Model of Growth through Creative Destruction," Econometrica, 60(2).

Akcigit, U., S. T. Ates, And G. Impullitti (2018): "Innovation and Trade Policy in a Globalized World," Discussion paper, National Bureau of Economic Research.

Alessandria, G. A., And H. Choi (2019): "The dynamics of the US trade balance and real exchange rate: The J curve and trade costs?," Discussion paper, National Bureau of Economic Research.

Alfaro, L., A. Cunat, H. Fadinger, and Y. Liu (2018): "The Real Exchange Rate, Innovation and Productivity: Heterogeneity, Asymmetries and Hysteresis," Discussion paper, National Bureau of Economic Research.

An, S., ANd F. SchorfHeIde (2007): "Bayesian analysis of DSGE models," Econometric reviews, 26(2-4), 113-172.

Anzontegui, D., D. Comin, M. Gertler, and J. Martinez (2019): "Endogenous technology adoption and R\&D as sources of business cycle persistence," American Economic Journal: Macroeconomics, 11(3), 67-110.

Ates, S., And F. SAFFIE (forthcoming): "Fewer but better: Sudden stops, firm entry, and financial selection," American Economic Journal: Macroeconomics.

Backus, D. K., P. J. Kehoe, and F. E. Kydland (1992): "International real business cycles," Journal of political Economy, 100(4), 745-775.

Baxter, M., And M. J. Crucini (1995): "Business Cycles and the Asset Structure of Foreign Trade," International Economic Review, 36(4), 821-854.

Beaudry, P., D. Galizia, and F. Portier (2020): "Putting the cycle back into business cycle analysis," American Economic Review, 110(1), 1-47.

Benguria, F., H. Matsumoto, and F. Saffie (2020): "Productivity and Trade Dynamics in Sudden Stops," Available at SSRN. 
Berka, M., M. B. Devereux, and C. Engel (2012): "Real Exchange Rate Adjustment in and out of the Eurozone," American Economic Review, 102(3), 179-85.

(2018): "Real Exchange Rates and Sectoral Productivity in the Eurozone," American Economic Review, 108(6), 1543-81.

Boenm, C. E., A. A. Levchenko, and N. Pandalai-Nayar (2020): "The Long and Short (Run) of Trade Elasticities," Discussion paper.

Campbell, J. R., J. D. Fisher, A. Justiniano, and L. Melosi (2017): "Forward guidance and macroeconomic outcomes since the financial crisis," NBER Macroeconomics Annual, 31(1), $283-357$.

Cascaldi-Garcia, D., And M. Vukotić (2020): "Patent-based news shocks," .

Chari, V. V., P. J. Kehoe, and E. R. McGrattan (2002): "Can sticky price models generate volatile and persistent real exchange rates?," The review of economic studies, 69(3), 533-563.

Christiano, L. J., R. Motto, and M. Rostagno (2014): "Risk Shocks," American Economic Review, 104(1), 27-65.

Colacito, R., And M. M. Croce (2011): "Risks for the long run and the real exchange rate," Journal of Political economy, 119(1), 153-181.

(2013): "International asset pricing with recursive preferences," The Journal of Finance, 68(6), 2651-2686.

Comin, D., and M. Gertler (2006): "Medium-term business cycles," American Economic Review, 96(3), 523-551.

Corsetti, G., L. Dedola, and S. Leduc (2008): "International risk sharing and the transmission of productivity shocks," The Review of Economic Studies, 75(2), 443-473.

Drozd, L. A., S. Kolbin, J. B. Nosal, Et AL. (2019): "The Trade-Comovement Puzzle," Discussion paper.

EAton, J., And S. Kortum (1999): "International technology diffusion: Theory and measurement," International Economic Review, 40(3), 537-570.

Eichenbaum, M., B. K. Johannsen, and S. Rebelo (forthcoming): "Monetary policy and the predictability of nominal exchange rates," The Review of Economic Studies.

Erceg, C. J., L. Guerrieri, And C. Gust (2006): "SIGMA: A New Open Economy Model for Policy Analysis," International Journal of Central Banking. 
FARHI, E., AND X. GABAIX (2015): "Rare disasters and exchange rates," The Quarterly Journal of Economics, 131(1), 1-52.

Fisher, J. (2014): "On the Structural Interpretation of the Smets-Wouters "Risk Premium" Shock," Discussion paper, Working Paper No. 2014-08, Federal Reserve Bank of Chicago.

Galí, J., F. Smets, and R. Wouters (2012): "Unemployment in an estimated new keynesian model," NBER macroeconomics annual, 26(1), 329-360.

Gavazzoni, F., And A. M. Santacreu (2019): "International R\&D spillovers and asset prices," Journal of Financial Economics.

Ghironi, F., And M. J. Melitz (2005): "International trade and macroeconomic dynamics with heterogeneous firms," The Quarterly Journal of Economics, 120(3), 865-915.

Goldschlag, N., T. J. Lybbert, and N. J. Zolas (2018): "Tracking the Technological Composition of Industries with Algorithmic Patent Concordances," .

Greenwood, J., Z. Hercowitz, and G. W. Huffman (1988): "Investment, capacity utilization, and the real business cycle," The American Economic Review, pp. 402-417.

Grossman, G. M., and E. Helpman (1991): "Quality ladders in the theory of growth," The review of economic studies, 58(1), 43-61.

Grüning, P. (2017): "International endogenous growth, macro anomalies, and asset prices," Journal of Economic Dynamics and Control, 78, 118-148.

Guerron-Quintana, P. A., and R. Jinnai (2019): "Financial frictions, trends, and the great recession," Quantitative Economics, 10(2), 735-773.

HeAthcote, J., And F. Perri (2002): "Financial autarky and international business cycles," Journal of monetary Economics, 49(3), 601-627.

Huo, Z., A. Levchenko, and N. Pandalai-Nayar (2018): "The Global Business Cycle: Measurement and Transmission," Discussion paper, Working Paper.

InklaAR, R., And M. P. Timmer (2014): "The relative price of services," Review of Income and Wealth, 60(4), 727-746.

IRwin, D. A., AND P. J. KLEnOW (1994): "Learning-by-doing spillovers in the semiconductor industry," Journal of political Economy, 102(6), 1200-1227.

Itskhoki, O., And D. Mukhin (2017): "Exchange rate disconnect in general equilibrium," Discussion paper, National Bureau of Economic Research. 
(2019): "Mussa puzzle redux," .

Jaimovich, N., And S. Rebelo (2009): "Can news about the future drive the business cycle?," American Economic Review, 99(4), 1097-1118.

JORDÀ, Ò. (2005): "Estimation and inference of impulse responses by local projections," American economic review, 95(1), 161-182.

Karabarbounis, L. (2014): "Home production, labor wedges, and international business cycles," Journal of Monetary Economics, 64, 68-84.

Lewis, L., R. Monarch, M. Sposi, and J. Zhang (2018): "Structural Change and Global Trade," .

Meese, R. A., And K. Rogoff (1983): "Empirical exchange rate models of the seventies: Do they fit out of sample," Journal of International Economics, 14(3), 24.

Ohanian, L. E., And A. RAFfo (2012): "Aggregate hours worked in OECD countries: New measurement and implications for business cycles," Journal of Monetary Economics, 59(1), 40-56.

Rabanal, P., And J. F. Rubio-Ramirez (2015): "Can international macroeconomic models explain low-frequency movements of real exchange rates?," Journal of International Economics, 96(1), 199-211.

RAFFo, A. (2010): Technology shocks: novel implications for international business cycles, vol. 7980. Diane Publishing.

Romer, P. M. (1990): "Endogenous technological change," Journal of political Economy, 98(5, Part 2), S71-S102.

RuhL, K. J., ET AL. (2008): "The international elasticity puzzle," unpublished paper, NYU.

SChmitt-Grohé, S., AND M. URIBE (2003): "Closing small open economy models," Journal of international Economics, 61(1), 163-185.

Smets, F., And R. Wouters (2007): "Shocks and frictions in US business cycles: A Bayesian DSGE approach," American economic review, 97(3), 586-606.

Steinsson, J. (2008): "The dynamic behavior of the real exchange rate in sticky price models," American Economic Review, 98(1), 519-33. 


\section{A Appendix: Data}

\section{A.1 Industry-level Exchange Rates}

To calculate industry-level exchange rates, we use the productivity database from KLEMS ${ }^{44}$ and Groningen Growth and Development Centre (GGDC) and nominal exchange rate data from FRED and World Bank World Development Indicators. To illustrate the methodology, let's first define some notation. Let $F X_{i, c, t}$ be the industry $i$ exchange rate of country $c$ (with the United States) in year $t$. GO_P $P_{i, c, t}^{j}$ represents the industry $i$ gross output price in country $c$ and year $t$ (with $t=$ base representing the value for some base year) in terms of country $j$ 's currency (with $j=i n d e x$ representing the corresponding price index rather than level). For example, $G O_{-} P_{i, c, b a s e}^{U S}$ represents the industry $i$ gross output price in country $c$ for some base year in terms of dollars. Lastly, exch.rate ent $_{t}$ represents the nominal exchange rate of country c's currency in terms of dollars. Let's then define the industry-level exchange rate as follows:

$$
\begin{aligned}
F X_{i, c, t} \equiv \frac{G O \_P_{i, c, t}^{U S}}{G O_{-} P_{i, U S, t}^{U S}} & =\frac{G O \_P_{i, c, t}^{c}}{G O_{-} P_{i, U S, t}^{U S}} \times \frac{1}{\text { exch.rate }_{c, t}} \\
& =\frac{G P_{i, c, t} / G O \_P_{i, c, b a s e}^{c}}{G O \_P_{i, U S, t}^{U S} / G O \_P_{i, U S, b a s e}^{U S}} \times \frac{A_{i, c}}{\text { exch.rate }_{c, t}} \\
& =\frac{G O \_P_{i, c, t}^{\text {index }}}{G O_{-} P_{i, U S, t}^{\text {index }}} \times \frac{A_{i, c}}{\text { exch.rate }_{c, t}}
\end{aligned}
$$

where the constant $A_{i, c}=G O_{-} P_{i, c, b a s e}^{c} / G O_{-} P_{i, U S, b a s e}^{U S}$. Note that exch.rate ${ }_{c, t}$ comes directly from the nominal exchange rate data, and $G O_{-} P^{i n d e x}$ is available for all countries in the KLEMS data (the gross output price index series is called $G O_{-} P$ ). Thus, the only thing remaining to calculate $F X_{i, c, t}$ is the time-constant $A_{i, c}$. GGDC gives gross output price estimates relative to US GDP for the year 2005 (in US dollars): $G O \_R P_{i, c, 2005} \equiv G O_{-} P_{i, c, 2005}^{U S} / G D P_{U S, 2005}^{U S}$. I calculate $A_{i, c}$ by taking the following ratio:

$$
\begin{aligned}
\frac{G O \_R P_{i, c, 2005}}{G G_{-} R P_{i, U S, 2005}} & =\frac{G O \_P_{i, c, 2005}^{U S} / G D P_{U S, 2005}^{U S}}{G{ }_{-} P_{i, U S, 2005}^{U S} / G D P_{U S, 2005}^{U S}}=\frac{G O_{-} P_{i, c, 2005}^{U S}}{G O_{-} P_{i, U S, 2005}^{U S}} \\
& =\frac{G P_{i, c, 2005}}{G O_{-} P_{i, U S, 2005}^{U S}} \times \frac{1}{\text { exch.rate }_{c, 2005}}=\frac{A_{i, c}}{\text { exch.rate }_{c, 2005}} \\
\Longrightarrow A_{i, c} & =\frac{G O \_R P_{i, c, 2005}}{G O \_R P_{i, U S, 2005}} \times \text { exch.rate }_{c, 2005} .
\end{aligned}
$$

Thus, we calculate industry-level exchange rates using the formula

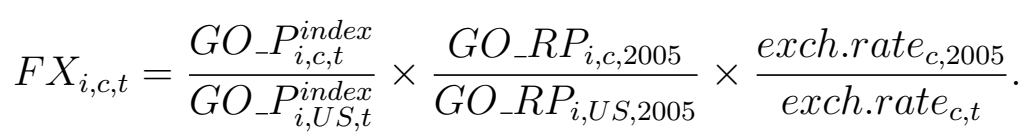

\footnotetext{
${ }^{44}$ KLEMS databases are from the EU, Canada, Japan, Russia, and India.
} 
Note that fixed effects regressions with $\ln F X_{i, c, t}$ eliminate any effect from mismeasurement on $A_{i, c}$.

\section{A.2 Technology Gaps using Patents}

To calculate technology gaps between sample countries and the United States, we use patent data from the United States Patent and Trademark Office (USPTO) PatentsView website. ${ }^{45}$ From these files, we have a data set with information on type (measured by CPC classification), year (measured by application year), and country (measured by country associated with inventor) of every new patent in the United States since 1970. We aggregate patents annually by country and by type at the two-digit $\mathrm{CPC}$ level to achieve a panel with country-type as the panel variable and year as the time variable. We then use a probability crosswalk from Goldschlag, Lybbert, and Zolas (2018) to convert the CPC classifications into two-digit ISIC rev. 4 groups. With these classifications, I can combine to achieve the industry groups as reported in KLEMS. For every observation (i.e., countryindustry in a year) I then calculate the technology gap between the given industry in that country and the industry in the United States as follows:

$$
T D_{i, c, t}=\ln \left(\frac{n_{i, c, t}}{n_{i, U S, t}}\right)
$$

where $n_{i, c, t}$ is the number of new industry- $i$ patents granted from country $c$ in year $t$. This measure is similar to the one used by Akcigit, Ates, and Impullitti (2018).

\section{A.3 Measures of Productivity Differences}

In addition to using patent data to estimate technology gaps, we also use for robustness purposes, two alternative measures of TFP. The first measure is taken from Huo, Levchenko, and Pandalai-Nayar (2018). They estimate the log-change in TFP, $d \ln Z_{i, c, t}^{46}$. Because the patent measure captures differences in growth, we define:

$$
T D_{i, c, t}^{H L P}=d \ln Z_{i, c, t}-d \ln Z_{i, U S, t}
$$

A second measure uses KLEMS data to estimate Solow residuals as a proxy for TFP. Huo, Levchenko, and Pandalai-Nayar (2018) characterize a log-change in Solow residual as

$d \ln S_{i, c, t}=d \ln Y_{i, c, t}-\alpha_{i} \eta_{i} d \ln m_{i, c, t}-\left(1-\alpha_{i}\right) \eta_{i} d \ln h_{i, c, t}-\left(1-\alpha_{i}\right) \eta_{i} d \ln N_{i, c, t}-\left(1-\eta_{i}\right) d \ln X_{i, c, t}$

where $Y_{i, c, t}=Z_{i, c, t}\left[\left(K_{i, c, t}^{\alpha_{i}} L_{i, c, t}^{1-\alpha_{i}}\right)^{\eta_{i}} X_{i, c, t}^{1-\eta_{i}}\right]^{\gamma}$ is real gross output, $m_{i, c, t}$ is the quantity of capital inputs, $h_{i, c, t}$ is the average hours worked, $N_{i, c, t}$ is the number of workers, and $X_{i, c, t}$ is the bundle of materials

\footnotetext{
${ }^{45}$ Specifically, we merge the patent, cpc_current, application, patent_inventor, location_inventor, and location data files.

${ }^{46}$ for any variable $B_{i, c, t}, d \ln B_{i, c, t} \equiv \ln \left(\frac{B_{i, c, t}}{B_{i, c, t-1}}\right)$
} 
inputs. Thus, the second measure is

$$
T D_{i, c, t}^{\text {solow }}=d \ln S_{i, c, t}-d \ln S_{i, U S, t}
$$

\section{A.4 Industry Groups in KLEMS Data}

Different releases of KLEMS use different revisions of ISIC codes. Older releases of KLEMS use ISIC rev. 3.1, while the most recent release of EUKLEMS uses ISIC rev. 4. This would not be an issue if there were a one-to-one mapping between the two revisions' industry groups; however, the switch to revision 4 causes some problems. Certain sectors are expanded to allow for more specific classification, and other sectors are combined so that one is unable to distinguish between them in the data. This precludes correspondence between the two ISIC revisions for these sectors. Two options exist for resolving this issue in this paper. The first option is to use only older versions of KLEMS and exclude data since 2007. The second option is to use all years of data available in KLEMS but exclude industry groups that don't have a one-to-one matching between the two revisions of ISIC. We have opted for the former option and include all industry groups at the cost of not having any observations after 2009. Because of the fact that only certain industries show up in the USPTO patent data, we are left with the industries shown in Table 7. All results are robust to focusing on the common industries for the longer period.

Table 7: Industry Groups in Sample

\begin{tabular}{lcc}
\hline \multicolumn{1}{c}{ Industry Description } & ISIC rev. 3.1 & \# of countries \\
\hline Food, beverages and tobacco & $15 \mathrm{t} 16$ & 17 \\
Wood and products of wood and cork & 20 & 1 \\
Pulp, paper products, printing and publishing & $21 \mathrm{t} 22$ & 14 \\
Coke, refined petroleum and nuclear fuel & 23 & 17 \\
Chemicals and chemical products & 24 & 23 \\
Rubber and plastics & 25 & 12 \\
Other non-metallic mineral products & 26 & 19 \\
Basic metals and fabricated metals & $27 \mathrm{t} 28$ & 19 \\
Manufacture of machinery & 29 & 19 \\
Electrical and optical equipment & $30 \mathrm{t} 33$ & 22 \\
Transport equipment & $34 \mathrm{t} 35$ & 15 \\
Manufacturing of furniture; recycling & $36 \mathrm{t} 37$ & 18 \\
Mining and quarrying & $\mathrm{C}$ & 5 \\
Electricity, gas and water supply & $\mathrm{E}$ & 18 \\
Construction & $\mathrm{F}$ & 9 \\
\hline
\end{tabular}

Table 8 present the sample of countries and summary statistics for each one. Our sample criterion requires 15 consecutive years of data, and we only include industries with 5 or more patents every year for each country. 
Table 8: Summary Statistics by Country

\begin{tabular}{lccccc}
\hline Country & Start Year & End Year & \# of industries & Mean $\ln F X$ & Mean TD \\
\hline Australia & 1971 & 2007 & 13 & -0.10 & -4.44 \\
Austria & 1972 & 2007 & 12 & -1.93 & -4.65 \\
Belgium & 1972 & 2007 & 11 & -2.71 & -4.56 \\
Canada & 1972 & 2008 & 14 & -0.01 & -3.24 \\
Czech Republic & 1995 & 2007 & 2 & -0.53 & -7.21 \\
Denmark & 1973 & 2007 & 10 & 0.02 & -5.19 \\
Finland & 1974 & 2007 & 12 & -1.14 & -4.91 \\
France & 1970 & 2007 & 14 & -1.18 & -2.93 \\
Germany & 1970 & 2007 & 14 & -0.37 & -1.80 \\
Greece & 1992 & 2007 & 2 & -2.59 & -8.07 \\
Hungary & 1991 & 2007 & 3 & -0.49 & -6.16 \\
India & 1981 & 2009 & 9 & -0.73 & -5.24 \\
Ireland & 1980 & 2007 & 7 & 0.10 & -6.41 \\
Italy & 1971 & 2007 & 12 & -5.61 & -3.81 \\
Japan & 1973 & 2009 & 15 & 0.30 & -1.22 \\
Luxembourg & 1976 & 2007 & 3 & -2.05 & -6.31 \\
Netherlands & 1972 & 2007 & 13 & -0.65 & -4.09 \\
Poland & 1995 & 2006 & 2 & -0.52 & -7.49 \\
Russian Federation & 1996 & 2009 & 9 & -0.63 & -5.39 \\
South Korea & 1978 & 2007 & 13 & -0.17 & -4.10 \\
Spain & 1974 & 2007 & 11 & -3.19 & -5.54 \\
Sweden & 1972 & 2007 & 13 & 0.09 & -4.01 \\
United Kingdom & 1971 & 2007 & 14 & -0.01 & -2.96 \\
\hline
\end{tabular}




\section{A.5 Robustness}

One potential concern is that our measure of technological distance captures other aspects of technology or demand usually present in aggregate productivity or Solow residual measures. To explore this alternative, we estimate the following regression:

$$
T D_{i, c, t}=\alpha+\beta_{1} T D_{i, c, t}^{\text {solow }}+\beta_{2} T D_{i, c, t}^{H L P} \delta_{t}+\mu_{i, c}+v_{i, c, t}
$$

where we remove the co-movement between our patent-based measure and traditional measures of productivity (Solow and Solow corrected by utilization). Table 9 replicates Table 6 using the estimated residuals $\hat{v}_{i, c, t}$ instead of $T D_{i, c, t}$. The main message of the empirical section is still unchanged.

Table 9: Regressing Real Exchange Rates on Residuals

\begin{tabular}{|c|c|c|c|c|c|c|c|}
\hline & $\overline{l \ln F X_{i, c, t}}$ & $\overline{l n} F X_{i, c, t}$ & $\overline{l n} F X_{i, c, t}$ & $\overline{\ln F X_{i, c, t}}$ & $\ln F X_{i, c, t}$ & 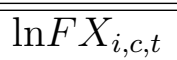 & $\overline{\ln F X_{i, c, t}}$ \\
\hline$\hat{v}_{i, c, t}$ & $\begin{array}{c}-0.0493 \\
(0.0999)\end{array}$ & $\begin{array}{c}0.0573 \\
(0.0975)\end{array}$ & $\begin{array}{l}0.0675 \\
(0.101)\end{array}$ & $\begin{array}{c}0.0833 \\
(0.0997)\end{array}$ & $\begin{array}{l}0.0148 \\
(0.104)\end{array}$ & $\begin{array}{c}-0.134^{*} \\
(0.0723)\end{array}$ & $\begin{array}{l}0.00392 \\
(0.0200)\end{array}$ \\
\hline$\hat{v}_{i, c, t-1}$ & $\begin{array}{r}-0.00152 \\
(0.0613)\end{array}$ & $\begin{array}{l}-0.0233 \\
(0.0573)\end{array}$ & $\begin{array}{l}-0.0348 \\
(0.0584)\end{array}$ & $\begin{array}{c}-0.0363 \\
(0.0573)\end{array}$ & $\begin{array}{l}-0.162^{* *} \\
(0.0673)\end{array}$ & $\begin{array}{l}-0.115^{* *} \\
(0.0585)\end{array}$ & $\begin{array}{l}-0.0197 \\
(0.0136)\end{array}$ \\
\hline$\hat{v}_{i, c, t-2}$ & $\begin{array}{l}-0.0190 \\
(0.0685)\end{array}$ & $\begin{array}{c}-0.0788 \\
(0.0497)\end{array}$ & $\begin{array}{l}-0.103^{* *} \\
(0.0491)\end{array}$ & $\begin{array}{c}-0.0906^{*} \\
(0.0516)\end{array}$ & $\begin{array}{c}-0.233^{* * *} \\
(0.0805)\end{array}$ & $\begin{array}{l}-0.0649 \\
(0.0668)\end{array}$ & $\begin{array}{l}-0.0114 \\
(0.0130)\end{array}$ \\
\hline$\hat{v}_{i, c, t-3}$ & $\begin{array}{r}-0.0837 \\
(0.105)\end{array}$ & $\begin{array}{l}-0.0926 \\
(0.0743)\end{array}$ & $\begin{array}{c}-0.116 \\
(0.0737)\end{array}$ & $\begin{array}{c}-0.124^{*} \\
(0.0724)\end{array}$ & $\begin{array}{c}-0.263^{* * *} \\
(0.0912)\end{array}$ & $\begin{array}{l}-0.0253 \\
(0.0491)\end{array}$ & $\begin{array}{r}-0.0368^{* *} \\
(0.0164)\end{array}$ \\
\hline$\hat{v}_{i, c, t-4}$ & $\begin{array}{c}-0.0434 \\
(0.166)\end{array}$ & $\begin{array}{l}-0.128 \\
(0.113)\end{array}$ & $\begin{array}{l}-0.134 \\
(0.110)\end{array}$ & $\begin{array}{l}-0.150 \\
(0.111)\end{array}$ & $\begin{array}{c}-0.255^{*} \\
(0.145)\end{array}$ & $\begin{array}{l}-0.0921 \\
(0.0686)\end{array}$ & $\begin{array}{l}-0.0389 \\
(0.0258)\end{array}$ \\
\hline $\operatorname{rulc}_{i, c, t}$ & & & & & $\begin{array}{c}4.506^{* * *} \\
(0.760)\end{array}$ & $\begin{array}{c}1.225^{* * *} \\
(0.178)\end{array}$ & \\
\hline Constant & Yes & Yes & Yes & Yes & Yes & Yes & Yes \\
\hline Observations & 4148 & 4148 & 4148 & 4147 & 3321 & 3111 & 4141 \\
\hline Cluster SE & Yes & Yes & Yes & Yes & Yes & No & Yes \\
\hline Country-Industry FE & No & No & No & Yes & Yes & Yes & Yes \\
\hline Year FE & Yes & Yes & Yes & Yes & Yes & No & Yes \\
\hline Country FE & No & Yes & Yes & - & - & - & - \\
\hline Industry FE & No & No & Yes & - & - & - & - \\
\hline Country-Year Interaction & No & No & No & No & No & No & Yes \\
\hline
\end{tabular}

Note: Column 6 fits an Arellano-Bond model with 3 lags on the dependent variable

Robust standard errors in parentheses

${ }^{*} p<0.10,{ }^{* *} p<0.05,{ }^{* * *} p<0.01$ 


\section{B Appendix: Model Equations}

\section{B.1 Characterization}

In this subsection, we collect the equations characterizing an equilibrium. To keep things a little shorter we drop the equations for stochastic processes. In the following equations $\nu_{t}^{x}$ with $x$ a letter are Lagrange multipliers.

$$
\begin{aligned}
& \prod_{s=0}^{t-1} \beta_{s}\left(c_{t}-\psi_{1, t} x_{t} l_{t}^{1+\psi_{2}}\right)^{-\sigma}-\nu_{t}^{c} P_{t}=0 \\
& -\prod_{s=0}^{t-1} \beta_{s}\left(c_{t}-\psi_{1, t} x_{t} l_{t}^{1+\psi_{2}}\right)^{-\sigma} \psi_{1, t}\left(1+\psi_{2}\right) x_{t} l_{t}^{\psi_{2}}+\nu_{t}^{c} W_{t} P_{t}=0 \\
& \nu_{t}^{c} P_{t} R_{t}^{k} k_{t-1}-\nu_{t}^{k} \delta_{k}^{\prime}\left(u_{t}\right) k_{t-1}=0 \\
& -P_{t} \nu_{t}^{c}+\nu_{t}^{k} q_{t}\left(1-\phi_{i}\left(\frac{i_{t}}{i_{t-1}}\right)-\phi_{i}^{\prime}\left(\frac{i_{t}}{i_{t-1}}\right) \frac{i_{t}}{i_{t-1}}\right)+q_{t+1} \nu_{t+1}^{k} \phi_{i}^{\prime}\left(\frac{i_{t+1}}{i_{t}}\right) \frac{i_{t+1}^{2}}{i_{t}^{2}}=0 \\
& -\nu_{t}^{k}+\nu_{t+1}^{k}\left(1-\delta_{k}\left(u_{t}\right)\right)+\nu_{t+1}^{c} P_{t+1} R_{t+1}^{k} u_{t+1}=0 \\
& -\nu_{t}^{c} P_{t}^{*}+\nu_{t+1}^{c} R_{t}^{*} P_{t+1}^{*} \exp \left(\frac{\bar{b}_{t}}{A_{t}}\right)^{-\phi} \exp \left(U_{t}\right) \exp \left(\frac{\bar{b}_{t-1}}{A_{t-1}}\right)^{-\phi_{1}}\left(\frac{\mathbb{E}_{t} R E R_{t+1}}{R E R_{t-1}}\right)^{-\phi_{2}}=0 \\
& k_{t}=\left(1-\delta_{k}\left(u_{t}\right)\right) k_{t-1}+q_{t}\left(1-\phi_{i}\left(\frac{i_{t}}{i_{t-1}}\right)\right) i_{t} \\
& x_{t}=\bar{c}_{t}^{\gamma} x_{t-1}^{1-\gamma} \\
& \beta^{t} \nu_{t}^{c}\left(P_{t} Y_{t}^{1-\rho} a_{D} y_{D, t}^{\rho-1}-p_{D, t}\right)+\psi_{t}\left(-\iota\left(\frac{\frac{y_{I, t}}{y_{D, t}}}{\frac{y_{I, t-1}}{y_{D, t-1}}}-1\right) \frac{-\frac{y_{I, t}}{y_{D, t}^{2}}}{\frac{y_{I, t-1}}{y_{D, t-1}}}\right)+\psi_{t+1}\left(-\iota\left(\frac{\frac{y_{I, t+1}}{y_{,, t+1}}}{\frac{y_{I, t}}{y_{D, t}}}-1\right) \frac{\frac{y_{I, t+1}}{y_{D, t+1}}}{y_{I, t}}\right)=0 \\
& \beta^{t} \nu_{t}^{c}\left(P_{t} Y_{t}^{1-\rho} a_{I} \phi_{t}^{\rho} y_{I, t}^{\rho-1}-p_{I, t}\right)+\psi_{t}\left(-\iota\left(\frac{\frac{y_{I, t}}{y_{D, t}}}{\frac{y_{I, t-1}}{y_{D, t-1}}}-1\right) \frac{\frac{1}{y_{D, t}}}{\frac{y_{I, t-1}}{y_{D, t-1}}}\right)+\psi_{t+1}\left(-\iota\left(\frac{\frac{y_{I, t+1}}{y_{D_{,}+t+1}}}{\frac{y_{I, t}}{y_{D, t}}}-1\right) \frac{\frac{y_{I, t+1}}{y_{D, t+1}}}{-\frac{y_{I, t}}{y_{D, t}}}\right)=0 \\
& \beta^{t} \nu_{t}^{c} P_{t} Y_{t}^{1-\rho} a_{I} \phi_{t}^{\rho-1} y_{I, t}^{\rho}-\psi_{t}=0
\end{aligned}
$$




$$
\begin{aligned}
& Y_{t}=\left(a_{D} y_{D, t}^{\rho}+a_{I}\left(\phi_{t} y_{I, t}\right)^{\rho}\right)^{\frac{1}{\rho}} \\
& \phi_{t}=1-\frac{\iota}{2}\left(\frac{\frac{y_{I, t}}{y_{D, t}}}{\frac{y_{I, t-1}}{y_{D, t-1}}}-1\right)^{2} \\
& y_{t}=Z_{t} \bar{K}_{t}^{\alpha_{K}} L_{t}^{\alpha_{L}} M_{t}^{\alpha_{M}} \\
& M_{t}=A_{t-1}^{\frac{1}{\mu}} m_{t} \\
& p_{D, t} \alpha_{L} \frac{y_{t}}{L_{t}}=P_{t} W_{t} \\
& p_{D, t} \alpha_{K} \frac{y_{t}}{\bar{K}_{t}}=P_{t} R_{t}^{k} \\
& p_{D, t} \alpha_{M} \frac{y_{t}}{M_{t}}\left(A_{t-1} m_{t}^{\mu}\right)^{\frac{1}{\mu}-1} m_{t}^{\mu-1}=p_{t} \\
& p_{D, t} \Omega_{t}^{g} \Omega_{t}^{l}=p_{I, t}^{*} \\
& \frac{1}{\mu} P_{t}=p_{t} \\
& \pi_{t}=\left(\frac{1}{\mu}-1\right) P_{t} m_{t}-\Phi \\
& H_{t}=\pi_{t}+\left(1-\delta_{a}\right) \Lambda_{t, t+1} H_{t+1} \\
& \Lambda_{t, t+1}=\frac{\nu_{t+1}^{c}}{\nu_{t}^{c}} \\
& N_{t}=\left(1-\delta_{n}\right) N_{t-1}+\gamma_{t} \\
& \gamma_{t}=\zeta \frac{\left(N_{t-1}+\tau N_{t-1}^{*}\right)^{1-\eta}}{S_{t}^{1-\eta}} S_{t} \\
& \zeta \frac{\left(N_{t-1}+\tau N_{t-1}^{*}\right)^{1-\eta}}{S_{t}^{1-\eta}} \Lambda_{t, t+1} J_{t+1}=P_{t}
\end{aligned}
$$




$$
\begin{gathered}
A_{t}=\left(1-\delta_{a}\right) A_{t-1}+\lambda_{t}\left(a_{t}\right)\left(N_{t-1}-A_{t-1}\right) \\
J_{t}=-P_{t} a_{t}+\Lambda_{t, t+1}\left(\lambda_{t}\left(a_{t}\right) H_{t+1}+\left(1-\lambda_{t}\left(a_{t}\right)\right)\left(1-\delta_{n}\right) J_{t+1}\right) \\
P_{t}=\Lambda_{t, t+1}\left(\lambda_{t}^{\prime}\left(a_{t}\right) H_{t+1}-\lambda_{t}^{\prime}\left(a_{t}\right)\left(1-\delta_{n}\right) J_{t+1}\right) \\
\lambda_{t}\left(a_{t}\right)=\kappa_{\lambda}\left(a_{t}\right)^{\mu_{\lambda}} \\
Y_{t}=c_{t}+i_{t}+S_{t}+\left(N_{t-1}-A_{t-1}\right) a_{t}+A_{t-1} m_{t}+G_{t} Y_{t}+\Phi A_{t-1} \\
b_{t}+b_{t}^{*}=0 \\
P_{t}^{*} b_{t}=p_{I, t}^{*} y_{I, t}^{*}-p_{I, t} y_{I, t}+P_{t}^{*} R_{t-1}^{*} b_{t-1} \\
y_{t}=y_{D, t}+y_{I, t}^{*} \theta^{G} \theta^{R} \\
L_{t}=l_{t} \\
k_{t-1} u_{t}
\end{gathered}
$$




\section{B.2 Market Clearing}

In this section, we collect the market clearing conditions:

$$
Y_{t}=C_{t}+I_{t}+S_{t}+\left(N_{t-1}-A_{t-1}\right) a_{t}+A_{t-1} m_{t}+G_{t} Y_{t}+\Phi A_{t-1}
$$

Here $G_{t}$ denotes a government spending shock following the law of motion:

$$
\log \left(G_{t}\right)=\bar{G}\left(1-\rho_{G}\right)+\rho_{G} \log \left(G_{t-1}\right)+\epsilon_{t}^{G} .
$$

where $\rho_{G}$ parametrizes the persistence and $\sigma_{G}$ the volatility of deviations from the mean of the logged government to output ratio $\bar{G} . \epsilon_{t}^{G}$ is an i.i.d. normally distributed disturbance with mean zero and variance one. Government spending is financed by lump sum taxes $T_{t}=G_{t} Y_{t-1}$.

International bond demand and supply have to be in equilibrium:

$$
b_{t}+b_{t}^{*}=0 \text {. }
$$

In addition, international goods market clearing requires:

$$
P_{t}^{*} b_{t}=p_{I, t}^{*} y_{I, t}^{*}-p_{I, t} y_{I, t}+P_{t}^{*} R_{t-1}^{*} b_{t-1} .
$$

Factor market clearing requires

$$
\begin{gathered}
\bar{K}_{D, t}+\bar{K}_{I, t}=k_{t-1} u_{t} \\
L_{D, t}+L_{I, t}=l_{t} \\
m_{D, t}+m_{I, t}=m_{t} .
\end{gathered}
$$

Profits payed to the household equal the profits from the intermediate good producer net of adoption and R\&D expenditures:

$$
\Pi_{t}=A_{t-1} \pi_{t}-S_{t}-\left(N_{t-1}-A_{t-1}\right) a_{t}
$$




\section{B.3 Re-arrange and Normalize}

Using the equations from the previous subsection of the appendix, we normalize the model by its stochastic trend to derive a stationary representation. We also simplify the model slightly.

- $\tilde{\nu}_{t}^{c}=\frac{\nu_{t}^{c}}{\prod_{s=0}^{t-1} \beta_{s} A_{t-1}^{-\sigma}} P_{t}$

- $\tilde{c}_{t}=\frac{c_{t}}{A_{t-1}}$

- $\tilde{x}_{t}=\frac{x_{t}}{A_{t-1}}$

- $\tilde{A}_{t}=\frac{A_{t}}{A_{t-1}}$

- $\tilde{W}_{t}=\frac{W_{t}}{A_{t-1}}$

- $\tilde{\nu}_{t}^{k}=\frac{\nu_{t}^{k}}{\prod_{s=0}^{t-1} \beta_{s} t A_{t-1}^{-\sigma}}$

- $R E R_{t}=\frac{P_{t}^{*}}{P_{t}}$

- $\tilde{q}_{t}=\frac{q_{t}}{P_{t}}$

- $\tilde{p}_{t}=\frac{p_{t}}{P_{t}}$

- $\tilde{p}_{t}^{*}=\frac{p_{t}^{*}}{P_{t}^{*}}$

- $\tilde{k}_{t-1}=\frac{k_{t-1}}{A_{t-1}}$

- $\tilde{\bar{K}}_{t}=\frac{\tilde{\bar{K}}_{t}}{A_{t-1}}$

- $\tilde{i}_{t}=\frac{i_{t}}{A_{t-1}}$

- $\tilde{Y}_{t}=\frac{Y_{t}}{A_{t-1}}$

- $\tilde{y}_{t}=\frac{y_{t}}{A_{t-1}}$

- $\tilde{a}_{t}=\frac{a_{t}}{A_{t-1}}$

- $\tilde{\pi}_{t}=\frac{\pi_{t} P_{t}}{A_{t-1}}$

- $\tilde{S}_{t}=\frac{S_{t}}{A_{t-1}}$

- $\tilde{\gamma}_{t}=\frac{\gamma_{t}}{A_{t-1}}$

- $\tilde{N}_{t}=\frac{N_{t}}{A_{t-1}}$

- $\tilde{B}_{t}=\frac{B_{t}}{A_{t-1}}$

- $\tilde{M}_{t}=\frac{M_{t}}{A_{t-1}^{\frac{1}{\mu}}}$ 
- $\tilde{y}_{D, t}=\frac{y_{D, t}}{A_{t-1}}$

- $\tilde{y}_{I, t}=\frac{y_{I, t}}{A_{t-1}^{*}}$

- $\Gamma_{t-1}=\frac{A_{t-1}^{*}}{A_{t-1}}$

- $\tilde{H}_{t}=\frac{H_{t}}{P_{t}}$

- $\tilde{J}_{t}=\frac{J_{t}}{P_{t}}$

- $\tilde{b}_{D, t}=\frac{b_{D, t}}{A_{t-1}}$

- $\tilde{b}_{I, t}=\frac{b_{I, t}}{A_{t-1}^{*}}$

$$
\begin{gathered}
\left(\tilde{c}_{t}-\psi_{1, t} \tilde{x}_{t} L_{t}^{1+\psi_{2}}\right)^{-\sigma}-\tilde{\nu}_{t}^{c}=0 \\
-\left(\tilde{c}_{t}-\psi_{1, t} \tilde{x}_{t} l_{t}^{1+\psi_{2}}\right)^{-\sigma} \psi_{1, t}\left(1+\psi_{2}\right) \tilde{x}_{t} l_{t}^{\psi_{2}}+\tilde{\nu}_{t}^{c} \tilde{W}_{t}=0 \\
\tilde{\nu}_{t}^{c} R_{t}^{k}-\delta_{k}^{\prime}\left(u_{t}\right) \tilde{\nu}_{t}^{k}=0
\end{gathered}
$$$$
-\tilde{\nu}_{t}^{c}+\tilde{\nu}_{t}^{k} q_{t}\left(1-\phi_{i}\left(\frac{\tilde{A}_{t-1} \tilde{i}_{t}}{\tilde{i}_{t-1}}\right)-\phi_{i}^{\prime}\left(\frac{\tilde{A}_{t-1} \tilde{i}_{t}}{\tilde{i}_{t-1}}\right) \frac{\tilde{A}_{t-1} \tilde{i}_{t}}{\tilde{i}_{t-1}}\right)+\beta_{t} \tilde{A}_{t}^{-\sigma} \tilde{\nu}_{t+1}^{k} q_{t+1} \phi_{i}^{\prime}\left(\frac{\tilde{A}_{t} \tilde{i}_{t+1}}{\tilde{i}_{t}}\right)\left(\frac{\tilde{A}_{t} \tilde{i}_{t+1}}{\tilde{i}_{t}}\right)^{2}=0
$$$$
-\tilde{\nu}_{t}^{k}+\tilde{A}_{t}^{-\sigma} \beta \tilde{\nu}_{t+1}^{k}\left(1-\delta_{k}\left(u_{t}\right)\right)+\tilde{A}_{t}^{-\sigma} \beta_{t} \tilde{\nu}_{t+1}^{c} R_{t+1}^{k} u_{t+1}=0
$$$$
-\tilde{\nu}_{t}^{c} R E R_{t}+\beta_{t} \tilde{\nu}_{t+1}^{c} R_{t}^{*} R E R_{t+1} \exp \left(U_{t}\right) \exp \left(\tilde{b}_{t}\right)^{-\phi_{1}}\left(\frac{\mathbb{E}_{t} R E R_{t+1}}{R E R_{t-1}}\right)^{-\phi_{2}}=0
$$$$
\tilde{k}_{t} \tilde{A}_{t}=\left(1-\delta_{k}\left(u_{t}\right)\right) \tilde{k}_{t-1}+q_{t}\left(1-\phi_{i}\left(\frac{\tilde{i}_{t} \tilde{A}_{t-1}}{\tilde{i}_{t-1}}\right)\right) \tilde{i}_{t}
$$$$
\tilde{x}_{t}=\left(\frac{\tilde{c}_{t}}{\tilde{A}_{t-1}}\right)^{\gamma}\left(\frac{\tilde{x}_{t-1}}{A_{t-1}}\right)^{1-\gamma}
$$

$\tilde{Y}_{t}^{1-\rho} a_{D} \tilde{y}_{D, t}^{\rho-1}+\tilde{Y}_{t}^{1-\rho} a_{I} \phi_{t}^{\rho-1} \tilde{y}_{I, t}^{\rho} \hat{\phi}_{t} \frac{\frac{\tilde{y}_{I, t}}{\tilde{y}_{D, t}^{2}}}{\frac{\tilde{y}_{I, t-1}}{\tilde{y}_{D, t-1}}} \Gamma_{t-1}^{1+\rho} \Gamma_{t-2}^{-1}-\beta \tilde{A}_{t}^{-\sigma} \frac{\tilde{\nu}_{t+1}^{c}}{\tilde{\nu}_{t}^{c}} \tilde{Y}_{t+1}^{1-\rho} a_{I} \phi_{t+1}^{\rho-1} \tilde{y}_{I, t+1}^{\rho} \hat{\phi}_{t+1} \frac{\frac{\tilde{y}_{I, t+1}}{\tilde{y}_{D, t+1}}}{\tilde{y}_{I, t}} \Gamma_{t}^{-\rho} \tilde{A}_{t}^{*}=\tilde{p}_{D, t}$ 


$$
\begin{aligned}
& \tilde{Y}_{t}^{1-\rho} a_{I} \phi_{t}^{\rho}\left(\tilde{y}_{I, t} \Gamma_{t-1}\right)^{\rho-1}-\tilde{Y}_{t}^{1-\rho} a_{I} \phi_{t}^{\rho-1} \tilde{y}_{I, t}^{\rho} \hat{\phi}_{t} \frac{\frac{1}{\tilde{y}_{D, t}}}{\frac{\tilde{y}_{I, t-1}}{\tilde{y}_{D, t-1}}} \Gamma_{t-1}^{\rho-1} \frac{\tilde{A}_{t-1}^{*}}{\tilde{A}_{t-1}} \\
& +\beta \tilde{A}_{t}^{-\sigma} \frac{\tilde{\nu}_{t+1}^{c}}{\tilde{\nu}_{t}^{c}} \tilde{Y}_{t+1}^{1-\rho} a_{I} \phi_{t+1}^{\rho-1} \tilde{y}_{I, t+1}^{\rho} \hat{\phi}_{t+1} \frac{\frac{\tilde{y}_{I, t+1}}{\tilde{y}_{D, t+1}}}{\frac{\tilde{y}_{I, t}^{2}}{\tilde{y}_{D, t}}} \Gamma_{t}^{\rho} \tilde{A}_{t}^{*} \frac{1}{\Gamma_{t-1}}=\tilde{p}_{I, t} R E R_{t} \\
& \tilde{Y}_{t}=\left(a_{D} \tilde{y}_{D, t}^{\rho}+a_{I}\left(\phi_{t} \tilde{y}_{I, t} \Gamma_{t-1}\right)^{\rho}\right)^{\frac{1}{\rho}} \\
& \phi_{t}=1-\frac{\iota}{2}\left(\frac{\frac{\tilde{y}_{I, t}}{\tilde{y}_{D, t}}}{\frac{\tilde{A}_{I, t-1}}{\tilde{y}_{D, t-1}}} \frac{\tilde{A}_{t-1}^{*}}{\tilde{A}_{t-1}}-1\right)^{2} \\
& \hat{\phi}_{t}=\iota\left(\frac{\frac{\tilde{y}_{I, t}}{\tilde{y}_{D, t}}}{\frac{\tilde{y}_{I, t-1}}{\tilde{y}_{D, t-1}}} \frac{\tilde{A}_{t-1}^{*}}{\tilde{A}_{t-1}}-1\right) \\
& \tilde{y}_{t}=Z_{t} \tilde{\bar{K}}_{t}^{\alpha_{K}} L_{t}^{\alpha_{L}} \tilde{M}_{t}^{\alpha_{M}} \\
& \tilde{M}_{t}=m_{t} \\
& \tilde{p}_{D, t} \alpha_{L} \frac{\tilde{y}_{t}}{L_{t}}=\tilde{W}_{t} \\
& \tilde{p}_{D, t} \alpha_{K} \frac{\tilde{y}_{t}}{\tilde{\bar{K}}_{t}}=R_{t}^{k} \\
& \tilde{p}_{D, t} \alpha_{M} \tilde{y}_{t} \tilde{M}_{t}^{-\mu} \tilde{m}_{t}^{\mu-1}=\tilde{p}_{t} \\
& \tilde{p}_{D, t} \theta^{G} \theta^{R}=\tilde{p}_{I, t}^{*} \\
& \frac{1}{\mu}=\tilde{p}_{t} \\
& \tilde{\pi}_{t}=\left(\frac{1}{\mu}-1\right) m_{t}-\Phi \\
& \tilde{H}_{t}=\tilde{\pi}_{t}+\left(1-\delta_{a}\right) \tilde{\Lambda}_{t, t+1} \tilde{H}_{t+1} \\
& \tilde{\Lambda}_{t, t+1}=\beta_{t} \tilde{A}_{t}^{-\sigma} \frac{\tilde{\nu}_{t+1}^{c}}{\tilde{\nu}_{t}^{c}}
\end{aligned}
$$




$$
\begin{aligned}
& \tilde{A}_{t} \tilde{N}_{t}=\left(1-\delta_{n}\right) \tilde{N}_{t-1}+\tilde{\gamma}_{t} \\
& \tilde{\gamma}_{t}=\zeta\left(\frac{\tilde{N}_{t-1}}{\tilde{A}_{t-1}}+\tau \frac{\tilde{N}_{t-1}^{*} \Gamma_{t-1}}{\tilde{A}_{t-1}}\right)^{1-\eta} \tilde{S}_{t}^{\eta} \\
& \frac{\zeta\left(\frac{\tilde{N}_{t-1}}{\tilde{A}_{t-1}}+\tau \frac{\tilde{N}_{t-1}^{*} \Gamma_{t-1}}{\tilde{A}_{t-1}}\right)^{1-\eta}}{\tilde{S}_{t}^{1-\eta}} \tilde{\Lambda}_{t, t+1} \tilde{J}_{t+1}=1 \\
& \tilde{A}_{t}=\left(1-\delta_{a}\right)+\lambda_{t}\left(\frac{\tilde{N}_{t-1}}{\tilde{A}_{t-1}}-1\right) \\
& \tilde{J}_{t}=-a_{t}+\tilde{\Lambda}_{t, t+1}\left(\lambda_{t}\left(a_{t}\right) \tilde{H}_{t+1}+\left(1-\lambda_{t}\left(a_{t}\right)\right)\left(1-\delta_{n}\right) \tilde{J}_{t+1}\right) \\
& 1=\tilde{\Lambda}_{t, t+1}\left(\lambda_{t}^{\prime}\left(a_{t}\right) \tilde{H}_{t+1}-\lambda_{t}^{\prime}\left(a_{t}\right)\left(1-\delta_{n}\right) \tilde{J}_{t+1}\right) \\
& \lambda_{t}\left(a_{t}\right)=\kappa_{\lambda}\left(a_{t}\right)^{\mu_{\lambda}} \\
& \tilde{Y}_{t}=\tilde{c}_{t}+\tilde{i}_{t}+\tilde{S}_{t}+\left(\frac{\tilde{N}_{t-1}}{\tilde{A}_{t-1}}-1\right) a_{t}+m_{t}+G_{t} \tilde{Y}_{t}+\Phi \\
& \tilde{b}_{t}+\tilde{b}_{t}^{*} \Gamma_{t-1}=0 \\
& R E R_{t} \tilde{b}_{t}=\tilde{p}_{I, t}^{*} y_{I, t}^{*}-\tilde{p}_{I, t} R E R_{t} \Gamma_{t-1} \tilde{y}_{I, t}+R E R_{t} R_{t-1}^{*} \frac{\tilde{b}_{t-1}}{\tilde{A}_{t-1}} \\
& \tilde{y}_{t}=\tilde{y}_{D, t}+\tilde{y}_{I, t}^{*} \theta^{G} \theta^{R} \\
& \tilde{\bar{K}}_{t}=\tilde{k}_{t-1} u_{t}
\end{aligned}
$$

\section{Appendix: Additional Tables}

Table 10 shows the parameter estimates in the simplified versions of the endogenous and exogenous growth models.

In turn, Table 11 displays the estimated parameters from the full endogenous and exogenous growth models. 
Table 10: Posterior Estimation - Minimal Data

\begin{tabular}{|l|c|c|}
\hline Parameter & Endogenous & Exogenous \\
\hline $100 * \sigma_{\psi_{1}}$ & 2.54 & 2.53 \\
$100 * \sigma_{\psi_{1}}^{*}$ & {$[2.32,2.76]$} & {$[2.32,2.75]$} \\
$100 * \sigma_{Z}$ & {$[1.65$} & 1.66 \\
& 0.22 & {$[1.51,1.80]$} \\
$100 * \sigma_{Z}^{*}$ & {$[0.20,0.25]$} & 0.24 \\
& 0.22 & {$[0.22,0.27]$} \\
$100 * \sigma_{g}$ & {$[0.22,0.24]$} & {$[0.21,0.26]$} \\
& 2.07 & 2.18 \\
$100 * \sigma_{g}^{*}$ & {$[1.86,2.28]$} & {$[1.99,2.38]$} \\
$100 * \sigma_{q}$ & 1.62 & 1.57 \\
$100 * \sigma_{q}^{*}$ & {$[1.45,1.78]$} & {$[1.43,1.71]$} \\
$\rho_{\psi_{1}}$ & 55.93 & 6.36 \\
$\rho_{\psi_{1}}^{*}$ & {$[5.34,6.53]$} & {$[5.74,6.99]$} \\
$\rho_{Z}$ & {$[2.98,3.62]$} & 3.74 \\
$\rho_{Z}^{*}$ & 0.968 & {$[3.39,4.09]$} \\
$\rho_{g}$ & {$[0.960,0.976]$} & $0.965,0.981]$ \\
$\rho_{g}^{*}$ & 0.916 & 0.915 \\
$\rho_{q}$ & {$[0.888,0.945]$} & {$[0.886,0.945]$} \\
$\rho_{q}^{*}$ & 0.983 & 0.975 \\
\hline \hline Log Data Density & {$[0.977,0.989]$} & {$[0.965,0.985]$} \\
\hline & 0.972 & 0.964 \\
& {$[0.966,0.978]$} & {$[0.953,0.976]$} \\
& 0.975 & 0.971 \\
& {$[0.968,0.981]$} & {$[0.965,0.978]$} \\
& 0.978 & 0.962 \\
& {$[0.971,0.986]$} & {$[0.949,0.975]$} \\
& 0.510 & 0.600 \\
& {$[0.416,0.605]$} & {$[0.503,0.696]$} \\
& 0.595 & 0.775 \\
& {$[0.497,0.692]$} & {$[0.697,0.861]$} \\
\hline
\end{tabular}

Notes: This table lists the posteriors used in the estimation. Parameters with a (\#) are absent in the comparison model without endogenous growth.

\section{C.1 Extra Figures}

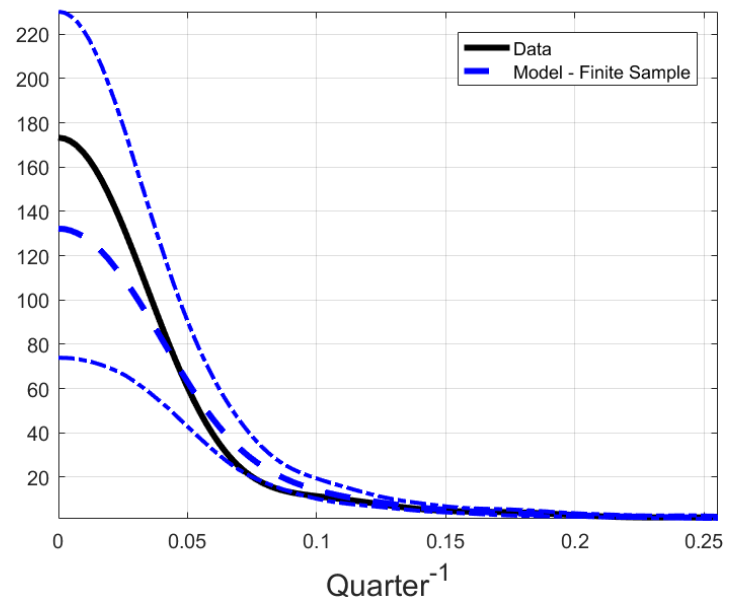

(a) Endogenous Growth

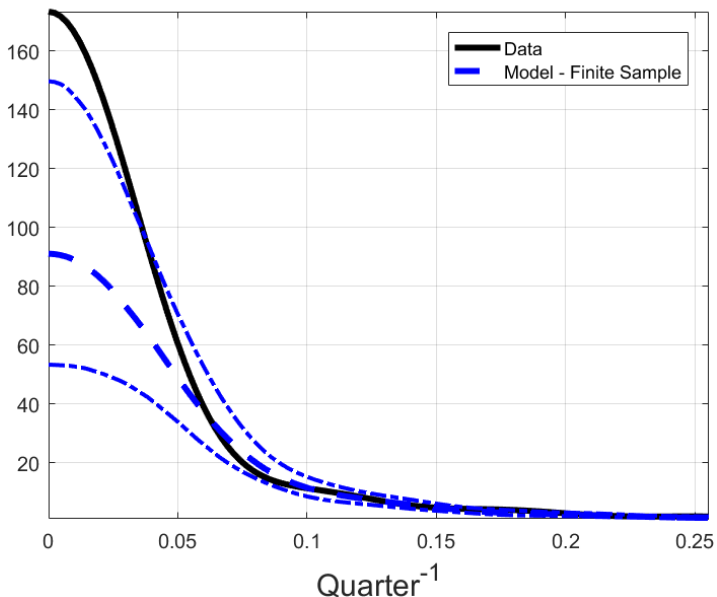

(b) Exogenous Growth

Figure 17: Measurement Error

Notes: The thick, blue, broken line shows the median model spectrum simulated as described in the text, and the thinner lines the 90 percent confidence intervals. The black line is the data spectrum. 
Table 11: Estimation Results - Main Specification 1 - Shock Processes

\begin{tabular}{|c|c|c|c|}
\hline Parameter & $\begin{array}{l}\text { Endogenous } \\
\text { Both Stages }\end{array}$ & $\begin{array}{l}\text { Endogenous } \\
\text { New Tech only }\end{array}$ & Exogenous \\
\hline $100 * \sigma_{\psi_{1}}$ & $\begin{array}{c}4.01 \\
{[2.91,5.13]}\end{array}$ & $\begin{array}{c}4.82 \\
{[3.57,6.07]}\end{array}$ & $\begin{array}{c}3.62 \\
{[2.57,4.66]}\end{array}$ \\
\hline $100 * \sigma_{\psi_{1}}^{*}$ & $\begin{array}{c}2.44 \\
{[1.78,3.10]}\end{array}$ & $\begin{array}{c}2.92 \\
{[2.18,3.63]}\end{array}$ & $\begin{array}{c}2.32 \\
{[1.66,2.97]}\end{array}$ \\
\hline $100 * \sigma_{Z}$ & $\begin{array}{c}0.20 \\
{[0.18,0.23]}\end{array}$ & $\begin{array}{c}0.21 \\
{[0.18,0.23]}\end{array}$ & $\begin{array}{c}0.23 \\
{[0.20,0.26]}\end{array}$ \\
\hline $100 * \sigma_{Z}^{*}$ & $\begin{array}{c}0.21 \\
{[0.19,0.23]}\end{array}$ & $\begin{array}{c}0.21 \\
{[0.19,0.23]}\end{array}$ & $\begin{array}{c}0.21 \\
{[0.19,0.23]}\end{array}$ \\
\hline $100 * \sigma_{\beta}$ & $\begin{array}{c}0.16 \\
{[0.07,0.24]}\end{array}$ & $\begin{array}{c}0.24 \\
{[0.08,0.42]}\end{array}$ & $\begin{array}{c}0.09 \\
{[0.07,0.10]}\end{array}$ \\
\hline $100 * \sigma_{\beta}^{*}$ & $\begin{array}{c}0.12 \\
{[0.07,0.17]}\end{array}$ & $\begin{array}{c}0.13 \\
{[0.08,0.18]}\end{array}$ & $\begin{array}{c}0.18 \\
{[0.11,0.25]}\end{array}$ \\
\hline $100 * \sigma_{g}$ & $\begin{array}{c}2.17 \\
{[1.97,2.35]}\end{array}$ & $\begin{array}{c}2.20 \\
{[1.99,2.41]}\end{array}$ & $\begin{array}{c}2.20 \\
{[1.99,2.39]}\end{array}$ \\
\hline $100 * \sigma_{g}^{*}$ & $\begin{array}{c}1.50 \\
{[1.35,1.65]}\end{array}$ & $\begin{array}{c}1.51 \\
{[1.37,1.65]}\end{array}$ & $\begin{array}{c}1.55 \\
{[1.42,1.68]}\end{array}$ \\
\hline $100 * \sigma_{q}$ & $\begin{array}{c}1.22 \\
{[0.90,1.53]}\end{array}$ & $\begin{array}{c}1.14 \\
{[0.81,1.46]}\end{array}$ & $\begin{array}{c}1.71 \\
{[1.03,2.35]}\end{array}$ \\
\hline $100 * \sigma_{q}^{*}$ & $\begin{array}{c}0.62 \\
{[0.48,0.76]}\end{array}$ & $\begin{array}{c}0.64 \\
{[0.46,0.78]}\end{array}$ & $\begin{array}{c}0.93 \\
{[0.60,1.26]}\end{array}$ \\
\hline $100 * \sigma_{\Omega^{g}}$ & $\begin{array}{c}3.44 \\
{[3.08,3.78]}\end{array}$ & $\begin{array}{c}3.45 \\
{[3.12,3.83]}\end{array}$ & $\begin{array}{c}3.45 \\
{[3.09,3.82]}\end{array}$ \\
\hline $100 * \sigma_{\Omega^{f}}$ & $\begin{array}{c}2.23 \\
{[1.99,2.48]}\end{array}$ & $\begin{array}{c}2.20 \\
{[1.96,2.43]}\end{array}$ & $\begin{array}{c}1.99 \\
{[1.78,2.20]}\end{array}$ \\
\hline $100 * \sigma_{\zeta}$ & $\begin{array}{c}1.24 \\
{[0.97,1.49]}\end{array}$ & $\begin{array}{c}1.57 \\
{[1.17,1.99]}\end{array}$ & \\
\hline $100 * \sigma_{\zeta}^{*}$ & $\begin{array}{c}1.39 \\
{[1.04,1.74]}\end{array}$ & $\begin{array}{c}1.62 \\
{[1.21,20.7]}\end{array}$ & \\
\hline$\rho_{\psi_{1}}$ & $\begin{array}{c}0.934 \\
{[0.922,0.947]}\end{array}$ & $\begin{array}{c}0.934 \\
{[0.922,0.945]}\end{array}$ & $\begin{array}{c}0.961 \\
{[0.950,0.973]}\end{array}$ \\
\hline$\rho_{\psi_{1}}^{*}$ & $\begin{array}{c}0.929 \\
{[0.904,0.954]}\end{array}$ & $\begin{array}{c}0.927 \\
{[0.901,0.949]}\end{array}$ & $\begin{array}{c}0.937 \\
{[0.911,0.964]}\end{array}$ \\
\hline$\rho_{Z}$ & $\begin{array}{c}0.926 \\
{[0.893,0.961]}\end{array}$ & $\begin{array}{c}0.940 \\
{[0.924,0.957]}\end{array}$ & $\begin{array}{c}0.902 \\
{[0.864,0.945]}\end{array}$ \\
\hline$\rho_{Z}^{*}$ & $\begin{array}{c}0.968 \\
{[0.960,0.977]}\end{array}$ & $\begin{array}{c}0.968 \\
{[0.959,0.977]}\end{array}$ & $\begin{array}{c}0.966 \\
{[0.954,0.979]}\end{array}$ \\
\hline$\rho_{\beta}$ & $\begin{array}{c}0.949 \\
{[0.904,0.985]}\end{array}$ & $\begin{array}{c}0.923 \\
{[0.857,0.984]}\end{array}$ & $\begin{array}{c}0.993 \\
{[0.990,0.996]}\end{array}$ \\
\hline$\rho_{\beta}^{*}$ & $\begin{array}{c}0.947 \\
{[0.920,0.974]}\end{array}$ & $\begin{array}{c}0.944 \\
{[0.920,0.971]}\end{array}$ & $\begin{array}{c}0.939 \\
{[0.910,0.969]}\end{array}$ \\
\hline$\rho_{g}$ & $\begin{array}{c}0.979 \\
{[0.971,0.987]}\end{array}$ & $\begin{array}{c}0.978 \\
{[0.970,0.986]}\end{array}$ & $\begin{array}{c}0.971 \\
{[0.963,0.979]}\end{array}$ \\
\hline$\rho_{g}^{*}$ & $\begin{array}{c}0.978 \\
{[0.969,0.986]}\end{array}$ & $\begin{array}{c}0.975 \\
{[0.965,0.986]}\end{array}$ & $\begin{array}{c}0.965 \\
{[0.952,0.978]}\end{array}$ \\
\hline$\rho_{q}$ & $\begin{array}{c}0.951 \\
{[0.927,0.975]}\end{array}$ & $\begin{array}{c}0.948 \\
{[0.922,0.973]}\end{array}$ & $\begin{array}{c}0.303 \\
{[0.129,0.470]}\end{array}$ \\
\hline$\rho_{q}^{*}$ & $\begin{array}{c}0.628 \\
{[0.387,0.893]}\end{array}$ & $\begin{array}{c}0.690 \\
{[0.509,0.957]}\end{array}$ & $\begin{array}{c}0.320 \\
{[0.123,0.512]}\end{array}$ \\
\hline$\rho_{\Omega^{g}}$ & $\begin{array}{c}0.961 \\
{[0.947,0.976]}\end{array}$ & $\begin{array}{c}0.963 \\
{[0.947,0.980]}\end{array}$ & $\begin{array}{c}0.984 \\
{[0.977,0.990]}\end{array}$ \\
\hline$\rho_{\Omega^{f}}$ & $\begin{array}{c}0.982 \\
{[0.972,0.992]}\end{array}$ & $\begin{array}{c}0.981 \\
{[0.972,0.991]}\end{array}$ & $\begin{array}{c}0.961 \\
{[0.941,0.984]}\end{array}$ \\
\hline$\rho_{\zeta}$ & $\begin{array}{c}0.974 \\
{[0.962,0.991]}\end{array}$ & $\begin{array}{c}0.966 \\
{[0.952,0.979]}\end{array}$ & \\
\hline$\rho_{\zeta}^{*}$ & $\begin{array}{c}0.902 \\
{[0.861,0.946]}\end{array}$ & $\begin{array}{c}0.896 \\
{[0.842,0.946]}\end{array}$ & \\
\hline$\rho_{U}$ & $\begin{array}{c}0.983 \\
{[0.973,0.994]}\end{array}$ & $\begin{array}{c}0.984 \\
{[0.975,0.993]}\end{array}$ & $\begin{array}{c}0.897 \\
{[0.854,0.942]}\end{array}$ \\
\hline $100 * \sigma_{U}$ & $\begin{array}{c}0.10 \\
{[0.08,0.13]}\end{array}$ & $\begin{array}{c}0.10 \\
{[0.08,0.12]}\end{array}$ & $\begin{array}{c}0.19 \\
{[0.11,0.27]}\end{array}$ \\
\hline
\end{tabular}

Notes: This table lists the posteriors used in the estimation. Parameters with a (\#) are absent in the comparison model without endogenous growth. 


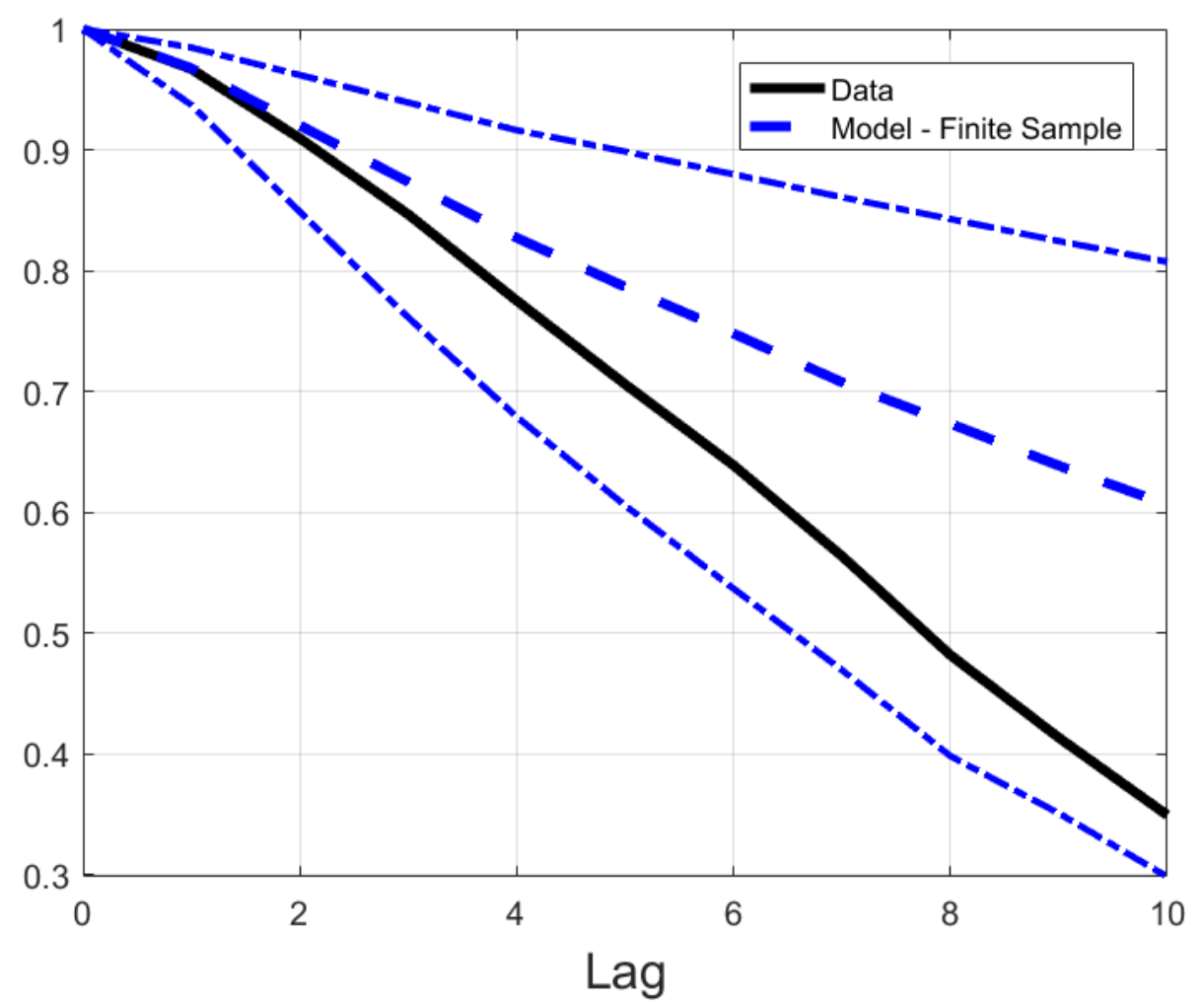

Figure 18: Autocorrelation - No UIP Shock

Notes: The thick, blue, broken line shows the median model autocorrelation simulated as described in the text, and the thinner lines the 90 percent confidence intervals. The black line is the autocorrelation in the data.

Table 12: Variance Decomposition - Endogenous Growth

\begin{tabular}{|l|ccccccccccccccc}
\hline & $\psi$ & $\psi^{*}$ & $g$ & $g^{*}$ & $Z$ & $Z^{*}$ & $q$ & $q^{*}$ & $\zeta$ & $\zeta^{*}$ & $\Omega^{g}$ & $\Omega^{f}$ & $\beta$ & $\beta^{*}$ & $\mathrm{U}$ \\
\hline$\Delta Y$ & 44.41 & 0.01 & 0.11 & 0.01 & 35.14 & 0.02 & 8.33 & 0.22 & 0.63 & 0.01 & 6.96 & 0.28 & 0.07 & 0.01 & 3.79 \\
$\Delta Y^{*}$ & 0.03 & 24.37 & 0.03 & 0.08 & 0.02 & 54.33 & 1.20 & 3.43 & 0.07 & 0.44 & 9.98 & 0.41 & 0.01 & 0.06 & 5.52 \\
$\Delta C$ & 15.14 & 0.02 & 18.07 & 0.02 & 10.89 & 0.09 & 0.25 & 0.04 & 22.54 & 0.06 & 4.23 & 1.25 & 25.96 & 0.01 & 1.42 \\
$\Delta C^{*}$ & 0.10 & 8.32 & 0.07 & 13.18 & 0.07 & 35.33 & 0.14 & 1.07 & 0.36 & 6.26 & 6.55 & 1.94 & 0.03 & 24.39 & 2.20 \\
$\Delta I$ & 31.40 & 0.03 & 6.47 & 0.00 & 26.15 & 0.10 & 16.12 & 0.22 & 8.17 & 0.02 & 3.36 & 0.57 & 4.60 & 0.00 & 2.78 \\
$\Delta I^{*}$ & 0.16 & 21.60 & 0.01 & 5.71 & 0.12 & 31.51 & 1.53 & 14.15 & 0.15 & 8.35 & 5.79 & 1.04 & 0.00 & 4.94 & 4.92 \\
$\Delta H$ & 98.04 & 0.00 & 0.02 & 0.00 & 1.14 & 0.00 & 0.31 & 0.01 & 0.00 & 0.00 & 0.24 & 0.09 & 0.02 & 0.00 & 0.12 \\
$\Delta H^{*}$ & 0.00 & 95.37 & 0.00 & 0.02 & 0.00 & 3.05 & 0.06 & 0.28 & 0.00 & 0.02 & 0.61 & 0.23 & 0.00 & 0.03 & 0.31 \\
U.S. Export/GDP & 1.13 & 0.30 & 2.37 & 1.03 & 0.81 & 1.48 & 7.68 & 0.21 & 6.88 & 1.06 & 9.69 & 2.96 & 0.49 & 0.26 & 63.65 \\
U.S. Import/GDP & 1.52 & 0.22 & 0.92 & 0.34 & 1.00 & 1.62 & 4.60 & 1.00 & 14.13 & 2.09 & 37.93 & 12.69 & 0.32 & 0.11 & 21.50 \\
RER & 1.16 & 0.39 & 0.91 & 0.43 & 0.79 & 2.35 & 6.41 & 0.64 & 22.65 & 2.62 & 0.00 & 15.42 & 0.29 & 0.16 & 45.78 \\
U.S. Solow Growth & 1.07 & 0.00 & 0.26 & 0.01 & 62.91 & 0.02 & 9.05 & 0.01 & 26.03 & 0.04 & 0.23 & 0.12 & 0.08 & 0.00 & 0.16 \\
G6 Solow Growth & 0.01 & 0.48 & 0.02 & 0.15 & 0.01 & 81.03 & 0.04 & 3.34 & 0.38 & 13.85 & 0.28 & 0.15 & 0.00 & 0.06 & 0.19 \\
Relative Solow & 1.20 & 0.42 & 3.40 & 1.73 & 0.92 & 4.41 & 1.12 & 0.01 & 75.79 & 8.15 & 0.00 & 1.18 & 0.74 & 0.45 & 0.48 \\
Relative TFP & 1.30 & 0.42 & 3.68 & 1.71 & 0.98 & 4.48 & 1.20 & 0.01 & 74.39 & 8.87 & 0.00 & 1.22 & 0.80 & 0.44 & 0.49 \\
\hline
\end{tabular}

Notes: This table lists the variance decomposition for selected variables from the endogenous growth model with R\&D measured as the sum of spending on both stages using the long-run theoretical moments. $\Delta$ indicates the growth rate of a variable. 


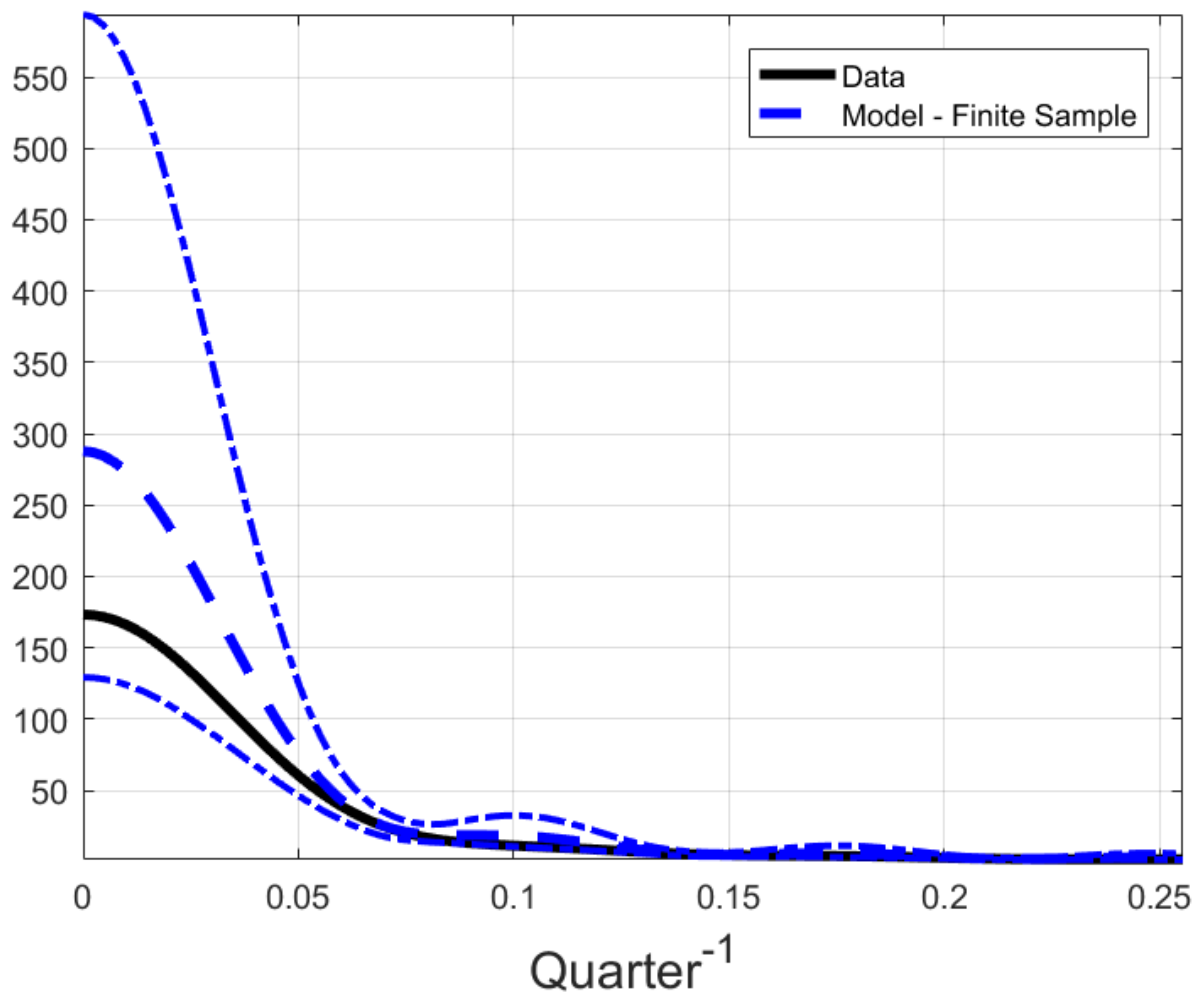

Figure 19: Spectrum - No UIP Shock

Notes: The thick, blue, broken line shows the median model spectrum simulated as described in the text, and the thinner lines the 90 percent confidence intervals. The black line is the data spectrum.

Table 13: Variance Decomposition - Exogenous Growth

\begin{tabular}{|l|ccccccccccccc}
\hline & $\psi$ & $\psi^{*}$ & $g$ & $g^{*}$ & $Z$ & $Z^{*}$ & $q$ & $q^{*}$ & $\Omega^{g}$ & $\Omega^{f}$ \\
\hline$\Delta Y$ & 36.31 & 0.04 & 1.25 & 0.05 & 36.38 & 0.06 & 11.67 & 0.21 & 7.56 & 0.45 & 2.23 & 0.06 & 3.73 \\
$\Delta Y^{*}$ & 0.12 & 22.00 & 0.14 & 1.07 & 0.16 & 50.43 & 1.03 & 5.51 & 11.39 & 0.69 & 0.33 & 1.45 & 5.70 \\
$\Delta C$ & 20.66 & 0.05 & 11.85 & 0.03 & 12.51 & 0.12 & 1.44 & 0.04 & 7.36 & 0.71 & 44.68 & 0.03 & 0.52 \\
$\Delta C^{*}$ & 0.20 & 9.83 & 0.09 & 7.96 & 0.17 & 33.12 & 0.21 & 0.70 & 11.69 & 1.12 & 0.41 & 33.68 & 0.81 \\
$\Delta I$ & 21.35 & 0.01 & 6.35 & 0.03 & 28.63 & 0.01 & 25.90 & 0.20 & 2.69 & 0.26 & 10.36 & 0.04 & 4.17 \\
$\Delta I^{*}$ & 0.02 & 19.26 & 0.10 & 6.82 & 0.06 & 34.30 & 1.20 & 15.20 & 5.00 & 0.50 & 0.13 & 9.42 & 7.98 \\
$\Delta H$ & 97.67 & 0.01 & 0.06 & 0.00 & 1.08 & 0.02 & 0.51 & 0.01 & 0.25 & 0.13 & 0.14 & 0.00 & 0.12 \\
$\Delta H^{*}$ & 0.04 & 95.72 & 0.01 & 0.08 & 0.06 & 2.32 & 0.09 & 0.37 & 0.58 & 0.31 & 0.02 & 0.13 & 0.28 \\
U.S. Export/GDP & 1.51 & 0.26 & 2.07 & 0.73 & 0.55 & 1.11 & 0.71 & 0.21 & 28.02 & 1.88 & 42.68 & 0.51 & 19.76 \\
U.S. Import/GDP & 2.41 & 0.47 & 0.43 & 0.21 & 1.23 & 1.24 & 2.55 & 0.74 & 70.33 & 7.91 & 3.77 & 0.24 & 8.48 \\
RER & 4.96 & 1.56 & 1.50 & 0.74 & 3.27 & 4.80 & 4.54 & 1.46 & 0.00 & 16.38 & 9.72 & 0.79 & 50.29 \\
U.S. Solow Growth & 1.26 & 0.01 & 1.31 & 0.00 & 78.63 & 0.03 & 15.89 & 0.01 & 0.21 & 0.35 & 2.13 & 0.00 & 0.17 \\
G6 Solow Growth & 0.04 & 0.75 & 0.00 & 0.95 & 0.04 & 89.64 & 0.02 & 6.29 & 0.27 & 0.46 & 0.02 & 1.31 & 0.21 \\
Relative Solow (Level) & 2.68 & 0.61 & 2.92 & 1.22 & 6.51 & 15.10 & 0.21 & 0.07 & 3.95 & 0.00 & 65.88 & 0.85 & 0.00 \\
Relative TFP (Level) & 0.00 & 0.00 & 0.00 & 0.00 & 30.25 & 69.75 & 0.00 & 0.00 & 0.00 & 0.00 & 0.00 & 0.00 & 0.00 \\
\hline
\end{tabular}

Notes: This table lists the variance decomposition for selected variables from the exogenous growth model using the long-run theoretical moments. $\Delta$ indicates the growth rate of a variable. 